\title{
Cochrane
}

Cochrane Database of Systematic Reviews

\section{Diagnostic accuracy of laparoscopy following computed} tomography (CT) scanning for assessing the resectability with curative intent in pancreatic and periampullary cancer (Review)

Allen VB, Gurusamy KS, Takwoingi Y, Kalia A, Davidson BR

Allen VB, Gurusamy KS, Takwoingi Y, Kalia A, Davidson BR.

Diagnostic accuracy of laparoscopy following computed tomography (CT) scanning for assessing the resectability with curative intent in pancreatic and periampullary cancer.

Cochrane Database of Systematic Reviews 2016, Issue 7. Art. No.: CD009323.

DOI: 10.1002/14651858.CD009323.pub3.

www.cochranelibrary.com

Diagnostic accuracy of laparoscopy following computed tomography (CT) scanning for assessing the resectability with curative intent in pancreatic and periampullary cancer (Review)

Copyright @ 2016 The Cochrane Collaboration. Published by John Wiley \& Sons, Ltd. 
TABLE OF CONTENTS

HEADER

ABSTRACT

PLAIN LANGUAGE SUMMARY . . . . . . . . . . . . . . . . . . . . . . . . . . . . . . . . . 2

BACKGROUND . . . . . . . . . . . . . . . . . . . . . . . . . . . . . . . . . . . . . 3

Figure 1. . . . . . . . . . . . . . . . . . . . . . . . . . . . . . . . . . . . . . 5

OBJECTIVES . . . . . . . . . . . . . . . . . . . . . . . . . . . . . . . . . . . . . 6

METHODS . . . . . . . . . . . . . . . . . . . . . . . . . . . . . . . . . . . . . . 6

Figure 2. . . . . . . . . . . . . . . . . . . . . . . . . . . . . . . . . . . . . . 8

RESULTS . . . . . . . . . . . . . . . . . . . . . . . . . . . . . . . . . . . . . . 9

Figure 3. . . . . . . . . . . . . . . . . . . . . . . . . . . . . . . . . . 11

Figure 4. . . . . . . . . . . . . . . . . . . . . . . . . . . . . . . . . . . . . . 12

Figure 5. . . . . . . . . . . . . . . . . . . . . . . . . . . . . . . . . . . . . . 13

Figure 6. . . . . . . . . . . . . . . . . . . . . . . . . . . . . . . . . . . . . . 15

DISCUSSION . . . . . . . . . . . . . . . . . . . . . . . . . . . . . . . . . . . . . 18

AUTHORS' CONCLUSIONS . . . . . . . . . . . . . . . . . . . . . . . . . . . . . . . . 19

ACKNOWLEDGEMENTS . . . . . . . . . . . . . . . . . . . . . . . . . . . . . . . . . 19

REFERENCES . . . . . . . . . . . . . . . . . . . . . . . . . . . . . . . . . . . . . . 19

CHARACTERISTICS OF STUDIES . . . . . . . . . . . . . . . . . . . . . . . . . . . . . . . . . . . . . . . . . .

DATA . . . . . . . . . . . . . . . . . . . . . . . . . . . . . . . . . . . . . . . . 67

Test 1. Diagnostic laparoscopy (all studies). . . . . . . . . . . . . . . . . . . . . . . . . . . . . . . . . . . $\quad . \quad 67$

Test 2. Diagnostic laparoscopy (pancreatic cancer only).

ADDITIONAL TABLES . . . . . . . . . . . . . . . . . . . . . . . . . . . . . . . . . . . 68

APPENDICES . . . . . . . . . . . . . . . . . . . . . . . . . . . . . . . . . . . . . . 77

WHAT'S NEW . . . . . . . . . . . . . . . . . . . . . . . . . . . . . . . . . . . . . 80

HISTORY . . . . . . . . . . . . . . . . . . . . . . . . . . . . . . . . . . . . . . . 80

CONTRIBUTIONS OF AUTHORS . . . . . . . . . . . . . . . . . . . . . . . . . . . . . . . . . . . . . . . . . . . .

DECLARATIONS OF INTEREST . . . . . . . . . . . . . . . . . . . . . . . . . . . . . . . . . . . 80

SOURCES OF SUPPORT . . . . . . . . . . . . . . . . . . . . . . . . . . . . . . . . . . . . . . . . . . . .

DIFFERENCES BETWEEN PROTOCOL AND REVIEW . . . . . . . . . . . . . . . . . . . . . . 81

INDEX TERMS . . . . . . . . . . . . . . . . . . . . . . . . . . . . . . . . . . . . 81

Diagnostic accuracy of laparoscopy following computed tomography (CT) scanning for assessing the resectability with curative intent in pancreatic and periampullary cancer (Review)

Copyright $\odot 2016$ The Cochrane Collaboration. Published by John Wiley \& Sons, Ltd. 
[Diagnostic Test Accuracy Review]

\title{
Diagnostic accuracy of laparoscopy following computed tomography (CT) scanning for assessing the resectability with curative intent in pancreatic and periampullary cancer
}

\author{
Victoria B Allen ${ }^{1}$, Kurinchi Selvan Gurusamy ${ }^{2}$, Yemisi Takwoingi ${ }^{3}$, Amun Kalia ${ }^{4}$, Brian R Davidson ${ }^{2}$ \\ ${ }^{1}$ Oxford University Clinical Academic Graduate School, Oxford University Hospitals NHS Trust, Oxford, UK. ${ }^{2}$ Department of \\ Surgery, Royal Free Campus, UCL Medical School, London, UK. ${ }^{3}$ Institute of Applied Health Research, University of Birmingham, \\ Birmingham, UK. ${ }^{4}$ University College London, London, UK
}

Contact address: Kurinchi Selvan Gurusamy, Department of Surgery, Royal Free Campus, UCL Medical School, Royal Free Hospital, Rowland Hill Street, London, NW3 2PF, UK. k.gurusamy@ucl.ac.uk.

Editorial group: Cochrane Upper GI and Pancreatic Diseases Group.

Publication status and date: New search for studies and content updated (no change to conclusions), published in Issue 7, 2016.

Review content assessed as up-to-date: 15 May 2016.

Citation: Allen VB, Gurusamy KS, Takwoingi Y, Kalia A, Davidson BR. Diagnostic accuracy of laparoscopy following computed tomography $(\mathrm{CT})$ scanning for assessing the resectability with curative intent in pancreatic and periampullary cancer. Cochrane Database of Systematic Reviews 2016, Issue 7. Art. No.: CD009323. DOI: 10.1002/14651858.CD009323.pub3.

Copyright (C) 2016 The Cochrane Collaboration. Published by John Wiley \& Sons, Ltd.

\begin{abstract}
A B S T R A C T
Background

Surgical resection is the only potentially curative treatment for pancreatic and periampullary cancer. A considerable proportion of patients undergo unnecessary laparotomy because of underestimation of the extent of the cancer on computed tomography (CT) scanning. Laparoscopy can detect metastases not visualised on CT scanning, enabling better assessment of the spread of cancer (staging of cancer). This is an update to a previous Cochrane Review published in 2013 evaluating the role of diagnostic laparoscopy in assessing the resectability with curative intent in people with pancreatic and periampullary cancer.
\end{abstract}

Objectives

To determine the diagnostic accuracy of diagnostic laparoscopy performed as an add-on test to CT scanning in the assessment of curative resectability in pancreatic and periampullary cancer.

\section{Search methods}

We searched the Cochrane Central Register of Controlled Trials (CENTRAL), MEDLINE via PubMed, EMBASE via OvidSP (from inception to 15 May 2016), and Science Citation Index Expanded (from 1980 to 15 May 2016).

\section{Selection criteria}

We included diagnostic accuracy studies of diagnostic laparoscopy in people with potentially resectable pancreatic and periampullary cancer on CT scan, where confirmation of liver or peritoneal involvement was by histopathological examination of suspicious (liver or peritoneal) lesions obtained at diagnostic laparoscopy or laparotomy. We accepted any criteria of resectability used in the studies. We included studies irrespective of language, publication status, or study design (prospective or retrospective). We excluded case-control studies.

Diagnostic accuracy of laparoscopy following computed tomography (CT) scanning for assessing the resectability with curative intent in pancreatic and periampullary cancer (Review)

Copyright $₫ 2016$ The Cochrane Collaboration. Published by John Wiley \& Sons, Ltd. 


\section{Data collection and analysis}

Two review authors independently performed data extraction and quality assessment using the QUADAS-2 tool. The specificity of diagnostic laparoscopy in all studies was 1 because there were no false positives since laparoscopy and the reference standard are one and the same if histological examination after diagnostic laparoscopy is positive. The sensitivities were therefore meta-analysed using a univariate random-effects logistic regression model. The probability of unresectability in people who had a negative laparoscopy (posttest probability for people with a negative test result) was calculated using the median probability of unresectability (pre-test probability) from the included studies, and the negative likelihood ratio derived from the model (specificity of 1 assumed). The difference between the pre-test and post-test probabilities gave the overall added value of diagnostic laparoscopy compared to the standard practice of CT scan staging alone.

\section{Main results}

We included 16 studies with a total of 1146 participants in the meta-analysis. Only one study including 52 participants had a low risk of bias and low applicability concern in the patient selection domain. The median pre-test probability of unresectable disease after CT scanning across studies was $41.4 \%$ (that is 41 out of 100 participants who had resectable cancer after CT scan were found to have unresectable disease on laparotomy). The summary sensitivity of diagnostic laparoscopy was $64.4 \%$ ( $95 \%$ confidence interval (CI) $50.1 \%$ to $76.6 \%$ ). Assuming a pre-test probability of $41.4 \%$, the post-test probability of unresectable disease for participants with a negative test result was 0.20 ( $95 \% \mathrm{CI} 0.15$ to 0.27$)$. This indicates that if a person is said to have resectable disease after diagnostic laparoscopy and CT scan, there is a $20 \%$ probability that their cancer will be unresectable compared to a $41 \%$ probability for those receiving $\mathrm{CT}$ alone.

A subgroup analysis of people with pancreatic cancer gave a summary sensitivity of $67.9 \%$ (95\% CI $41.1 \%$ to $86.5 \%$ ). The post-test probability of unresectable disease after being considered resectable on both CT and diagnostic laparoscopy was $18 \%$ compared to $40.0 \%$ for those receiving $\mathrm{CT}$ alone.

\section{Authors' conclusions}

Diagnostic laparoscopy may decrease the rate of unnecessary laparotomy in people with pancreatic and periampullary cancer found to have resectable disease on CT scan. On average, using diagnostic laparoscopy with biopsy and histopathological confirmation of suspicious lesions prior to laparotomy would avoid 21 unnecessary laparotomies in 100 people in whom resection of cancer with curative intent is planned.

\section{PLAIN LANGUAGE SUMMARY}

\section{What is the diagnostic accuracy of laparoscopic staging following a CT scan for assessing whether pancreatic and periampullary cancer is resectable?}

\section{Background}

The pancreas is an organ situated in the abdomen close to the junction of the stomach and small bowel. It secretes digestive juices which are necessary for the digestion of all food materials. The digestive juices secreted in the pancreas drain into the upper part of the small bowel via the pancreatic duct. The bile duct is a tube which drains bile from the liver and gallbladder. The pancreatic and bile ducts share a common path just before they drain into the small bowel. This area is called the periampullary region. Surgical removal is the only potentially curative treatment for cancers arising from the pancreatic and periampullary regions. A considerable proportion of patients undergo unnecessary major open abdominal exploratory operation (laparotomy) because their CT scan has underestimated the spread of cancer. If during the major open operation the cancer is found to have spread within the abdomen, patients are referred for alternate treatments such as chemotherapy, which do not cure the cancer but may improve survival.

This major open abdominal operation can be avoided if the spread of cancer within the abdomen is known, called 'staging' the cancer. The minimum test used for staging is usually the computed tomography (CT) scan. However, CT scan can understage the cancer, that is it can underestimate the spread of cancer. Laparoscopy, a procedure whereby a small telescope is inserted inside the abdomen through a small (keyhole) surgical incision, can detect spread not identified on CT scanning. Different studies report different accuracy of laparoscopy in assessing whether the cancer can be removed. Our aim therefore was to find out the average diagnostic accuracy of laparoscopy for staging pancreatic and periampullary cancers considered to be removable after a CT scan. This review is an update of our previous review.

Diagnostic accuracy of laparoscopy following computed tomography (CT) scanning for assessing the resectability with curative intent in 
A glossary of terms is provided in Appendix 1.

\section{Study characteristics}

We performed a thorough literature search to identify studies published up to 15 May 2016. We identified 16 studies reporting information on 1146 people with pancreatic or periampullary cancers which were considered to be eligible for potentially curative surgery based on CT scan staging. These studies evaluated diagnostic laparoscopy and compared results of the procedure with the eventual diagnosis by the surgeon that the cancer was not resectable during major abdominal operation or examination under microscope.

\section{Quality of evidence}

All of the studies were of unclear or low methodological quality in one or more aspects, which may undermine the validity of our findings.

\section{Key results}

Of those people with what CT suggests seems to be a potentially surgically curable cancer, the percentage in whom more extensive cancer was found on further staging with diagnostic laparoscopy or laparotomy ranged between $17 \%$ and $82 \%$ across studies. The median percentage of people in whom cancer spread was not detected by CT scan was $41 \%$. Adding staging laparoscopy to CT scan might decrease the number of people with unremovable disease undergoing unnecessary major operations to $20 \%$ compared to those who undergo unnecessary major operation after CT scan alone (41\%). This means that using diagnostic laparoscopy could halve the rate of unnecessary major open operations in people undergoing major surgery for potentially surgically curable pancreatic cancer.

\section{B A C K G R O U N D}

Periampullary cancer develops near the ampulla of Vater (National Cancer Institute 2011a). This includes cancer of the head and neck of the pancreas, cancer of the distal end of the bile duct, cancer of the ampulla of Vater, and cancer of the second part of the duodenum. Pancreaticoduodenectomy is the main treatment for cancers arising in the head of the pancreas, ampulla, and second part of the duodenum. Surgical resection is generally considered to be the only cure for pancreatic cancer. However, only $15 \%$ to $20 \%$ of people with pancreatic cancers undergo potentially curative resection (Conlon 1996; Engelken 2003; Michelassi 1989; Shahrudin 1997; Smith 2008). In all other people, the cancers are not resected because of infiltration of local structures, disseminated disease, or because the person is deemed unfit to undergo major surgery. Computed tomography (CT scan) is generally used for staging pancreatic and periampullary cancers (National Cancer Institute $2011 b$ ). Despite undergoing routine CT scanning to stage the disease (Mayo 2009), a substantial proportion of patients (approximately $10 \%$ to $25 \%$ ) undergo unnecessary laparotomy (opening the abdomen using a large incision) with lack of curative resectability identified only during the laparotomy (Lillemoe 1999; Mayo 2009). Laparoscopy can be used to detect metastatic disease in people with periampullary cancer.

\section{Target condition being diagnosed}

Inability to perform curative resectability of pancreatic and periampullary cancer ('unresectable' cancers)

\section{Index test(s)}

Diagnostic laparoscopy involves the use of a laparoscope (a telescope inserted into the abdominal cavity through a keyhole incision) to visualise and explore the abdominal organs. Also known as staging laparoscopy, it is used following initial staging by CT scanning. Any spread of cancer to the liver, peritoneum, or adjacent structures can be visualised during diagnostic laparoscopy. A biopsy of the suspicious lesion can be performed, and the biopsy specimen can be examined under the microscope to confirm that the suspicious lesion is spread of cancer.

\section{Clinical pathway}

No standard algorithm is currently available for assessing the resectability of pancreatic and periampullary cancers, with clinicians following their own algorithms based on either their clinical experience or education. Almost all current algorithms include a CT scan as one of the tests (National Cancer Institute 2011b). CT may be the only test performed before laparotomy. Other tests such as diagnostic laparoscopy, positron emission tomography (PET)

Diagnostic accuracy of laparoscopy following computed tomography (CT) scanning for assessing the resectability with curative intent in 3 pancreatic and periampullary cancer (Review)

Copyright () 2016 The Cochrane Collaboration. Published by John Wiley \& Sons, Ltd. 
scanning, magnetic resonance imaging (MRI), or endoscopic ultrasound (EUS) may be used in addition to CT scan to assess resectability. The possible clinical pathway in the staging of pancreatic cancers is shown in Figure 1. Another review is assessing the accuracy of these various tests and CT scanning (Gurusamy 2015).

Diagnostic accuracy of laparoscopy following computed tomography (CT) scanning for assessing the resectability with curative intent in 
Figure I. Clinical pathway.EUS: endoscopic ultrasoundMRI: magnetic resonance imagingPET: positron emission tomography

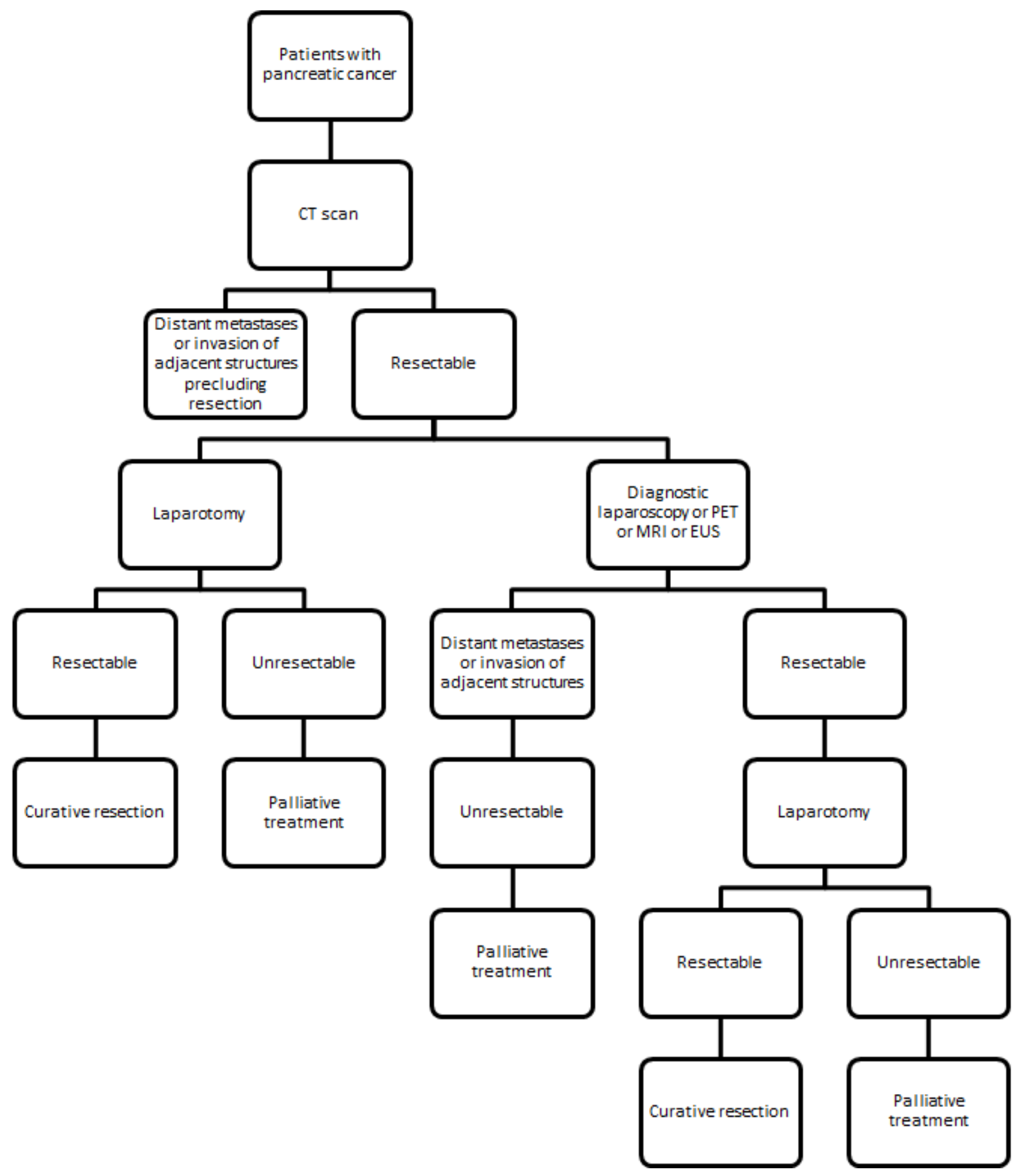

Diagnostic accuracy of laparoscopy following computed tomography (CT) scanning for assessing the resectability with curative intent in 


\section{Prior test(s)}

The minimum prior test should be CT, and the cancer should be resectable with curative intent on the basis of the CT scan to be included in this review. Other tests such as PET scanning, MRI, or EUS might be used in addition to CT scanning to assess resectability prior to diagnostic laparoscopy. We included participants in this review irrespective of whether they underwent these other tests prior to diagnostic laparoscopy.

\section{Role of index test(s)}

Diagnostic laparoscopy can be considered as an add-on test to the CT scan prior to laparotomy done with the intention of performing a potentially curative resection.

\section{Alternative test(s)}

Other tests such as PET scanning, laparoscopic ultrasound, or EUS may be used as alternative tests to diagnostic laparoscopy in people considered to have CT resectable pancreatic and periampullary cancer. As mentioned earlier, PET scanning and EUS may also be used prior to diagnostic laparoscopy. Laparoscopic ultrasound may be used in combination with diagnostic laparoscopy, and the strategy for determining test positivity of the combination may be either test positive or both tests positive.

\section{Rationale}

Diagnostic laparoscopy allows internal visualisation of the abdomen and can detect any peritoneal spread of the cancer or the involvement of any adjacent structures. A biopsy and histopathological examination of any suspicious lesion can be performed and an unnecessary laparotomy to attempt curative resection avoided. If this add-on test can identify unresectable cancers without laparotomy, it might decrease the costs and morbidity associated with unnecessary laparotomy. This is an update to an earlier Cochrane Review assessing the resectability with curative intent in pancreatic and periampullary cancer published in 2013 (Allen 2013).

\section{O B J E C T IVES}

To determine the diagnostic accuracy of diagnostic laparoscopy performed as an add-on test to CT scanning in the assessment of curative resectability in pancreatic and periampullary cancer.

\section{Secondary objectives}

We planned to explore the following sources of heterogeneity.

1. Studies at low risk of bias versus those at unclear or high risk of bias based on methodological quality assessment using the QUADAS-2 tool (Whiting 2011).

2. Full-text publications versus abstracts (this can inform about publication bias since there may be an association between the results of the study and the study reaching full publication status) (Eloubeidi 2001).

3. Prospective studies versus retrospective studies.

4. Proportion of participants with pancreatic cancer, ampullary cancer, and bile duct cancers (although classified as periampullary cancers, each has a different prognosis) (Klempnauer 1995). The additional value of diagnostic laparoscopy may be different because of the extent of spread in these different types of periampullary cancers.

5. Procedures performed under the same anaesthetic versus procedures performed under a different anaesthetic (there are likely to be differences in the histopathological examinations since the former procedure is associated with frozen section biopsy, while the latter procedure is likely to be associated with paraffin section). Paraffin section is considered to be the gold standard in identifying cancer. Frozen sections can be associated with false-negative results (Yeo 2002). However, frozen section results are always confirmed by paraffin section histological examinations.

6. Different definitions for resectable cancer on laparotomy. Different surgeons may consider cancer unresectable differently, i.e. they will have different criteria for unresectability on laparotomy (other than the consensus criteria for resectability). For example, one surgeon may judge that the cancer is unresectable on laparotomy because of the involvement of the vessel and consider the reference standard to be positive. This will result in a false-negative result for laparoscopy. Another surgeon may judge the same cancer to be resectable despite the involvement of the vessel and proceed with resection. The reference standard will be negative in this situation, resulting in a true-negative result for laparoscopy. This might have an intrinsic threshold effect.

7. Additional pre-tests performed (besides CT scan). This can alter the pre-test probability of unresectability and can help in the assessment of the additional value of diagnostic laparoscopy under various situations.

\section{METHODS}

Diagnostic accuracy of laparoscopy following computed tomography (CT) scanning for assessing the resectability with curative intent in 


\section{Criteria for considering studies for this review}

\section{Types of studies}

We included studies that evaluated the accuracy of diagnostic laparoscopy in the appropriate patient population (see below) irrespective of language or publication status, or whether data were collected prospectively or retrospectively. However, we excluded case reports which did not provide sufficient diagnostic test accuracy data. We also excluded case-control studies, which are prone to bias (Whiting 2011).

\section{Participants}

People about to undergo curative resection for pancreatic and periampullary cancer with no contraindications (such as metastatic disease) for curative resection on CT scan, and who were anaesthetically fit to undergo major surgery.

\section{Index tests}

We included only diagnostic laparoscopy in which histopathological confirmation of metastatic spread was obtained on a paraffin section.

\section{Target conditions}

The target conditions were unresectable pancreatic and periampullary cancers, that is diagnostic laparoscopy was considered to be a positive test if the pancreatic or periampullary cancer was unresectable. In these cancers it is not possible to perform curative resectability. There are no uniform criteria for resectability of pancreatic and periampullary cancer. Consensus exists for the definition of borderline resectable cancers (Abrams 2009). Therefore, where there is less tissue involvement than in a borderline resectable cancer, the tumour can be considered as resectable. We accepted any criteria of resectability used by the study authors and acknowledge that this could potentially create a threshold effect. In general, the cancer would not be resected if liver or peritoneal metastases were noted, or if the cancer had invaded important adjacent blood vessels that are beyond the criteria for borderline resectable cancers, for example greater than $180^{\circ}$ involvement of the superior mesenteric artery.

\section{Reference standards}

Confirmation of liver or peritoneal involvement by histopathological examination of suspicious (liver or peritoneal) lesions obtained at diagnostic laparoscopy or laparotomy. We accepted only paraffin section histology as the reference standard. In clinical practice, depending on the urgency of the results, a frozen section biopsy may be done to obtain immediate results. However, this is always confirmed by subsequent paraffin section histology (which can take several days) because frozen section biopsy is not as reliable as paraffin section histology. We also accepted the surgeon's judgement of unresectability at laparotomy when biopsy confirmation was not possible. For example, if the tumour has invaded the adjacent blood vessels the surgeon may not resect the tumour because of the danger posed by resecting part of a large blood vessel, and so biopsy confirmation cannot be obtained.

\section{Diagnostic laparoscopy results versus reference standard results}

A schematic diagram of the results of diagnostic laparoscopy against those of histopathology or laparotomy is shown in Figure 2. Positive histopathology of a biopsy taken during diagnostic laparoscopy confirms the presence of cancer (true positive). Thus, the index test and the reference standard are one and the same if there is positive histopathology after laparoscopy. As a result, false positives are not possible, and there is no sampling error associated with specificity because it is by definition equal to 1 . If the histopathology is negative, the surgeon will perform a laparotomy. The cancer may be resectable with curative intent (true negative) or may not be resectable with curative intent (false negative) based on histopathological confirmation or the surgeon's judgement of unresectability on laparotomy if biopsy confirmation cannot be obtained.

Diagnostic accuracy of laparoscopy following computed tomography (CT) scanning for assessing the resectability with curative intent in 
Figure 2. Schematic diagram indicating how true-positive, false-negative, and true-negative test results were determined.

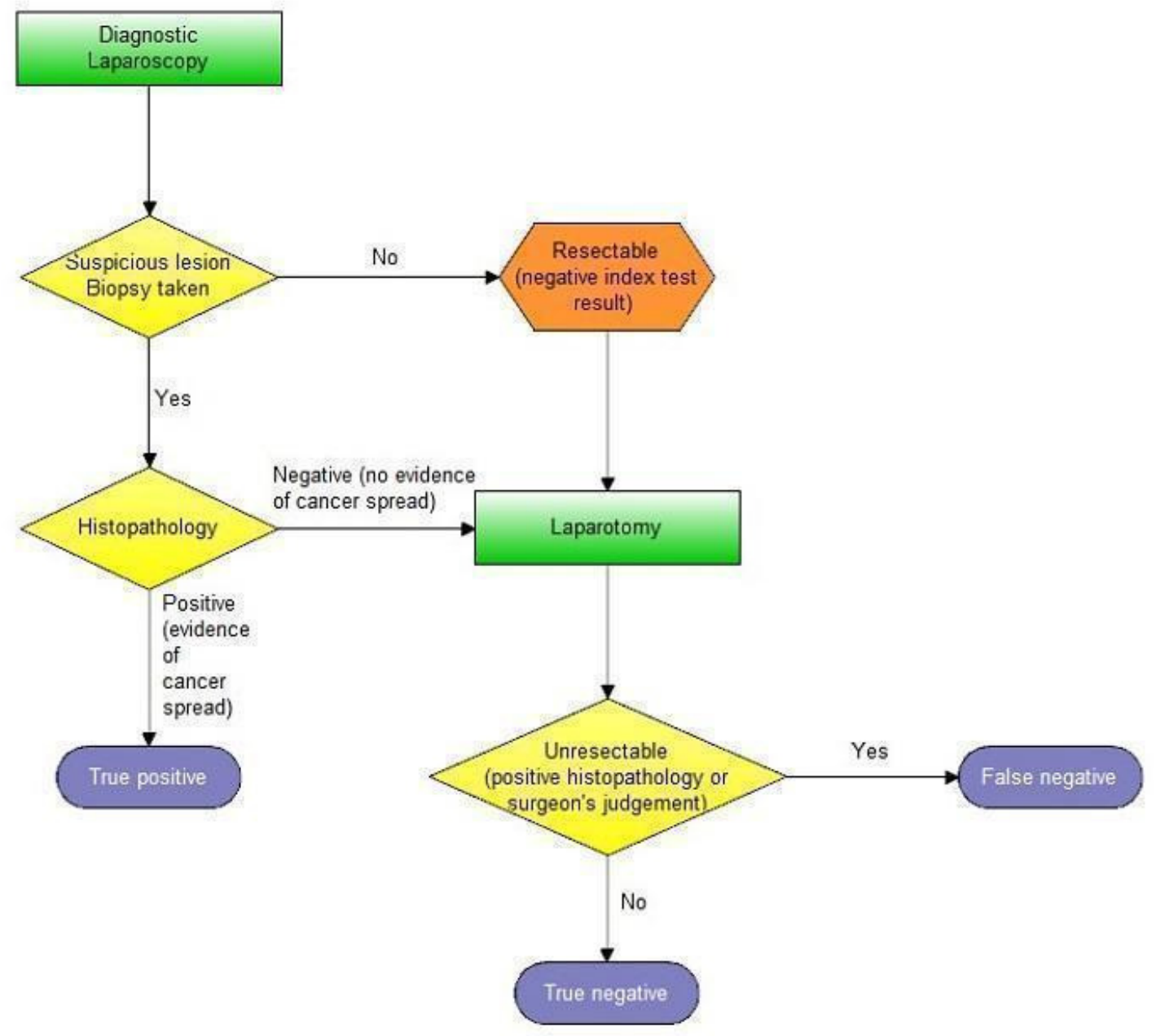

\section{Search methods for identification of studies}

We included all studies irrespective of language of publication and publication status. We obtained translations of any non-English articles.

\section{Electronic searches}

We searched the following databases until 15 May 2016.

1. Cochrane Central Register of Controlled Trials

(CENTRAL) in the Cochrane Library (Issue 5, 2016) (Appendix 2).

2. MEDLINE via PubMed (January 1946 to May 2016)
(Appendix 3).

3. EMBASE via OvidSP (January 1947 to May 2016) (Appendix 4).

4. Science Citation Index Expanded (January 1980 to May 2016) (Appendix 5).

\section{Searching other resources}

We searched the references of the included studies to identify additional studies. We also searched for articles related to the included studies by performing the 'related search' function in MEDLINE (PubMed) and EMBASE (OvidSP) and a 'citing reference' search (by searching the articles which cited the included articles) in Sci-

Diagnostic accuracy of laparoscopy following computed tomography (CT) scanning for assessing the resectability with curative intent in 
ence Citation Index Expanded and EMBASE (OvidSP) (Sampson 2008).

\section{Data collection and analysis}

\section{Selection of studies}

Two review authors (VA and KG or AK) independently searched the references to identify relevant studies. We obtained the full texts for references considered relevant by at least one of the review authors. Two review authors screened the full-text papers against the inclusion criteria. Any differences in study selection were arbitrated by BRD.

\section{Data extraction and management}

Two review authors independently extracted the following data from each included study, resolving any differences by discussion with BRD.

- First author.

- Year of publication.

- Study design (prospective or retrospective; cross-sectional studies or randomised clinical trials).

- Inclusion and exclusion criteria for individual studies.

- Total number of participants.

- Number of females.

- Average age of the participants.

- Type of cancer (i.e. head and neck of pancreas, body and tail of pancreas, ampullary cancers, cancer of the lower end of the bile duct).

- Criteria for unresectability at diagnostic laparoscopy (index test) and at laparotomy (reference standard).

- Preoperative tests carried out prior to diagnostic laparoscopy.

- Description of the index test.

- Reference standard.

- Number of true positives, true negatives, and false negatives.

- Complications of diagnostic laparoscopy.

The unit of analysis was the participant, meaning that if multiple metastases were found in a participant with a negative index test, the number of false negatives was considered to be one. This is because it is the presence rather than the number of metastases which is important in determining the curative resectability of patients. We considered participants with uninterpretable diagnostic laparoscopy results (no matter the reason given for lack of interpretation) as negative for the test since in clinical practice laparotomy would be carried out on these patients. However, we included such participants in the analysis only if the results of laparotomy were available. We sought further information from study authors if necessary.

\section{Assessment of methodological quality}

Two review authors (VA and KG) independently assessed study quality using the QUADAS-2 assessment tool (Whiting 2011). Any differences were resolved by BRD. The criteria used to classify the different studies are shown in Table 1. We considered studies which were classified as 'low risk of bias' and 'low concern' in all the domains as having high methodological quality.

\section{Statistical analysis and data synthesis}

The index test used was diagnostic laparoscopy with biopsy and histopathological confirmation. For the reason mentioned earlier, false positives were not possible. We therefore performed meta-analysis of only sensitivities by using a univariate randomeffects logistic regression model. The analysis was done using the NLMIXED procedure in SAS version 9.2 (SAS Institute Inc, Cary, North Carolina, USA) (Appendix 6). We used the ESTIMATE statement in NLMIXED to obtain the negative likelihood ratio by using a function of the estimated summary sensitivity and a specificity of 1 . The median pre-test probability of unresectability was calculated from the pre-test probabilities of the included studies. We calculated the proportion of participants classified as having resectable disease by CT scanning and diagnostic laparoscopy who were actually found to be unresectable at laparotomy (post-test probability) using the median pre-test probability and the negative likelihood ratio (see Appendix 7 for details). The difference in the unresectability proportions (post-test probability minus pre-test probability) gave the overall added value of diagnostic laparoscopy compared to the standard practice of CT scan staging alone.

\section{Investigations of heterogeneity}

We planned to explore heterogeneity by using the different sources of heterogeneity as covariate(s) in the regression model. However, this was not possible because the information was either not available or was the same in all the studies.

\section{Sensitivity analyses}

We did not plan any sensitivity analyses.

\section{R E S U L T S}

\section{Results of the search}

We identified a total of 14,254 references through the electronic searches of the Cochrane Upper Gastrointestinal and Pancreatic Diseases Group Controlled Trials Register and CENTRAL ( $\mathrm{n}=$ 
191), MEDLINE ( $\mathrm{n}=5228)$, EMBASE $(\mathrm{n}=4460)$, and Science Citation Index $(n=4375)$. Figure 3 shows the flow of references through the selection process. We excluded 7264 duplicates and clearly irrelevant references through reading the abstracts. We retrieved 213 references for further assessment. We identified no references through scanning reference lists of the identified studies. Of the 213 references, we excluded 194 for the reasons listed in the Characteristics of excluded studies table. In one study (Hashimoto 2015), all 11 participants who underwent diagnostic laparoscopy and laparotomy had resectable pancreatic cancers. There were therefore no true positives and false negatives for estimation of sensitivity, and we excluded this study from the review. We included 18 references of 16 studies. 
Figure 3. Flow diagram of study selection.

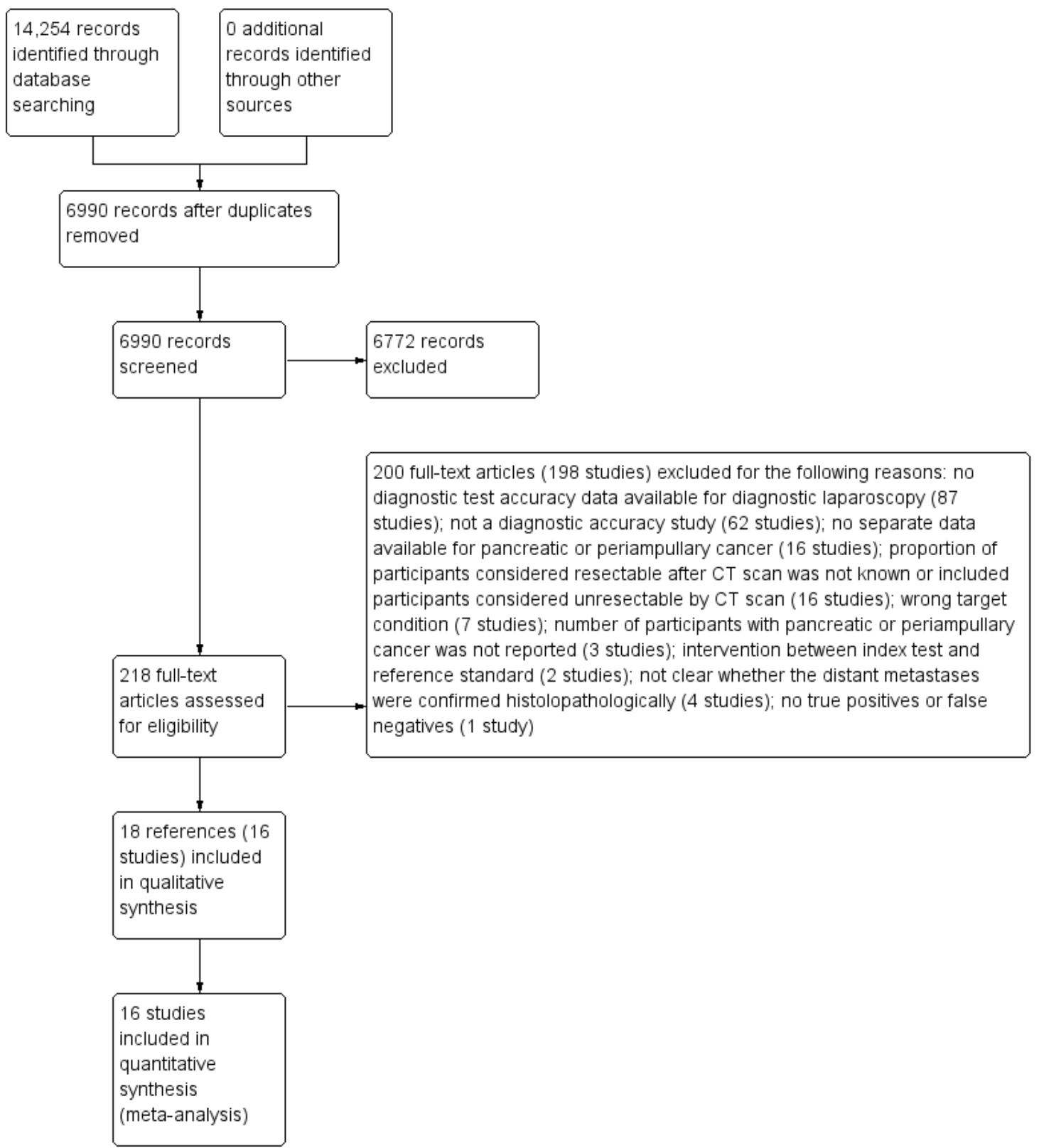

Diagnostic accuracy of laparoscopy following computed tomography (CT) scanning for assessing the resectability with curative intent in 


\section{Methodological quality of included studies}

The methodological quality of the included studies is shown in the Characteristics of included studies table, Figure 4, and Figure 5.

Figure 4. Risk of bias and applicability concerns graph: review authors' judgements about each domain presented as percentages across included studies.

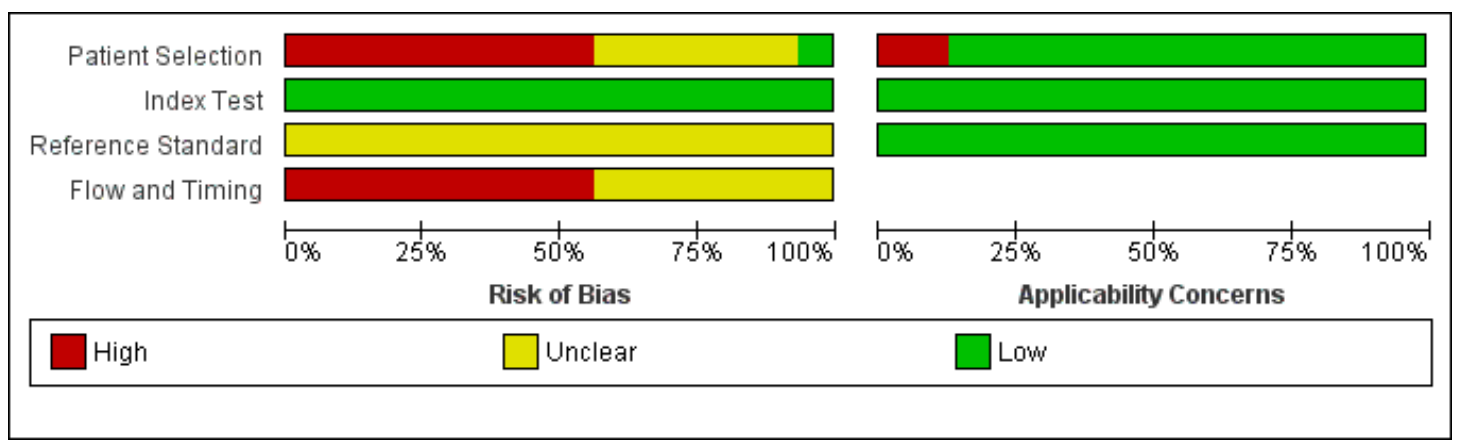

Diagnostic accuracy of laparoscopy following computed tomography (CT) scanning for assessing the resectability with curative intent in 
Figure 5. Risk of bias and applicability concerns summary: review authors' judgements about each domain for each included study.

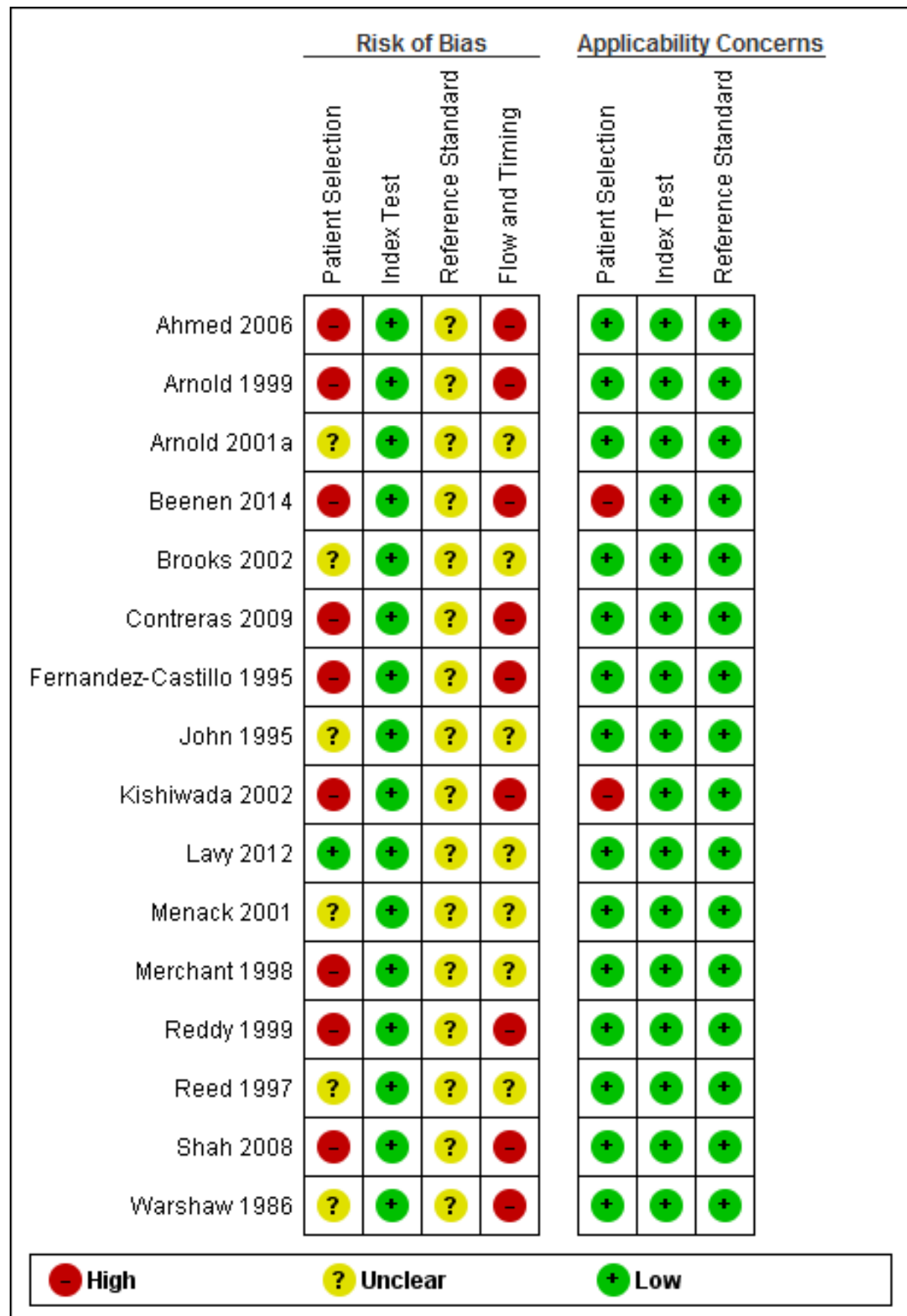

Diagnostic accuracy of laparoscopy following computed tomography (CT) scanning for assessing the resectability with curative intent in 
There was a high risk of bias regarding the selection of participants in most studies (Ahmed 2006; Arnold 1999; Arnold 2001a; Beenen 2014; Brooks 2002; Contreras 2009; John 1995; Kishiwada 2002; Lavy 2012; Menack 2001; Merchant 1998; Reddy 1999; Reed 1997; Shah 2008; Warshaw 1986). This was because the studies did not explicitly state whether a consecutive or random sample of patients was recruited or whether they had made inappropriate exclusions. Only one study had low risk of bias and low applicability concerns regarding the selection of participants (Fernandez-Castillo 1995).

There were no risk of bias issues or concerns regarding applicability of the index test in any of the studies, as was anticipated (Table 1). As anticipated, it proved impossible to determine whether an appropriate reference standard was used. This is because even in the presence of predefined criteria for unresectability, it may not be ethical to biopsy and confirm that the tumour has invaded the blood vessels because of the risk of major bleeding. Thus it was not possible to determine whether the cancer was truly unresectable. None of the studies reported whether the margins of the resected lesions were clear of cancer. It was therefore not possible to determine whether the cancer was truly resectable with curative intent. None of the studies reported the time interval between diagnostic laparoscopy and laparotomy. In addition, many studies had excluded some patients inappropriately. All of the studies were therefore at unclear or high risk of bias in the flow and timing domain.

\section{Findings}

All of the included studies assessed pancreatic or periampullary cancer. The 16 included studies involved a total of 1146 participants (Data and analyses). The age of participants in the included studies ranged between 15 and 87 years. Studies that provided demographic details of participants reported roughly equal numbers of males and females. Seven studies included only people with pancreatic cancer (Ahmed 2006; Arnold 2001a; Contreras 2009; Fernandez-Castillo 1995; Kishiwada 2002; Lavy 2012; Warshaw
1986), and two studies included only people with periampullary malignancies (Beenen 2014; Brooks 2002). The remaining studies did not provide information regarding the specific type of cancer they considered.

The details of the CT scan; other tests the participants underwent in addition to the CT scan; probability of CT resectable disease identified as unresectable by diagnostic laparoscopy or laparotomy (pre-test probability); reasons for CT resectable disease identified as unresectable by diagnostic laparoscopy; probability of CT and diagnostic laparoscopy resectable disease identified as unresectable at laparotomy (post-test probability); and the reasons for CT and diagnostic laparoscopy resectable disease identified as unresectable at laparotomy are all shown in Table 2.

The pre-test probability of unresectability (due to distant metastases or local infiltration) after CT scanning ranged from $17.4 \%$ to $82 \%$ in the included studies. The median pre-test probability was $41.4 \%$, meaning that a person that was said to be resectable on CT scanning still had a $41.4 \%$ chance that their cancer would be unresectable. Visual inspection of the data in Table 2 did not suggest a relationship between the type of CT scan (such as helical CT or multi-detector row CT, with or without a pancreatic protocol) or date of publication and the pre-test probability of unresectable disease.

The summary estimate of sensitivity was $64.4 \%$ (95\% confidence interval (CI) 50.1 to 76.6), and the summary negative likelihood ratio was 0.36 (95\% CI 0.24 to 0.52 ). Using the median pre-test probability of unresectable disease of 0.414 , the post-test probability of unresectable disease for participants with a negative test result was 0.20 (95\% CI 0.15 to 0.27$)$. This means that if a person is said to have resectable disease after diagnostic laparoscopy (and a CT scan), there is a $20 \%$ chance that their cancer will be unresectable. The post-test probability of unresectable disease is shown at different pre-test probabilities of unresectable disease in Figure 6.

Diagnostic accuracy of laparoscopy following computed tomography (CT) scanning for assessing the resectability with curative intent in 
Figure 6. Post-test probability of unresectability for various pre-test probabilities.

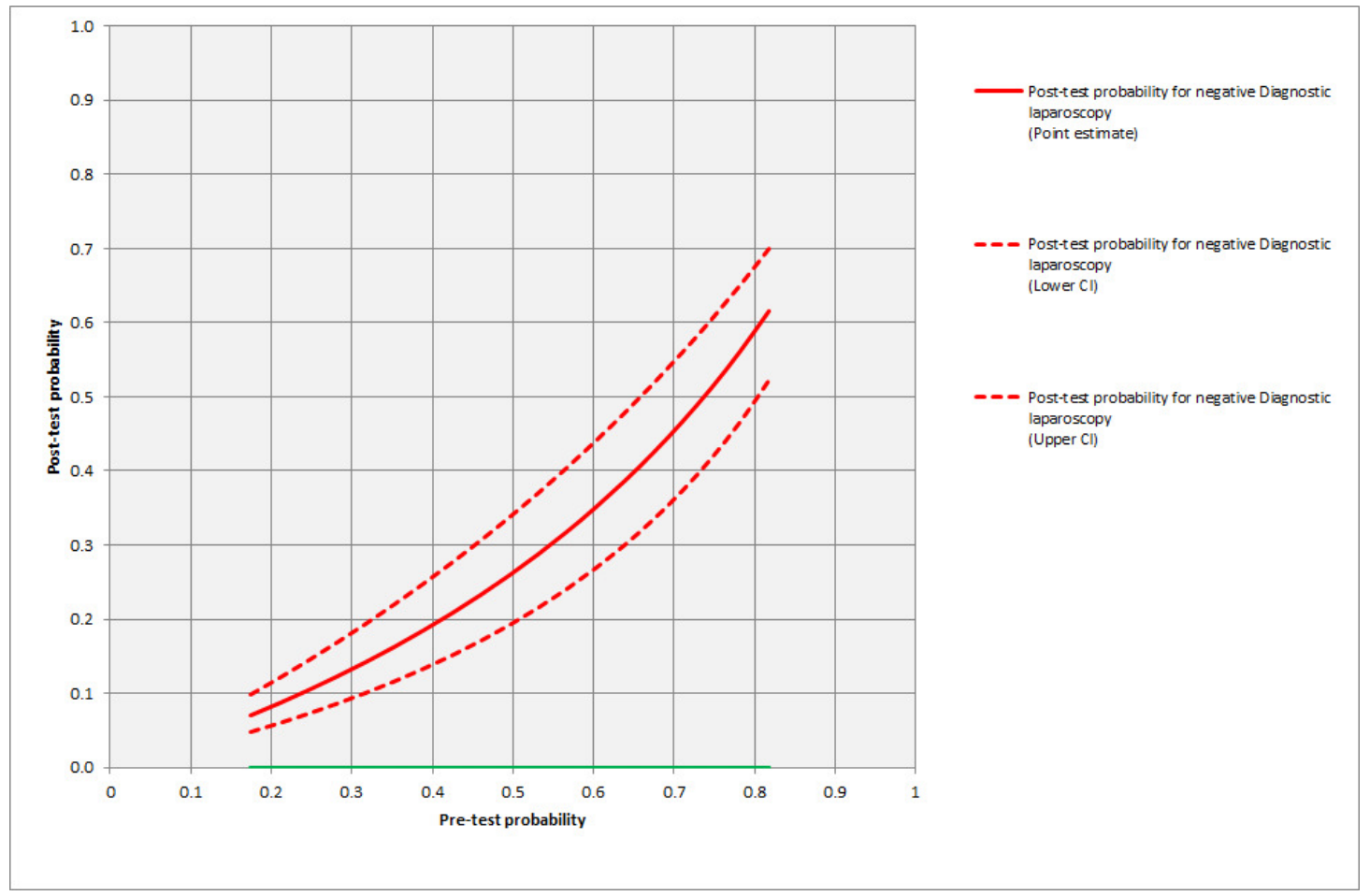

None of the studies reported any complications related to diagnostic laparoscopy. In some instances diagnostic laparoscopy provided an inconclusive result, that is it was unclear whether the participant had resectable or unresectable disease. Eight studies reported drop-out rates of: 37.3\% (Ahmed 2006), 29.8\% (Arnold 1999), 36.1\% (Beenen 2014), 67.5\% (Contreras 2009), 4.4\% (Fernandez-Castillo 1995), 10.6\% (Merchant 1998), 1.0\% (Reddy 1999), and 61.2\% (Shah 2008). In four of these studies the participants underwent laparotomy directly (Ahmed 2006; Beenen 2014; Contreras 2009; Shah 2008), and there was no indication of the selection criteria used for participants who had diagnostic laparoscopy. The other studies did not report drop-out rates.

A subgroup analysis of studies that included only participants with pancreatic cancer gave a summary sensitivity of $67.9 \%$ (95\% CI $41.1 \%$ to $86.5 \%)$. The summary negative likelihood ratio was 0.32 (95\% CI 0.15 to 0.68 ). The median pre-test probability of unresectability was $40.0 \%$ in this subgroup of studies. Using this pre-test probability, the post-test probability of unresectable disease after negative diagnostic laparoscopy was 0.18 (95\% CI 0.31 to 0.92 ).

We also performed a post hoc meta-regression of studies published before and after the year 2000, to test whether the sensitivity of diagnostic laparoscopy was different in the last decade, because major technological innovations in CT scans such as helical CT scans and multi-slice CT scans became widely available in the last decade. The likelihood ratio test comparing the model with and without this covariate gave a $P$ value of 1.0, indicating no evidence of a statistically significant difference in sensitivity between studies published before or after the year 2000 .

We found an inconsistency in one study between the results reported in the main text of the study and a flow diagram which summarised the results (Kishiwada 2002). In our previous review we investigated the effect of this inconsistency by conducting a sensitivity analysis, which showed no change in the estimates of the summary sensitivity and the confidence intervals (Allen 2013). In another sensitivity analysis, we imputed missing data as falsenegative results (that is diagnostic laparoscopy incorrectly classified unresectable disease as resectable in all the missing participants) (Allen 2013). We have not presented the results of the first sensitivity analysis in this update since only participant was misclassified, and the impact on results was negligible. We did not perform the second sensitivity analysis since the reasons for not performing diagnostic laparoscopy were not reported, and it is unlikely that all the participants in diagnostic laparoscopy would have false-negative results.

Diagnostic accuracy of laparoscopy following computed tomography (CT) scanning for assessing the resectability with curative intent in 


\section{Summary of findings}

\begin{tabular}{|c|c|}
\hline Population & $\begin{array}{l}\text { Males and females aged } 15 \text { to } 87 \text { years with potentially resectable pancreatic or } \\
\text { periampullary carcinoma on computed tomography (CT) scanning }\end{array}$ \\
\hline Setting & Surgical centres in the USA, Germany, the UK, Japan, Israel, and the Netherlands \\
\hline Index test & Diagnostic laparoscopy with histologic confirmation \\
\hline Reference standard & $\begin{array}{l}\text { Paraffin section histology on diagnostic laparoscopy or laparotomy or surgeon's } \\
\text { judgement of unresectability on laparotomy } \\
\text { True positive: Suspicious lesion on diagnostic laparoscopy confirmed to be } \\
\text { cancer by a histopathological examination of biopsy obtained during diagnostic } \\
\text { laparoscopy } \\
\text { False positive: This is not possible since laparotomy will only be performed if } \\
\text { histopathology of the biopsy of the suspicious lesion on diagnostic laparoscopy } \\
\text { shows no evidence of cancer } \\
\text { False negative: No evidence of unresectability by diagnostic laparoscopy but } \\
\text { evidence of unresectability on laparotomy } \\
\text { True negative: No evidence of unresectability by diagnostic laparoscopy and } \\
\text { laparotomy }\end{array}$ \\
\hline Number of studies & 16 studies \\
\hline Summary sensitivity & $64.4 \%$ (95\% confidence interval $50.1 \%$ to $76.6 \%)$ \\
\hline Consistent results & No \\
\hline Uncertainty (overall risk of bias) & High \\
\hline Other limitations & $\begin{array}{l}\text { Different definitions of unresectability because studies used surgeon's judgement } \\
\text { of unresectability on laparotomy when biopsy confirmation was not possible }\end{array}$ \\
\hline $\begin{array}{l}\text { Pre-test probability from included stud- } \\
\text { ies }^{1}\end{array}$ & $\begin{array}{l}\text { Post-test probability of unresectable Percentage of patients for whom un- } \\
\text { disease for patients with a negative test necessary laparotomy can be avoided }{ }^{3} \\
\text { result ( } 95 \% \text { confidence interval) }{ }^{2}\end{array}$ \\
\hline Minimum = 17.4 & $7.0(4.9$ to 9.8$)$ \\
\hline Lower quartile = 34.7 & $15.9(11.4$ to 21.6$)$ \\
\hline Median $=41.4$ & 20.1 (14.7 to 26.8$)$ \\
\hline Upper quartile $=62.7$ & $37.4(29.0$ to 46.6$)$ \\
\hline Maximum = 81.8 & $61.5(52.3$ to 70.0$)$ \\
\hline
\end{tabular}

Diagnostic accuracy of laparoscopy following computed tomography (CT) scanning for assessing the resectability with curative intent in 

resection purposes. These pre-test probabilities are the minimum, middle, and maximum values obtained from the included studies

${ }^{1}$ Probability of someone having unresectable disease at laparotomy after CT indicated that the disease is resectable.

${ }^{2}$ Probability of someone having unresectable disease after the CT and diagnostic laparoscopy indicated that the disease is resectable.

${ }^{3}$ Calculated as the difference between the post-test probability and the pre-test probability.

All probabilities are reported in the table as percentages. 


\section{DISCUSSION}

\section{Summary of main results}

We have summarised the results in Summary of findings. The addition of diagnostic laparoscopy to CT scanning decreases the probability of unresectable disease from $41 \%$ to $20 \%$. This means that for every 100 patients who receive a CT scan followed by diagnostic laparoscopy, 21 patients (41 minus 20) will avoid major laparotomy compared to with CT scanning alone. Although this review included studies which were more than 10 years old, with improvements in CT scanning possible over this period, the probability of unresectability was high (63.2\%) even after multidetector row CT using a pancreatic protocol (Table 2). Diagnostic laparoscopy can either be performed as a separate procedure or immediately prior to major laparotomy as part of a larger procedure. These two different approaches have distinct advantages and disadvantages. The advantages of performing diagnostic laparoscopy as part of a larger procedure are that the patient needs only one hospital admission and one general anaesthetic. However, if the patient is diagnosed as having unresectable disease at laparoscopy and the subsequent laparotomy is then cancelled, it means that operation theatre time is wasted. It is also not possible to use paraffin section, the gold standard test, to confirm a histological diagnosis of cancer if diagnostic laparoscopy is undertaken as part of a larger procedure. If laparoscopy is performed as a separate diagnostic procedure, the patient must undergo the burden of two separate hospital admissions and anaesthetics, but no operation theatre time will be wasted if they are found to have unresectable disease. The time delay between the two separate procedures also allows the use of paraffin sections.

We found no complications related to diagnostic laparoscopy in this systematic review, however the literature reports an injury rate of $0.23 \%$ involving major blood vessels or the bowel (Azevedo 2009). This indicates that diagnostic laparoscopy should only be performed by appropriately trained healthcare professionals with expertise in the conduct of diagnostic laparoscopy and biopsy during diagnostic laparoscopy.

\section{Strengths and weaknesses of the review}

A strength of this review is that we placed no restrictions on the language of publication and conducted a comprehensive search. We avoided the use of search filters and undertook additional searches to find related articles. We also performed a citation search. We therefore minimised the risk of missing relevant studies. Little is known about the mechanisms of publication bias for diagnostic accuracy studies, and so it is not possible to estimate the impact of unpublished studies on our findings. Nevertheless, the studies included in this systematic review are likely to be the majority of studies that provide evidence on this topic. Another strength of this review is that we used a recommended approach for metaanalysis.

Our review has some weaknesses. Firstly, our findings are based on studies with low methodological quality, and there was considerable between-study heterogeneity. There were between-study differences in the conduct and interpretation of diagnostic laparoscopy (in terms of what constitutes a suspicious lesion) and differences in the assessment of resectability on laparotomy. Despite the observed differences in the conduct and interpretation of diagnostic laparoscopy, the procedure appeared to decrease the number of unnecessary laparotomies in 15 of the 16 included studies. With regards to methodological quality, the presence of selection bias may raise doubts about the applicability of our findings in clinical practice. Secondly, determination of unresectability on laparotomy relies on the judgement of individual surgeons, which may not have been appropriate in some of the studies. This could have caused an error in the estimation of diagnostic accuracy. Thirdly, an inappropriate delay between diagnostic laparoscopy and laparotomy can result in patients who had previously resectable cancer developing unresectable cancer because of local or distant spread. This will underestimate the accuracy of diagnostic laparoscopy. Fourthly, inappropriate exclusion of patients is likely to result in an error in the estimation of diagnostic accuracy if the excluded patients had low likelihood of unresectability or high likelihood of unresectability. We performed a sensitivity analysis imputing the results according to the worst-case scenario, that is as false negatives. As mentioned earlier, indeterminate results at diagnostic laparoscopy will result in the patients undergoing laparotomy.

We were able to identify one previous systematic review on this topic (Chang 2009). Despite the inclusion of studies in which histopathological confirmation of suspicious lesions was not obtained, and the lack of meta-analysis on the diagnostic accuracy of diagnostic laparoscopy, the authors of the review suggested that diagnostic laparoscopy decreases unnecessary laparotomy by $4 \%$ to $36 \%$ and that diagnostic laparoscopy has a role in staging pancreatic cancer (Chang 2009). We agree broadly with the conclusions of the authors of the identified systematic review (Chang 2009).

\section{Applicability of findings to the review question}

This review is only applicable to people with pancreatic and periampullary cancer who have had a CT scan which demonstrated resectable disease prior to diagnostic laparoscopy. This review is also applicable only when the interval between diagnostic laparoscopy and laparotomy is sufficient to obtain histopathology results but not too long for the cancer to spread. Diagnostic laparoscopy appears to be beneficial in avoiding unnecessary laparotomies, and the morbidity associated with diagnostic laparoscopy is low. Costeffectiveness needs to be formally assessed to inform clinical and policy decision making in state-funded health care. 


\section{AUTHORS' CONCLUSIONS}

\section{Implications for practice}

Although the methodological quality of the evidence was limited, diagnostic laparoscopy appears to be useful in decreasing the proportion of people with pancreatic and periampullary cancer that were found to have resectable disease on CT scanning who will undergo unnecessary laparotomy.

\section{Implications for research}

1. Well-designed diagnostic test accuracy studies are needed to reliably estimate the accuracy of diagnostic laparoscopy. Comparison with positron emission tomography (PET) scanning, endoscopic ultrasound (EUS), and laparoscopic ultrasound may further demonstrate the value of diagnostic laparoscopy in staging pancreatic and periampullary cancers.
2. The conclusion of this study needs regular review as the quality of CT scanning improves, and diagnostic laparoscopy should be compared with other tests for staging pancreatic and periampullary cancers.

3. Cost-effectiveness studies should be undertaken to determine whether diagnostic laparoscopy should be routinely performed in state-funded clinical practice.

\section{ACKNOWLEDGEMENTS}

We thank the Cochrane Upper Gastrointestinal and Pancreatic Diseases Group, the UK Support Unit for Diagnostic Test Accuracy (DTA) Reviews, and the DTA editorial team for their advice in the preparation of this review.

\section{R E F E R E N C E S}

\section{References to studies included in this review}

Ahmed 2006 \{published data only\}

Ahmed SI, Bochkarev V, Oleynikov D, Sasson AR. Patients with pancreatic adenocarcinoma benefit from staging laparoscopy. Journal of Laparoendoscopic \& Advanced Surgical Techniques 2006;16(5):458-63.

Arnold 1999 \{published data only\}

Arnold JC, Neubauer HJ, Zopf T, Schneider A, Benz C, Adamek HE, et al. Improved tumor staging by diagnostic laparoscopy. Zeitschrift Fur Gastroenterologie 1999;37(6): 483-8.

Arnold 2001a \{published data only\}

Arnold JC, Schneider AR, Zopf T, Neubauer HJ, Jakobs R, Benz C, et al. Laparoscopic tumor staging in gastrointestinal carcinomas: significance of internal medicine laparoscopy [Laparoskopisches tumorstaging bei gastrointestinalen karzinomen: bedeutung der internistischen laparoskopie]. Zeitschrift Fur Gastroenterologie 2001;39 Suppl 1:19-23.

Beenen 2014 \{published data only\}

Beenen E, van Roest MHG, Sieders E, Peeters P, Porte RJ, de Boer MT, et al. Staging laparoscopy in patients scheduled for pancreaticoduodenectomy minimizes hospitalization in the remaining life time when metastatic carcinoma is found. European Journal of Surgical Oncology 2014;40(8):989-94.

Brooks 2002 \{published data only\} Brooks AD, Mallis MJ, Brennan MF, Conlon KC. The value of laparoscopy in the management of ampullary, duodenal, and distal bile duct tumors. Journal of Gastrointestinal Surgery 2002; Vol. 6, issue 2:139-45.

Contreras 2009 \{published data only\} Contreras CM, Stanelle EJ, Mansour J, Hinshaw JL, Rikkers LF, Rettammel R, et al. Staging laparoscopy enhances the detection of occult metastases in patients with pancreatic adenocarcinoma. Journal of Surgical Oncology 2009;100(8): 663-9.

Fernandez-Castillo 1995 \{published data only\} Fernandez-Castillo C, Rattner DW, Warshaw AL. Further experience with laparoscopy and peritoneal cytology in the staging of pancreatic cancer. British Journal of Surgery 1995; 82(8):1127-9.

John 1995 \{published data only\} John TG, Greig JD, Carter DC, Garden OJ. Carcinoma of the pancreatic head and periampullary region. Tumor staging with laparoscopy and laparoscopic ultrasonography. Annals of Surgery 1995; Vol. 221, issue 2:156-64.

Kishiwada 2002 \{published data only\}

Kishiwada M, Kawarada Y, Taoka H, Isaji S. Management of advanced pancreatic cancer: Staging laparoscopy and immunochemotherapy - a new treatment strategy. Hepatogastroenterology 2002;49(48):1704-6.

Lavy 2012 \{published data only\} Lavy R, Gatot I, Markon I, Shapira Z, Chikman B, Copel $\mathrm{L}$, et al. The role of diagnostic laparoscopy in detecting minimal peritoneal metastatic deposits in patients with pancreatic cancer scheduled for curative resection. Surgical Laparoscopy, Endoscopy and Percutaneous Techniques 2012;22 (4):358-60.

Menack 2001 \{published data only\} Menack MJ, Spitz JD, Arregui ME. Staging of pancreatic and ampullary cancers for resectability using laparoscopy with laparoscopic ultrasound. Surgical Endoscopy 2001;15 (10):1129-34.

Merchant 1998 \{published data only\} Conlon KC, Dougherty E, Klimstra DS, Coit DG, Turnbull AD, Brennan MF. The value of minimal access surgery in the staging of patients with potentially resectable

Diagnostic accuracy of laparoscopy following computed tomography (CT) scanning for assessing the resectability with curative intent in 19 pancreatic and periampullary cancer (Review) 
peripancreatic malignancy. Annals of Surgery 1996;223(2): 134-40.

Merchant NB, Conlon KC. Laparoscopic evaluation in pancreatic cancer. Seminars in Surgical Oncology 1998;15 (3):155-65.

Minnard EA, Conlon KC, Hoos A, Dougherty EC, Hann LE, Brennan MF. Laparoscopic ultrasound enhances standard laparoscopy in the staging of pancreatic cancer. Annals of Surgery 1998;228(2):182-7.

Reddy 1999 \{published data only\}

Reddy KR, Levi J, Livingstone A, Jeffers L, Molina E, Kligerman S, et al. Experience with staging laparoscopy in pancreatic malignancy. Gastrointestinal Endoscopy 1999;49 (4 Part 1):498-503.

Reed 1997 \{published data only\}

Reed WP, Mustafa IA. Laparoscopic screening of surgical candidates with pancreatic cancer or liver tumors. Surgical Endoscopy 1997;11(1):12-4.

Shah 2008 \{published data only\}

Shah D, Fisher WE, Hodges SE, Wu MF, Hilsenbeck SG, Charles Brunicardi F. Preoperative prediction of complete resection in pancreatic cancer. The Journal of Surgical Research 2008;147(2):216-20.

Warshaw 1986 \{published data only\} Warshaw AL, Tepper JE, Shipley WU. Laparoscopy in the staging and planning of therapy for pancreatic cancer. American Journal of Surgery 1986;151(1):76-80.

\section{References to studies excluded from this review}

Abdalla 2003 \{published data only\}

Abdalla EK, Barnett CC, Pisters PW, Cleary KR, Evans DB, Feig BW, et al. Subaquatic laparoscopy for staging of intraabdominal malignancy. Journal of the American College of Surgeons 2003;196(1):155-8.

Adisa 2014 \{published data only\}

Adisa AO, Lawal OO, Adesunkanmi AR, Adejuyigbe O. Impact of introduction of laparoscopic surgery on management of unresolved intra-abdominal malignancies in a West African hospital. World Journal of Surgery 2014; 38(10):2519-24.

Alexakis 2015 \{published data only\} Alexakis N, Gomatos IP, Sbarounis S, Toutouzas K, Katsaragakis S, Zografos G, et al. High serum Ca 19-9 but not tumor size should select patients for staging laparoscopy in radiological resectable pancreas head and peri-ampullary cancer. European Journal of Surgical Oncology 2015;41(2): 265-9.

Altieri 1982 \{published data only\}

Altieri A, Roggia G, Ciavarella G, Tricarico F. The contribution of laparoscopy to the diagnosis of abdominal masses. Personal experience. [Italian]. Minerva Chirurgica 1982;37(5):427-9.

Andren-Sandberg 1998 \{published data only\} Andren-Sandberg A, Lindberg CG, Lundstedt C, Ihse I. Computed tomography and laparoscopy in the assessment of the patient with pancreatic cancer. Journal of the American College of Surgeons 1998;186(1):35-40.

Arnold 2001 \{published data only\} Arnold JC, Schneider ARJ, Zopf T, Riemann JF. Laparoscopic tumor staging - a safe method in the hands of internists. Klinikarzt 2001;30(5):142-6.

Atanov 1972 \{published data only\}

Atanov YP, Gallinger YI. Laparoscopy in the diagnosis of some abdominal tumors. Sovetskaya Meditsina 1972;35(5): 93-8.

Awad 1997 \{published data only\}

Awad SS, Colletti L, Mulholland M, Knol J, Rothman ED, Scheiman J, et al. Multimodality staging optimizes resectability in patients with pancreatic and ampullary cancer. American Surgeon 1997;63(7):634-8.

Baghbanian 2013 \{published data only\}

Baghbanian M, Salmanroghani H, Baghbanian A, Bakhtpour M, Shabazkhani B. Efficacy of multi-detector computerized tomography scan, endoscopic ultrasound, and laparoscopy for predicting tumor resectability in pancreatic adenocarcinoma. Indian Journal of Gastroenterology 2013; 32(6):376-80.

Baghbanian 2014 \{published data only\} Baghbanian M, Salmanroghani H, Baghbanian A, Bakhtpour M, Shabazkhani B. Resectability of the pancreatic adenocarcinoma: A study from Iran. Advanced Biomedical Research 2014;3:265.

Balcom 2000 \{published data only\} Balcom JH, Fernandez-del Castillo C. Can we predict resectability in pancreatic cancer?. Annals of Gastroenterology 2000;13(3):201-6.

Barabino 2011 \{published data only\}

Barabino M, Santambrogio R, Pisani Ceretti A, Scalzone R, Montorsi M, Opocher E. Is there still a role for laparoscopy combined with laparoscopic ultrasonography in the staging of pancreatic cancer?. Surgical Endoscopy 2011;25(1):160-5.

Barrat 1998 \{published data only\}

Barrat C, Champault G, Catheline JM. Is laparoscopic evaluation of digestive cancers legitimate? A prospective study of 109 cases. Annales De Chirurgie 1998;52(7):602-6.

Barreiro 2002 \{published data only\} Barreiro CJ, Lillemoe KD, Koniaris LG, Sohn TA, Yeo CJ, Coleman J, et al. Diagnostic laparoscopy for periampullary and pancreatic cancer: What is the true benefit?. Journal of Gastrointestinal Surgery 2002;6(1):75-81.

Barthet 2007 \{published data only\} Barthet M, Moutardier V, Marciano S. Pancreatic adenocarcinoma: Which assessment to appreciate the resection?. Gastroenterologie Clinique Et Biologique 2007;31 (2):216-21

Baumgarten 1984 \{published data only\} Baumgarten R, Fengler JD. Current diagnostic value of laparoscopy. Zeitschrift für ärztliche Fortbildung 1984;78 (20):841-2.

Diagnostic accuracy of laparoscopy following computed tomography (CT) scanning for assessing the resectability with curative intent in 
Beger 1997 \{published data only\}

Beger HG, Schoenberg MH. The role of laparoscopy and ultrasonography in pancreatic head carcinoma. HPB Surgery 1997;10(3):186-8.

Belagyi 2000 \{published data only\}

Belagyi T, Olah A. Pancreatic head mass: what can be done? Diagnosis: laparoscopy. Journal of the Pancreas 2000;1 (3 Suppl):123-6.

Bemelman 1995 \{published data only\}

Bemelman WA, de Wit LT, van Delden OM, Smits NJ, Obertop H, Rauws EJ, et al. Diagnostic laparoscopy combined with laparoscopic ultrasonography in staging of cancer of the pancreatic head region. British Journal of Surgery 1995;82(6):820-4.

Bohmig 2001 \{published data only\} Bohmig M, Wiedenmann B, Rosewicz S. Diagnosis and staging of carcinoma of the pancreas. [German]. Deutsche Medizinische Wochenschrift 2001;126(5):113-6.

Borbath 2005 \{published data only\}

Borbath I, Van Beers BE, Lonneux M, Schoonbroodt D, Geubel A, Gigot JF, et al. Preoperative assessment of pancreatic tumors using magnetic resonance imaging, endoscopic ultrasonography, positron emission tomography and laparoscopy. Pancreatology 2005;5(6):553-61.

Boselli 2000 \{published data only\}

Boselli C, Trebuchet G, Bufalari A, De Santis F, Cirocchi R, Giustozzi G. Laparoscopic staging in surgical oncology. EAES: Proceedings of the 8th International Congress of the European Association for Endoscopic Surgery. 2000: $647-52$.

Bottger 1998 \{published data only\} Bottger TC, Boddin J, Duber C, Heintz A, Kuchle $\mathrm{R}$, Junginger T. Diagnosing and staging of pancreatic carcinoma - what is necessary?. Oncology 1998;55(2): 122-9.

Boyce 1992 \{published data only\} Boyce HW, Henning H. Diagnostic laparoscopy 1992: Time for a new look. Endoscopy 1992;24(8):671-3.

Caldironi 1996 \{published data only\} Caldironi MW, Zani S, Mazzucco M, Paccagnella D, Aldinio MT, Costantin G, et al. Ultrasound-guided fine needle biopsy and laparoscopy in the study of pancreatic masses: report on 136 cases. General \& Diagnostic Pathology 1996;141(5-6):313-8.

Callery 1997 \{published data only\} Callery MP, Strasberg SM, Doherty GM, Soper NJ, Norton JA. Staging laparoscopy with laparoscopic ultrasonography: optimizing resectability in hepatobiliary and pancreatic malignancy. Journal of the American College of Surgeons 1997;185(1):33-9.

Callery 2009 \{published data only\} Callery MP, Chang KJ, Fishman EK, Talamonti MS, William Traverso L, Linehan DC. Pretreatment assessment of resectable and borderline resectable pancreatic cancer:
Expert consensus statement. Annals of Surgical Oncology 2009;16(7):1727-33.

Camacho 2005 \{published data only\}

Camacho D, Reichenbach D, Duerr GD, Venema TL, Sweeney JF, Fisher WE. Value of laparoscopy in the staging of pancreatic cancer. Journal of the Pancreas 2005;6(6): 552-61.

Carmichael 1995 \{published data only\} Carmichael AR, Jackson BT. Diagnostic laparoscopy combined with laparoscopic ultrasonography in staging of cancer of the pancreatic head region. British Journal of Surgery 1995;82(12):1703-4.

Carpenter 1996 \{published data only\} Carpenter SL, Scheiman JM. Pancreatic imaging. Current Opinion in Gastroenterology 1996;12(5):442-7.

Catheline 1998 \{published data only\} Catheline JM, Polliand C, Risk N, Barrat C, Champault G. Staging of pancreatic cancer by laparoscopy and laparoscopic ultrasonography. Chirurgie 1998;123(3):271-9.

Catheline 1999 \{published data only\} Catheline JM, Turner R, Rizk N, Barrat C, Champault G. The use of diagnostic laparoscopy supported by laparoscopic ultrasonography in the assessment of pancreatic cancer. Surgical Endoscopy 1999;13(3):239-45.

Chambon 1995 \{published data only\} Chambon JP, Bosse JL, Denimal F, Porte H, Quandalle P. Place of celioscopy in the diagnosis of invasiveness of digestive cancers. Annales de Chirurgie 1995;49(6):513-8.

Champault 1996 \{published data only\} Champault G, Catheline JM, Rizk N, Boutelier P. The use of laparoscopic ultrasound in the staging of pancreatic cancers. Annales de Chirurgie 1996;50(10):875-85.

Champault 1997 \{published data only\} Champault G. The use of laparoscopic ultrasound in the assessment of pancreatic cancer. Wiad Lek 1997;50 Suppl Pt 1:195-203.

Charukhchyan 1998 \{published data only\} Charukhchyan SA, Lucas GW. Lesser sac endoscopy and laparoscopy in pancreatic carcinoma definitive diagnosis, staging and palliation. American Journal of Surgery 1998;64 (9):809-14.

Cipollone 2012 \{published data only\} Cipollone I, Kelly M, Corbally C, Torreggiani W, Ridgway PF, Conlon KC. Is there still a utility for selected laparoscopic staging in pancreas cancer with contemporary multi detector CT scanning?. Pancreatology 2012;12(3): e12.

Conlon 1997 \{published data only\} Conlon KCP, Minnard EA. The value of laparoscopic staging in upper gastrointestinal malignancy. Oncologist 1997;2(1):10-7.

Conlon 1999 \{published data only\} Conlon KC. Value of laparoscopic staging for upper gastrointestinal malignancies. Journal of Surgical Oncology 1999;71(2):71-3.

Diagnostic accuracy of laparoscopy following computed tomography (CT) scanning for assessing the resectability with curative intent in 21 pancreatic and periampullary cancer (Review)

Copyright () 2016 The Cochrane Collaboration. Published by John Wiley \& Sons, Ltd. 
Conlon 2002 \{published data only\}

Conlon KC, McMahon RL. Minimally invasive surgery in the diagnosis and treatment of upper gastrointestinal tract malignancy. Annals of Surgical Oncology 2002;9(8):725-37.

Connor 2004 \{published data only\}

Connor S, Neoptolemos JP. Laparoscopy is still necessary in the assessment of peri-ampullary neoplasia. Pancreatology 2004;4(5):415-6.

Croome 2009 \{published data only\}

Croome K, Jayaraman S, Schlachta C. Preoperative staging in cancer of the pancreatic head: is there room for improvement?. Asia-Pacific Journal of Clinical Oncology 2009;5:A192.

Croome 2010 \{published data only\}

Croome KP, Jayaraman S, Schlachta CM. Preoperative staging of cancer of the pancreatic head: Is there room for improvement?. Canadian Journal of Surgery 2010;53(3): $171-4$.

Cuesta 1993 \{published data only\} Cuesta MA, Meijer S, Borgstein PJ, Sibinga Mulder L, Sikkenk AC. Laparoscopic ultrasonography for hepatobiliary and pancreatic malignancy. British Journal of Surgery 1993;80(12):1571-4.

Cuschieri 1978 \{published data only\} Cuschieri A, Hall AW, Clark J. Value of laparoscopy in the diagnosis and management of pancreatic carcinoma. Gut 1978;19(7):672-7.

Cuschieri 1988 \{published data only\} Cuschieri A. Laparoscopy for pancreatic cancer: does it benefit the patient?. European Journal of Surgical Oncology 1988;14(1):41-4.

D'Angelica 2003 \{published data only\} D'Angelica M, Fong Y, Weber S, Gonen M, DeMatteo $\mathrm{RP}$, Conlon K, et al. The role of staging laparoscopy in hepatobiliary malignancy: Prospective analysis of 401 cases. Annals of Surgical Oncology 2003;10(2):183-9.

Dadan 1980 \{published data only\}

Dadan H, Boron P, Szpakowicz T, Nowak H, Kurasz $\mathrm{S}$, Zalewski J, et al. Diagnostic value of preoperative laparoscopy in detection of neoplastic changes. Polski Przeglad Chirurgiczny 1980;52(4):307-10.

Doran 2004 \{published data only\}

Doran HE, Bosonnet L, Connor S, Jones L, Garvey C, Hughes M, et al. Laparoscopy and laparoscopic ultrasound in the evaluation of pancreatic and periampullary tumours. Digestive Surgery 2004;21(4):305-13.

Doucas 2007 \{published data only\}

Doucas H, Sutton CD, Zimmerman A, Dennison AR, Berry DP. Assessment of pancreatic malignancy with laparoscopy and intraoperative ultrasound. Surgical Endoscopy 2007;21 (7):1147-52.

Duffy 2008 \{published data only\}

Duffy A, O'Reilly EM. What is the optimal treatment of localized pancreatic adenocarcinoma?. Oncology-New York 2008;22(11):1283-91.
Durup Scheel-Hincke 1999 \{published data only\}

Durup Scheel-Hincke J, Mortensen MB, Qvist N,

Hovendal CP. TNM staging and assessment of resectability of pancreatic cancer by laparoscopic ultrasonography. Surgical Endoscopy 1999;13(10):967-71.

Eigler 1999 \{published data only\} Eigler FW, Hossfeld DK, Junginger T, Kloppel G, Kruck P, Meyer HJ, et al. Guidelines for exocrine pancreas carcinoma. Onkologe 1999;5(3):257-60.

Ellsmere 2005 \{published data only\} Ellsmere J, Mortele K, Sahani D, Maher M, Cantisani V, Wells W, et al. Does multidetector-row CT eliminate the role of diagnostic laparoscopy in assessing the resectability of pancreatic head adenocarcinoma?. Surgical Endoscopy 2005;19(3):369-73.

Enestvedt 2008 \{published data only\} Enestvedt CK, Mayo SC, Diggs BS, Mori M, Austin DA, Shipley DK, et al. Diagnostic laparoscopy for patients with potentially resectable pancreatic adenocarcinoma: Is it costeffective in the current era?. Journal of Gastrointestinal Surgery 2008;12(7):1177-84.

Mayo SC, Austin DF, Sheppard BC, Mori M, Shipley DK, Billingsley KG. Evolving preoperative evaluation of patients with pancreatic cancer: Does laparoscopy have a role in the current era?. Journal of the American College of Surgeons 2009;208(1):87-95.

Fernandez-del Castillo 1994 \{published data only\} Fernandez-del Castillo C, Warshaw AL. Preoperative evaluation of adenocarcinoma of the pancreas: Massachusetts General Hospital experience. Cancer Bulletin 1994;46(6):492-8.

Fernandez-del Castillo 1998 \{published data only\} Fernandez-del Castillo C, Warshaw AL. Laparoscopic staging and peritoneal cytology. Surgical Oncology Clinics of North America 1998;7(1):135-42.

Ferrone 2006 \{published data only\}

Ferrone CR, Haas B, Tang L, Coit DG, Fong Y, Brennan MF, et al. The influence of positive peritoneal cytology on survival in patients with pancreatic adenocarcinoma. Journal of Gastrointestinal Surgery 2006;10(10):1347-53.

Feussner 2000 \{published data only\}

Feussner H, Baumgartner M, Siewert JR. Extended diagnostic laparoscopy (EDL). Acta Chirurgica Austriaca 2000;32(5):212-20.

Fevery 1985 \{published data only\} Fevery J, Baert AL, Marchal GM, Broeckaert L, De Groote J, Vantrappen G. The value of computed tomography, ultrasonography, and peritoneoscopy with biopsy in the detection of liver metastases secondary to gastroenterological tumors. Acta Gastro-Enterologica Belgica 1985; 48(2):105-10.

Fockens 1993 \{published data only\}

Fockens P, Huibregtse K. Staging of pancreatic and ampullary cancer by endoscopy. Endoscopy 1993;25(1): $52-7$.

Diagnostic accuracy of laparoscopy following computed tomography (CT) scanning for assessing the resectability with curative intent in 
Friess 1997 \{published data only\}

Friess H, Baer HU, Sadowski C, Buchler MW. Efficacy and economic aspects of preoperative diagnosis: laparoscopy is useful in only $13 \%$ of patients with pancreatic carcinoma. Langenbecks Archiv für Chirurgie. Supplement. Kongressband 1997;114:474-6.

Friess 1998 \{published data only\}

Friess H, Kleeff J, Silva JC, Sadowski C, Baer HU, Buchler $\mathrm{MW}$. The role of diagnostic laparoscopy in pancreatic and periampullary malignancies. Journal of the American College of Surgeons 1998;186(6):675-82.

Fristrup 2006 \{published data only\}

Fristrup CW, Mortensen MB, Pless T, Durup J, Ainsworth A, Hovendal C, et al. Combined endoscopic and laparoscopic ultrasound as preoperative assessment of patients with pancreatic cancer. HPB 2006;8(1):57-60.

Fukumoto 1989 \{published data only\}

Fukumoto Y, Okita K, Takemoto T. Utility of laparoscopic ultrasonography in the diagnosis of hepato-biliary and pancreatic carcinoma. Zeitschrift Fur Gastroenterologie 1989; 27(Special Issue):92-7.

Garcea 2012 \{published data only\}

Garcea G, Cairns V, Berry DP, Neal CP, Metcalfe MS, Dennison AR. Improving the diagnostic yield from staging laparoscopy for periampullary malignancies: the value of preoperative inflammatory markers and radiological tumor size. Pancreas 2012;41(2):233-7.

Garofalo 2009 \{published data only\}

Garofalo A, Valle M. Laparoscopy in the management of peritoneal carcinomatosis. The Cancer Journal 2009; 15(3): $190-5$.

Gouma 1996 \{published data only\}

Gouma DJ, de Wit LT, Nieveen van Dijkum E, Van Delden O, Bemelman WA, Rauws EA, et al. Laparoscopic ultrasonography for staging of gastrointestinal malignancy. Scandinavian Journal of Gastroenterology 1996;31 Suppl 218:43-9.

Gouma 1999 \{published data only\} Gouma DJ, van Dijkum E, Obertop H. The standard diagnostic work-up and surgical treatment of pancreatic head tumours. European Journal of Surgical Oncology 1999; 25(2):113-23

Gouma 2002 \{published data only\} Gouma DJ, Obertop H. Management of hepatobiliary and pancreatic disorders at the Academic Medical Center Amsterdam, Netherlands. HPB 2002;4(1):35-7.

Hann 1997 \{published data only\}

Hann LE, Conlon KC, Dougherty EC, Hilton S, Bach AM, Brennan MF. Laparoscopic sonography of peripancreatic tumors: Preliminary experience. American Journal of Roentgenology 1997;169(5):1257-62.

Hashimoto 2015 \{published data only\} Hashimoto D, Chikamoto A, Sakata K, Nakagawa S, Hayashi H, Ohmuraya M, et al. Staging laparoscopy leads to rapid induction of chemotherapy for unresectable pancreatobiliary cancers. Asian Journal of Endoscopic Surgery 2015;8(1):59-62.

Healthcare 1999 \{published data only\}

Healthcare IBvoorz. Laparoscopy in pancreas cancer - primary research (brief record). Diemen: Healthcare Insurance Board/College voor Zorgverzekeringen (CVZ), 1999.

Heger 2008 \{published data only\}

Heger U, Buchler MW, Weitz J. Diagnostics of pancreatic carcinoma. Tumor Diagnostik und Therapie 2008;29(5): 246-9.

Hernandezguio 1965 \{published data only\} Hernandezguio C. Our experiences with laparoscopic exploration. Revista Española de las Enfermedades del Aparato Digestivo y de la Nutrición 1965;24:216-23.

Herrera 2003 \{published data only\} Herrera MF, Velazquez D, Bezauri P, Angeles-Angeles A, Uscanga LF, Robles-Diaz G. Role of laparoscopy with ultrasound in the staging process of pancreatic and ampullary tumors. Gaceta Médica de México 2003;139(1): $21-5$.

Hidalgo 2004 \{published data only\}

Hidalgo Pascual M, Ferrero Herrero E, Castillo Fe MJ, Guadarrama Gonzalez FJ, Pelaez Torres P, Botella Ballesteros F. Epidemiology and diagnosis of the pancreatic cancer. Revista Espanola de Enfermedades Digestivas 2004;96(10): 714-22.

Hohenberger 2000 \{published data only\} Hohenberger P, Hunerbein M, Rau B, Schlag PM. Staging laparoscopy - indication, surgical technique and significance in the therapeutical concept of malignant tumors. Viszeralchirurgie 2000;35(1):2-7.

Holzman 1997 \{published data only\} Holzman MD, Reintgen KL, Tyler DS, Pappas TN. The role of laparoscopy in the management of suspected pancreatic and periampullary malignancies. Journal of Gastrointestinal Surgery 1997;1(3):236-43.

Hunerbein 1999 \{published data only\} Hunerbein M, Rau B, Schlag PM. Role of staging laparoscopy. Minimally invasive and endoscopic therapy in pancreas carcinoma. Onkologe 1999;5(3):203-7.

Hunerbein 2001 \{published data only\} Hunerbein M, Rau B, Hohenberger P, Schlag PM. Value of laparoscopic ultrasound for staging of gastrointestinal tumors. Der Chirurg; Zeitschrift für alle Gebiete der operativen Medizen 2001;72(8):914-9.

Ialongo 2010 \{published data only\} Ialongo P, Ferrarese F, Pannarale O, Panebianco A, Volpi A, Palasciano N. The role of laparoscopy in surgical treatment of pancreatic cancer [Il ruolo della laparoscopia nel trattamento chirurgico del carcinoma pancreatico]. Annali Italiani di Chirurgia 2010;81(4):295-9.

Ialongo 2015 \{published data only\} Ialongo P, Milella M, Pascazio B, Prestera A, Pannarale $\mathrm{O}$, Panebianco A, et al. Laparoscopic management of

Diagnostic accuracy of laparoscopy following computed tomography (CT) scanning for assessing the resectability with curative intent in 23 pancreatic and periampullary cancer (Review)

Copyright $\odot 2016$ The Cochrane Collaboration. Published by John Wiley \& Sons, Ltd. 
pancreatic cancer. Our experience. Annali Italiani di Chirurgia 2015;86:518-23.

Ido 1982 \{published data only\}

Ido K. Laparoscopic observation of pancreatic cancer. Gastroenterological Endoscopy 1982;24(7):1164-5.

Ihse 1984 \{published data only\} Ihse I, Isaksson G. Preoperative and operative diagnosis of pancreatic cancer. World Journal of Surgery 1984;8(6): 846-53.

Ishida 1983 \{published data only\}

Ishida H. Peritoneoscopy and pancreas biopsy in the diagnosis of pancreatic diseases. Gastrointestinal Endoscopy 1983;29(3):211-8.

Ishida 1984 \{published data only\}

Ishida H, Dohzono T, Furukawa Y. Laparoscopy and biopsy in the diagnosis of malignant intra-abdominal tumors. Endoscopy 1984;16(4):140-2.

Ivanov 1989 \{published data only\}

Ivanov S, Keranov S. Laparoscopic assessment of the operability of pancreatic cancer. Khirurgiia 1989;42(1): $12-4$

Jackowski 1997 \{published data only\} Jackowski M, Juzkow H, Szeliga J, Zalucki M, Nowak M, Jedrzejczyk W. Laparoscopic staging in neoplastic diseases clinical experience. Acta Endoscopica Polona 1997;7(1):3-5.

Jakobs 1999 \{published data only\}

Jakobs R, Martin WR, Riemann JF. Current diagnostic possibilities of pancreas carcinoma. Onkologe 1999;5(3): 194-202.

Jarnagin 2000 \{published data only\} Jarnagin WR, Bodniewicz J, Dougherty E, Conlon K, Blumgart LH, Fong Y. A prospective analysis of staging laparoscopy in patients with primary and secondary hepatobiliary malignancies. Journal of Gastrointestinal Surgery 2000;4(1):34-42.

Jayakrishnan 2015 \{published data only\} Jayakrishnan TT, Nadeem H, Groeschl RT, George B, Thomas JP, Ritch PS, et al. Diagnostic laparoscopy should be performed before definitive resection for pancreatic cancer: A financial argument. HPB 2015;17(2):131-9.

Jerby 1998 \{published data only\}

Jerby BL, Milsom JW. Role of laparoscopy in the staging of gastrointestinal cancer. Oncology 1998;12(9):1353-60.

Jimenez 2000 \{published data only\}

Jimenez RE, Warshaw AL, Fernandez-del Castillo C. Laparoscopy and peritoneal cytology in the staging of pancreatic cancer. Journal of Hepato-Biliary-Pancreatic Surgery 2000;7(1):15-20.

Jimenez 2000a \{published data only\}

Jimenez RE, Warshaw AL, Rattner DW, Willett CG, McGrath D, Fernandez-del Castillo C. Impact of laparoscopic staging in the treatment of pancreatic cancer. Archives of Surgery 2000;135(4):409-14.
John 1999 \{published data only\}

John TG, Wright A, Allan PL, Redhead DN, Paterson-

Brown S, Carter DC, et al. Laparoscopy with laparoscopic ultrasonography in the TNM staging of pancreatic carcinoma. World Journal of Surgery 1999;23(9):870-81.

Juzkow 1996 \{published data only\}

Juzkow H, Jackowski M, Jedrzejczyk W. Laparoscopy as a diagnostic and therapeutic method in the treatment of pancreatic carcinoma. Acta Endoscopica Polona 1996;6(1): 31-3.

Kadar 1997 \{published data only\}

Kadar E, Nagy P, Faludi S, Jakab F. Diagnostic-staging laparoscopy. Acta Chirurgica Hungarica 1997;36(1-4): 160-1.

Kanazawa 1983 \{published data only\}

Kanazawa H, Sakamoto F, Makino T. Laparoscopy in upper GI malignancies. Gastroenterological Endoscopy 1983;25(9): 1353-65.

Kaplan 1979 \{published data only\} Kaplan LR. Medicine grand rounds. Laparoscopy in internal medicine. Minnesota Medicine 1979;62(12): 889-93.

Karachristos 2005 \{published data only\} Karachristos A, Scarmeas N, Hoffman JP. CA 19-9 levels predict results of staging laparoscopy in pancreatic cancer. Journal of Gastrointestinal Surgery 2005;9(9):1286-92.

Kellokumpu 1996 \{published data only\} Kellokumpu I, Victorzon M. The role of laparoscopic staging in the assessment of metastasis of upper quadrant abdominal neoplasms. Duodecim 1996; Vol. 112, issue 4: 257-62.

Kelly 2009 \{published data only\} Kelly KJ, Wong J, Gladdy R, Moore-Dalal K, Woo Y, Gonen M, et al. Prognostic impact of RT-PCR-based detection of peritoneal micrometastases in patients with pancreatic cancer undergoing curative resection. Annals of Surgical Oncology 2009;16(12):3333-9.

Khamdanov 1983 \{published data only\} Khamdanov K, Sabirov BU, Salokhiddinov BM. Laparoscopy in diseases of the liver, biliary tract, and pancreas. Khirurgiia 1983, (8):143-6.

Kiyonaga 1982 \{published data only\}

Kiyonaga G, Miyamoto S, Kita R, Yukawa E. Laparoscopy and biopsy. Nippon Rinsho 1982;40(3):660-9.

Klingler 2000 \{published data only\}

Klingler A, Klocker J, Springer R, Kober F, Glaser K. Combined laparoscopy and laparoscopic ultrasonography in the oncologic diagnostics of pancreas and liver. Acta Chirurgica Austriaca 2000;32(5):228-32.

Krahenbuhl 1997 \{published data only\} Krahenbuhl L, Buchler MW. Update in laparoscopic surgery. Digestive Surgery 1997;14(5):331-2. 
Krustev 1998 \{published data only\}

Krustev N, Grigorov N. Laparoscopy and laparoscopic echography in the diagnosis of pancreatic diseases. Khirurgiia 1998;51(2):20-4.

Kubyshkin 2000 \{published data only\} Kubyshkin VA, Vishnevskii VA, Airapetian AT, Karmazanovskii GG, Kuntsevich GI, Starkov IG. Differential diagnosis of pancreatic head cancer. Khirurgiia 2000;11:19-23.

Kuster 1967 \{published data only\} Kuster G, Biel F. Accuracy of laparoscopic diagnosis. The American Journal of Medicine 1967;42(3):388-93.

Kwon 2002 \{published data only\} Kwon AH, Inui H, Kamiyama Y. Preoperative laparoscopic examination using surgical manipulation and ultrasonography for pancreatic lesions. Endoscopy 2002;34 (6):464-8

Lavonius 2001 \{published data only\}

Lavonius MI, Laine S, Salo S, Sonninen P, Ovaska J. Role of laparoscopy and laparoscopic ultrasound in staging of pancreatic tumours. Annales Chirurgiae et Gynaecologiae 2001;90(4):252-5.

Lightdale 1992 \{published data only\} Lightdale CJ. Laparoscopy for cancer staging. Endoscopy 1992;24(8):682-6.

Liu 2004 \{published data only\}

Liu RC, Traverso LW. Laparoscopic staging should be used routinely for locally extensive cancer of the pancreatic head. Journal of Gastrointestinal Surgery 2004;8(8):923-4.

Long 2005 \{published data only\}

Long EE, Van Dam J, Weinstein S, Jeffrey B, Desser T, Norton JA. Computed tomography, endoscopic, laparoscopic, and intra-operative sonography for assessing resectability of pancreatic cancer. Surgical Oncology 2005; 14(2):105-13

Luque-de Leon 1998 \{published data only\} Luque-de Leon E, Tsiotos GG, Balsiger BM, Barnwell J, Burgart L, Sarr MG. Staging laparoscopy for pancreatic cancer should be used to select the best palliation, not to increase resection rate. Gastroenterology 1998;114(4): A1407.

Luque-de Leon 1999 \{published data only\}

Luque-de Leon E, Tsiotos GG, Balsiger B, Barnwell J, Burgart LJ, Sarr MG. Staging laparoscopy for pancreatic cancer should be used to select the best means of palliation and not only to maximize the resectability rate. Journal of Gastrointestinal Surgery 1999;3(2):111-7.

Macutkiewicz 2009 \{published data only\}

Macutkiewicz C, Manu M, Sherlock D, O’Reilly D.

Platelet-lymphocyte ratio and serum carbohydrate antigen 19-9 levels aid in patient selection for staging laparoscopy in suspected pancreatic malignancy. Pancreatology 2009;9(4): 525.

Madsen 1994 \{published data only\}

Madsen MR, Bau Mortensen M, Hovendal C. Explorative laparotomy or laparoscopy in patients with carcinoma of the stomach and pancreas?. Minimally Invasive Therapy 1994;3

(5):267-70.

Madsen 1994a \{published data only\}

Madsen MR, Mortensen MB, Hovendal CP. Preoperative laparoscopic evaluation of patients with upper gastrointestinal cancer. Ugeskrift For Laeger 1994;156(34): 4810-2.

Maire 2004 \{published data only\}

Maire F, Sauvanet A, Trivin F, Hammel P, O’Toole D, Palazzo L, et al. Staging of pancreatic head adenocarcinoma with spiral CT and endoscopic ultrasonography: An indirect evaluation of the usefulness of laparoscopy. Pancreatology 2004;4(5):436-40.

Maithel 2008 \{published data only\} Maithel SK, Maloney S, Winston C, Gonen M, D'Angelica MI, DeMatteo RP, et al. Preoperative CA 19-9 and the yield of staging laparoscopy in patients with radiographically resectable pancreatic adenocarcinoma. Annals of Surgical Oncology 2008;15(12):3512-20.

Meduri 1994 \{published data only\} Maffei Faccioli A, Meduri F, Caldironi MW, Diana F, Losacco L, Merenda R, et al. The role of laparoscopy and peritoneal cytology in the preoperative staging of pancreatic carcinoma. Chirurgia Italiana 1994;46(2):26-9.

Meduri F, Diana F, Merenda R, Caldironi MW, Zuin

A, Losacco L, et al. Implication of laparoscopy and peritoneal cytology in the staging of early pancreatic cancer. Zentralblatt für Pathologie 1994; Vol. 140, issue 3:243-6.

Metcalfe 2003 \{published data only\} Metcalfe MS, Maddern GJ. Laparoscopic staging of upper gastrointestinal malignancy. ANZ Journal of Surgery 2003; 73(10):782-3.

Meyer 1973 \{published data only\} Meyer Burg J, Ziegler U, Kirstaedter HJ, Palme G. Peritoneoscopy in carcinoma of the pancreas. Report of 20 cases. Endoscopy 1973;5(2):86-90.

Misra 2012 \{published data only\}

Misra N, Battersby C, Staettner S, Grimes N, McChesney E, Poston G, et al. The role of laparoscopy and tumour biomarkers in potentially resectable hepatobiliary disease; experience from a regional hepatobiliary centre. $H P B$ 2012; 14:555-6.

Molnar 2010 \{published data only\} Molnar G, Iancu C, Munteanu D, Muntean V, Al Hajjarz $\mathrm{N}$, Bala $\mathrm{O}$, et al. The role of diagnostic laparoscopy in periampullary and pancreatic cancers. A study based on 27 cases. Chirurgia 2010;105(3):383-6.

Morak 2009 \{published data only\} Morak MJ, Hermans JJ, Smeenk HG, Renders WM, Nuyttens JJ, Kazemier G, et al. Staging for locally advanced pancreatic cancer. European Journal of Surgical Oncology 2009;35(9):963-8.

Morganti 2005 \{published data only\} Morganti AG, Brizi MG, Macchia G, Sallustio G, Costamagna G, Alfieri S, et al. The prognostic effect of

Diagnostic accuracy of laparoscopy following computed tomography (CT) scanning for assessing the resectability with curative intent in 25 pancreatic and periampullary cancer (Review)

Copyright $\odot 2016$ The Cochrane Collaboration. Published by John Wiley \& Sons, Ltd. 
clinical staging in pancreatic adenocarcinoma. Annals of Surgical Oncology 2005;12(2):145-51.

Mortensen 1996 \{published data only\}

Mortensen MB, Scheel-Hincke JD, Madsen MR, Qvist N, Hovendal C. Combined endoscopic ultrasonography and laparoscopic ultrasonography in the pretherapeutic assessment of resectability in patients with upper gastrointestinal malignancies. Scandinavian Journal of Gastroenterology 1996;31(11):1115-9.

Muniraj 2013 \{published data only\}

Muniraj T, Barve P. Laparoscopic staging and surgical treatment of pancreatic cancer. North American Journal of Medical Sciences 2013;5(1):1-9.

Muntean 2009 \{published data only\}

Muntean V, Oniu T, Lungoci C, Fabian O, Munteanu D, Molnar G, et al. Staging laparoscopy in digestive cancers. Journal of Gastrointestinal and Liver Diseases 2009;18(4): 461-7.

Munteanu 2010 \{published data only\}

Munteanu D, Iancu C, Munteanu A, Muntean V, Molnar $\mathrm{G}$, Mocan T, et al. Is staging laparoscopy in radiologically resectable pancreatic tumours still useful?. European Journal of Surgical Oncology 2010;36(9):899.

Murugiah 1993 \{published data only\} Murugiah M, Paterson-Brown S, Windsor JA, Miles WF, Garden OJ. Early experience of laparoscopic ultrasonography in the management of pancreatic carcinoma. Surgical Endoscopy 1993;7(3):177-81.

Nagy 1999 \{published data only\}

Nagy A, Pardavi G, Olah A. The role of diagnostic laparoscopy in staging of pancreatic cancers. Acta chirurgica Hungarica 1999;38(2):193-6.

Nieveen 1996 \{published data only\}

Nieveen van Dijkum EJ, Romijn MG, Terwee CB, van der Meulen JH, de Haes JC, de Wit LT, et al. Value of laparoscopic staging and palliative treatment of periampullary tumors; the Stentby Study. Nederlands Tijdschrift Voor Geneeskunde 1996;140(50):2523-4.

Nieveen 1997 \{published data only\}

Nieveen van Dijkum EJ, de Wit LT, van Delden OM, Rauws EA, van Lanschot JJ, Obertop H, et al. The efficacy of laparoscopic staging in patients with upper gastrointestinal tumors. Cancer 1997;79(7):1315-9.

Nieveen 1998 \{published data only\}

Nieveen van Dijkum EJ, Sturm PD, de Wit LT, Offerhaus J, Obertop H, Gouma DJ. Cytology of peritoneal lavage performed during staging laparoscopy for gastrointestinal malignancies: is it useful?. Annals of Surgery 1998;228(6): 728-33.

Nieveen 1999 \{published data only\}

Nieveen van Dijkum EJ, de Wit LT, van Delden OM, Kruyt PM, van Lanschot JJ, Rauws EA, et al. Staging laparoscopy and laparoscopic ultrasonography in more than 400 patients with upper gastrointestinal carcinoma. Journal of the American College of Surgeons 1999;189(5):459-65.
Nieveen 2000 \{published data only\}

Nieveen van Dijkum EJM, Romijn MG, Terwee CB, de Wit LT, van der Meulen JHP, Bossuyt PMM, et al. Randomised study of laparoscopy and laparoscopic ultrasonography (LLU) for periampullary tumors: Effect on staging and treatment. European of Journal of Gastroenterology \& Hepatology 2000;12:A51.

\section{Nieveen 2003 \{published data only\}} Nieveen van Dijkum EJM, Romijn MG, Terwee CB, De Wit L, Van Der Meulen JHP, Lameris JS, et al. Laparoscopic staging in patients with a peripancreatic tumour is of limited value for diagnosis and palliative treatment. Nederlands Tijdschrift Voor Geneeskunde 2003;147(36):1734-40.

Nieveen 2003a \{published data only\}

Nieveen van Dijkum EJM, Romijn MG, Terwee CB, de Wit LT, Van der Meulen JHP, Lameris HS, et al. Laparoscopic staging and subsequent palliation in patients with peripancreatic carcinoma. Annals of Surgery 2003;237 (1):66-73.

\section{Occelli 1999 \{published data only\}}

Occelli G, Feroce A, Barrat C, Catheline JM, Champault G. Staging of pancreatic cancer by laparoscopy and laparoscopic ultrasonography. Chirurgia 1999;12(5):379-87.

Palanivelu 2001 \{published data only\} Palanivelu C, Rajan PS, Kumar SK, Parthasarathi R. Role of laparoscopy in pancreatic surgery. Journal International Medical Sciences Academy 2001;14(3):137-9.

Parks 2000 \{published data only\} Parks RW, Garden OJ. Staging laparoscopy for pancreatic carcinoma: Can it be cost effective?. Asian Journal of Surgery 2000;23(3):187-90.

Pedrazzoli 1994 \{published data only\}

Pedrazzoli S, Sperti C, Pasquali C. Prediction of resectability and of surgical risk in pancreatic carcinoma; conditioning factors of survival after resective intervention. Chirurgia Italiana 1994;46(2):30-8.

Pelton 1998 \{published data only\} Pelton JJ. Routine diagnostic laparoscopy is unnecessary in staging tumors of the pancreatic head. Southern Medical Journal 1998;91(2):182-6.

Pietrabissa 1996 \{published data only\} Pietrabissa A, Di Candio G, Giulianotti PC, Carobbi A, Boggi U, Mosca F. Operative technique for the laparoscopic staging of pancreatic malignancy. Minimally Invasive Therapy \& Allied Technologies 1996;5(3):274-80.

Pietrabissa 1996a \{published data only\} Pietrabissa A, Di Candio G, Giulianotti PC, Mosca F. Laparoscopic exposure of the pancreas and staging of pancreatic cancer. Seminars in Laparoscopic Surgery 1996;3 (1):3-9.

Pietrabissa 1999 \{published data only\} Pietrabissa A, Caramella D, Di Candio G, Carobbi A, Boggi U, Rossi G, et al. Laparoscopy and laparoscopic ultrasonography for staging pancreatic cancer: Critical appraisal. World Journal of Surgery 1999;23(10):998-1003.

Diagnostic accuracy of laparoscopy following computed tomography (CT) scanning for assessing the resectability with curative intent in 26 pancreatic and periampullary cancer (Review)

Copyright () 2016 The Cochrane Collaboration. Published by John Wiley \& Sons, Ltd. 
Pisters 2001 \{published data only\}

Pisters PW, Lee JE, Vauthey JN, Charnsangavej C, Evans DB. Laparoscopy in the staging of pancreatic cancer. British Journal of Surgery 2001;88(3):325-37.

Potkonjak 1974 \{published data only\} Potkonjak D, Filipovic Ristic B, Bjelic J. Comparison of laparoscopic, surgical and histologic findings in the diagnosis of malignant tumors of the pancreas. Medicinski Arhiv 1974;28(2):195-8.

Ramshaw 1999 \{published data only\}

Ramshaw BJ, Esartia P, Mason EM, Wilson R, Duncan $\mathrm{T}$, White J, et al. Laparoscopy for diagnosis and staging of malignancy. Seminars in Surgical Oncology 1999;16(4): $279-83$.

Ribero 1994 \{published data only\}

Ribero F, Comotti F, Scaglia M, Ragusa L. Diagnosticoperative laparoscopy. Our experience. Minerva Chirurgica 1994;49(6):533-7.

Rodgers 2003 \{published data only\}

Rodgers MS, Windsor JA, Koea JB, McCall JL. Laparoscopic staging of upper gastrointestinal malignancy. ANJ Journal of Surgery 2003;73(10):806-10.

Rothlin 1996 \{published data only\}

Röthlin M. Diagnostic laparoscopy and laparoscopic ultrasonography: value of staging and assessment of resectability of pancreatic carcinoma [Diagnostische laparoskopie und laparoskopische sonographie: stellenwert fur staging und resektabilitatsabklarung beim pankreaskarzinom]. Swiss Surgery 1996;Suppl 4:25-8.

Rumstadt 1997 \{published data only\}

Rumstadt B, Schwab M, Schuster K, Hagmuller E, Trede $\mathrm{M}$. The role of laparoscopy in the preoperative staging of pancreatic carcinoma. Journal of Gastrointestinal Surgery 1997;1(3):245-50.

Rumstadt 1997a \{published data only\}

Rumstadt B, Trede M. The role of laparoscopy and ultrafast magnetic resonance imaging in the preoperative staging of pancreatic carcinoma. Problems in General Surgery 1997;14 (2):59-64.

Saeian 1999 \{published data only\} Saeian K, Rajender Reddy K. Staging laparoscopy: A peek may save a cut. Endoscopy 1999;31(5):389-91.

Sand 1996 \{published data only\}

Sand J, Marnela K, Airo I, Nordback I. Staging of abdominal cancer by local anesthesia outpatient laparoscopy. Hepatogastroenterology 1996;43(12):1685-8.

Santoro 2012 \{published data only\} Santoro PM, Abdel-Misih RZ, Petrelli NJ, Bennett JJ. Is laparoscopy still needed for staging "resectable" pancreatic cancer?. Annals of Surgical Oncology 2012;19:S162.

Sato 1985 \{published data only\}

Sato W. Laparoscopic biopsy of the pancreas. Gastroenterological Endoscopy 1985;27(10):1940-9.
Satoi 2011 \{published data only\}

Satoi S, Yanagimoto H, Toyokawa H, Inoue K, Wada K, Yamamoto T, et al. Selective use of staging laparoscopy based on carbohydrate antigen 19-9 level and tumor size in patients with radiographically defined potentially or borderline resectable pancreatic cancer. Pancreas 2011;40 (3):426-32.

Schachter 1999 \{published data only\} Schachter P, Avni Y, Rosen A, Czerniak A. Evaluation of laparoscopy and laparoscopic ultrasound in diagnosis and treatment of pancreatic lesions. Harefuah 1999;137(12): 593-7, 680 .

Schmidt 1997 \{published data only\} Schmidt J, Zirngibl H, Heinmoller E, Schuckel E, Jauch KW. Laparoscopy and intraoperative peritoneal cytology as predictors of operability in pancreatic carcinoma. Acta Chirurgica Austriaca 1997;29(2):90-4.

Schmied 2000 \{published data only\} Schmied BM, Z'Graggen K, Redaelli CA, Buchler MW. Problems in staging of pancreatic and hepatobiliary tumours. Annals of Oncology 2000;11 Suppl 3:161-4.

Schmielau 1997 \{published data only\} Schmielau J, Schmiegel WH. Diagnosis of pancreatic carcinoma. Medizinische Klinik 1997;92(9):525-6.

Schneider 2003 \{published data only\} Schneider AR, Adamek HE, Layer G, Riemann JF, Arnold JC. Staging of abdominal metastases in pancreatic carcinoma by diagnostic laparoscopy and magnetic resonance imaging. Zeitschrift für Gastroenterologie 2003;41(8):697-702.

Schnelldorfer 2014 \{published data only\} Schnelldorfer T, Gagnon AI, Birkett RT, Reynolds G, Murphy KM, Jenkins RL. Staging laparoscopy in pancreatic cancer: A potential role for advanced laparoscopic techniques. Journal of the American College of Surgeons 2014; 218(6):1201-6.

Schrenk 1994 \{published data only\} Schrenk P, Woisetschlager R, Wayand WU, Rieger R, Sulzbacher H. Diagnostic laparoscopy - a survey of 92 patients. American Journal of Surgery 1994;168(4):348-51.

Schrenk 1995 \{published data only\} Schrenk P, Wayand W. Value of diagnostic laparoscopy in abdominal malignancies. International Surgery 1995;80(4): 353-5.

Schwab 1996 \{published data only\} Schwab M, Schwall G, Richter A, Trede M. Is diagnostic laparoscopy a reliable addition to preoperative staging of pancreatic carcinoma?. Langenbecks Archiv für Chirurgie. Supplement. Kongressband 1996;113:565-7.

Sperlongano 2005 \{published data only\} Sperlongano P, Avenia N. Does laparoscopy have a role in pancreatic cancer?. Il Giornale di Chirurgia 2005;26(8-9): 293-4.

Sperlongano 2006 \{published data only\} Sperlongano P, Pisaniello D, Piatto A, Parmeggiani D, Sperlongano R, Avenia N, et al. The role of laparoscopy in pancreatic surgery. Frontiers in Bioscience 2006;11:2203-5.

Diagnostic accuracy of laparoscopy following computed tomography (CT) scanning for assessing the resectability with curative intent in 27 pancreatic and periampullary cancer (Review)

Copyright $\odot 2016$ The Cochrane Collaboration. Published by John Wiley \& Sons, Ltd. 
Tang 2001 \{published data only\}

Tang CN, Siu WT, Li MKW. Use of diagnostic laparoscopy and laparoscopic ultrasound in the management of upper gastrointestinal malignancy. Annals of the College of Surgeons of Hong Kong 2001;5(1):19-24.

Tapper 2011 \{published data only\}

Tapper E, Kalb B, Martin DR, Kooby D, Adsay NV, Sarmiento JM. Staging laparoscopy for proximal pancreatic cancer in a magnetic resonance imaging-driven practice: what's it worth?. HPB 2011;13(10):732-7.

Taylor 2001 \{published data only\}

Taylor AM, Roberts SA, Manson JM. Experience with laparoscopic ultrasonography for defining tumour resectability in carcinoma of the pancreatic head and periampullary region. British Journal of Surgery 2001;88(8): 1077-83.

Terrosu 2000 \{published data only\}

Terrosu G, Cedolini C, Baccarani U, Vianello V, Bruschi F, Uzzau A, et al. Echolaparoscopy in the staging of abdominal neoplasms. Prospective study. Annali Italiani di Chirurgia 2000;71(2):199-204.

Thomson 2006 \{published data only\}

Thomson BN, Parks RW, Redhead DN, Welsh FK, Madhavan KK, Wigmore SJ, et al. Refining the role of laparoscopy and laparoscopic ultrasound in the staging of presumed pancreatic head and ampullary tumours. British Journal of Cancer 2006;94(2):213-7.

Tilleman 2004 \{published data only\} Tilleman EH, Busch OR, Bemelman WA, van Gulik TM, Obertop H, Gouma DJ. Diagnostic laparoscopy in staging pancreatic carcinoma: developments during the past decade. Journal of Hepato-Biliary-Pancreatic Surgery 2004;11(1): 11-6.

Tilleman 2004a \{published data only\} Tilleman EH, Kuiken BW, Phoa SS, de Castro SM, Busch OR, Obertop $\mathrm{H}$, et al. Limitation of diagnostic laparoscopy for patients with a periampullary carcinoma. European Journal of Surgical Oncology 2004;30(6):658-62.

Toughrai 2013 \{published data only\} Toughrai I, Ait Laalim S, Ibn Majdoub K, Mazaz K. Resectability evaluation in pancreatic cancer. Presse Medicale 2013;42(9 Pt 1):1171-5.

van Delden 1996 \{published data only\} van Delden OM, Smits NJ, Bemelman WA, de Wit LT, Gouma DJ, Reeders JW. Comparison of laparoscopic and transabdominal ultrasonography in staging of cancer of the pancreatic head region. Journal of Ultrasound in Medicine 1996;15(3):207-12.

van Dijkum 1997 \{published data only\} van Dijkum E, deWit LT, van Delden OM, Rauws EAJ, van Lanschot JJB, Obertop H, et al. The efficacy of laparoscopic staging in patients with upper gastrointestinal tumors. Cancer 1997;79(7):1315-9.
Velanovich 1998 \{published data only\}

Velanovich V. Staging laparoscopy in the management of intra-abdominal malignancies. Surgery 1998;124(4): 773-81.

Velanovich 2004 \{published data only\} Velanovich V. The effects of staging laparoscopy on trocar site and peritoneal recurrence of pancreatic cancer. Surgical Endoscopy 2004;18(2):310-3.

Velasco 2000 \{published data only\}

Velasco JM, Rossi H, Hieken TJ, Fernandez M. Laparoscopic ultrasound enhances diagnostic laparoscopy in the staging of intra-abdominal neoplasms. American Surgeon 2000;66(4):407-11.

Vollmer 2002 \{published data only\} Vollmer CM, Drebin JA, Middleton WD, Teefey SA, Linehan DC, Soper NJ, et al. Utility of staging laparoscopy in subsets of peripancreatic and biliary malignancies. Annals of Surgery 2002;235(1):1-7.

Warshaw 1990 \{published data only\} Warshaw AL, Gu ZY. Laparoscopy for preoperative staging of malignant tumors of the foregut. Esophageal, gastric, and pancreatic cancer. Problems in General Surgery 1990;7 (Special Issue):65-74.

Warshaw 1990a \{published data only\} Warshaw AL, Gu ZY, Wittenberg J, Waltman AC. Preoperative staging and assessment of resectability of pancreatic cancer. Archives of Surgery 1990;125(2):230-3.

Watanabe 1993 \{published data only\} Watanabe M, Akagi S, Uchida Y, Kohge N, Fukumoto S. Role of laparoscopy in the diagnosis of pancreatic cancer. Digestive Endoscopy 1993;5(1):55-61.

Weiner 1995 \{published data only\} Weiner R, Winterberg U, Bockhorn H. Laparoscopic staging of gastrointestinal tumors. Zentralblatt für Chirurgie 1995;120(5):350-2.

White 2001 \{published data only\} White RR, Paulson EK, Freed KS, Keogan MT, Hurwitz HI, Lee $\mathrm{C}$, et al. Staging of pancreatic cancer before and after neoadjuvant chemoradiation. Journal of Gastrointestinal Surgery 2001;5(6):626-33.

White 2004 \{published data only\} White RR, Pappas TN. Laparoscopic staging for hepatobiliary carcinoma. Journal of Gastrointestinal Surgery 2004;8(8):920-2.

White 2008 \{published data only\} White R, Winston C, Gonen M, D'Angelica M, Jarnagin W, Fong Y, et al. Current utility of staging laparoscopy for pancreatic and peripancreatic neoplasms. Journal of the American College of Surgeons 2008;206(3):445-50.

Wilson 2010 \{published data only\} Wilson CH, White SA. Single-centre experience of laparoscopic pancreatic surgery. British Journal of Surgery. 2010;97(12):1891-2.

Diagnostic accuracy of laparoscopy following computed tomography (CT) scanning for assessing the resectability with curative intent in 
Yoshida 2002 \{published data only\}

Yoshida T, Matsumoto T, Morii Y, Ishio T, Kitano

S, Yamada Y, et al. Staging with helical computed tomography and laparoscopy in pancreatic head cancer. Hepatogastroenterology 2002;49(47):1428-31.

Zhao 2003 \{published data only\}

Zhao ZW, He JY, Tan G, Wang HJ, Li KJ. Laparoscopy and laparoscopic ultrasonography in judging the resectability of pancreatic head cancer. Hepatobiliary \& Pancreatic Diseases International 2003;2(4):609-11.

\section{Additional references}

\section{Abrams 2009}

Abrams RA, Lowy AM, O’Reilly EM, Wolff RA, Picozzi VJ, Pisters PW. Combined modality treatment of resectable and borderline resectable pancreas cancer: Expert consensus statement. Annals of Surgical Oncology 2009;16(7):1751-6.

\section{Azevedo 2009}

Azevedo JL, Azevedo OC, Miyahira SA, Miguel GP, Becker $\mathrm{OM} \mathrm{Jr}$, Hypolito $\mathrm{OH}$, et al. Injuries caused by Veress needle insertion for creation of pneumoperitoneum: a systematic literature review. Surgical Endoscopy 2009;23(7):1428-32.

\section{Chang 2009}

Chang L, Stefanidis D, Richardson WS, Earle DB, Fanelli $\mathrm{RD}$. The role of staging laparoscopy for intraabdominal cancers: an evidence-based review. Surgical Endoscopy 2009; 23(2):231-41.

\section{Conlon 1996}

Conlon KC, Klimstra DS, Brennan MF. Long-term survival after curative resection for pancreatic ductal adenocarcinoma. Clinicopathologic analysis of 5-year survivors. Annals of Surgery 1996;223(3):273-9.

\section{Eloubeidi 2001}

Eloubeidi MA, Wade SB, Provenzale D. Factors associated with acceptance and full publication of GI endoscopic research originally published in abstract form. Gastrointestinal Endoscopy 2001;53(3):275-82.

Engelken 2003

Engelken FJ, Bettschart V, Rahman MQ, Parks RW, Garden OJ. Prognostic factors in the palliation of pancreatic cancer. European Journal of Surgical Oncology 2003;29(4):368-73.

\section{Gurusamy 2015}

Gurusamy KS, Davidson BR. Diagnostic accuracy of different imaging modalities following computed tomography (CT) scanning for assessing the resectability with curative intent in pancreatic and periampullary cancer. Cochrane Database of Systematic Reviews 2015, Issue 2. [DOI: $10.1002 / 14651858 . C D 011515]$

\section{Klempnauer 1995}

Klempnauer J, Ridder GJ, Pichlmayr R. Prognostic factors after resection of ampullary carcinoma: multivariate survival analysis in comparison with ductal cancer of the pancreatic head. British Journal of Surgery 1995;82(12):1686-91.

\section{Lillemoe 1999}

Lillemoe KD, Cameron JL, Hardacre JM, Sohn TA, Sauter $\mathrm{PK}$, Coleman J, et al. Is prophylactic gastrojejunostomy indicated for unresectable periampullary cancer? A prospective randomized trial. Annals of Surgery 1999;230 (3):322-8.

\section{Mayo 2009}

Mayo SC, Austin DF, Sheppard BC, Mori M, Shipley DK, Billingsley KG. Evolving preoperative evaluation of patients with pancreatic cancer: does laparoscopy have a role in the current era?. Journal of the American College of Surgeons 2009;208(1):87-95.

\section{Michelassi 1989}

Michelassi F, Erroi F, Dawson PJ, Pietrabissa A, Noda S, Handcock M, et al. Experience with 647 consecutive tumors of the duodenum, ampulla, head of the pancreas, and distal common bile duct. Annals of Surgery 1989;210 (4):544-54.

\section{National Cancer Institute 2011a}

National Cancer Institute (US National Institutes of Health). Dictionary of cancer terms. Periampullary cancer. http://www.cancer.gov/dictionary/?CdrID $=543930$ (accessed on 17 April 2011).

\section{National Cancer Institute 2011b}

National Cancer Institute (US National Institutes of Health). Dictionary of cancer terms. CT scan. http:// www.cancer.gov/dictionary?CdrID=46033 (accessed on 17 April 2011).

\section{Sampson 2008}

Sampson M, Shojania KG, McGowan J, Daniel R, Rader T, Iansavichene AE, et al. Surveillance search techniques identified the need to update systematic reviews. Journal of Clinical Epidemiology 2008;61(8):755-62.

\section{Shahrudin 1997}

Shahrudin MD. Carcinoma of the pancreas: resection outcome at the University Hospital Kuala Lumpur. International Surgery 1997;82(3):269-74.

\section{Smith 2008}

Smith RA, Bosonnet L, Ghaneh P, Sutton R, Evans J, Healey $\mathrm{P}$, et al. The platelet-lymphocyte ratio improves the predictive value of serum CA19-9 levels in determining patient selection for staging laparoscopy in suspected periampullary cancer. Surgery 2008;143(5):658-66.

\section{Whiting 2011}

Whiting PF, Rutjes AW, Westwood ME, Mallett S, Deeks JJ, Reitsma JB, et al. QUADAS-2: a revised tool for the quality assessment of diagnostic accuracy studies. Annals of Internal Medicine 2011;155(8):529-36.

\section{Yeo 2002}

Yeo CJ, Cameron JL, Lillemoe KD, Sohn TA, Campbell KA, Sauter PK, et al. Pancreaticoduodenectomy with or without distal gastrectomy and extended retroperitoneal lymphadenectomy for periampullary adenocarcinoma, part 2: randomized controlled trial evaluating survival,

Diagnostic accuracy of laparoscopy following computed tomography (CT) scanning for assessing the resectability with curative intent in 
morbidity, and mortality. Annals of Surgery 2002;236(3):

$355-66$.

\section{References to other published versions of this review}

Allen 2013

Allen VB, Gurusamy KS, Takwoingi Y, Kalia A, Davidson

BR. Diagnostic accuracy of laparoscopy following computed tomography (CT) scanning for assessing the resectability with curative intent in pancreatic and periampullary cancer. Cochrane Database of Systematic Reviews 2013, Issue 11. [DOI: 10.1002/14651858.CD009323.pub2]

* Indicates the major publication for the study 


\section{CHARACTERISTICS OF STUDIES}

\section{Characteristics of included studies [ordered by study ID]}

\section{Ahmed 2006}

\begin{tabular}{ll}
\hline Study characteristics & \\
\hline Patient sampling & $\begin{array}{l}\text { Sample size: } 37 \\
\text { Females: Not stated } \\
\text { Age: Not stated }\end{array}$ \\
\hline $\begin{array}{l}\text { Patient characteristics and set- } \\
\text { ting }\end{array}$ & $\begin{array}{l}\text { Patients with potentially resectable, histologically confirmed pancreatic adenocarcinoma (after CT } \\
\text { scan) }\end{array}$ \\
\hline Setting: Surgical centre in the USA \\
\hline Index tests & $\begin{array}{l}\text { Diagnostic laparoscopy } \\
\text { Criteria for positive diagnosis: Tumours were considered locally advanced and unresectable if la- } \\
\text { paroscopic examination revealed peritoneal or liver metastasis, coeliac artery or para-aortic lymph } \\
\text { node involvement, or tumour invasion or encasement of the coeliac axis or hepatic artery }\end{array}$ \\
\hline
\end{tabular}

Target condition and reference standard(s)
Target condition: Unresectability

Reference standard: Laparotomy for patients with no evidence of metastases on laparoscopy; biopsy with histolopathological confirmation of spread for patients with suspected metastases

Criteria for positive diagnosis: Tumours were considered locally advanced and unresectable if laparoscopic examination revealed peritoneal or liver metastasis, coeliac artery or para-aortic lymph node involvement, or tumour invasion or encasement of the coeliac axis or hepatic artery

Flow and timing

Number of indeterminates for whom the results of reference standard were available: Not stated Number of patients who were excluded from the analysis: $22(37.3 \%)$

Comparative

Notes

Methodological quality

\begin{tabular}{|c|c|c|c|}
\hline Item & Authors' judgement & Risk of bias & Applicability concerns \\
\hline
\end{tabular}

DOMAIN 1: Patient Selection

Was a consecutive or random Unclear sample of patients enrolled?

Was a case-control design Yes avoided?

Did the study avoid inappropri- No ate exclusions?

Diagnostic accuracy of laparoscopy following computed tomography (CT) scanning for assessing the resectability with curative intent in 


\section{Low}

DOMAIN 2: Index Test All tests

Were the index test results in- Yes terpreted without knowledge of the results of the reference standard?

Low

\section{DOMAIN 3: Reference Standard}

Is the reference standards likely Unclear

to correctly classify the target

condition?

Were the reference standard re- No sults

interpreted without knowledge

of the results of the index tests?

Low

\section{DOMAIN 4: Flow and Timing}

Was there an appropriate inter- Unclear

val between index test and ref-

erence standard?

Did all patients receive the same No

reference standard?

Were all patients included in the No analysis?

\section{Arnold 1999}

\section{Study characteristics}

\begin{tabular}{ll}
\hline Patient sampling & $\begin{array}{l}\text { Sample size: } 33 \\
\text { Females: Not stated } \\
\text { Age: Not stated }\end{array}$ \\
\hline $\begin{array}{l}\text { Patient characteristics and set- } \\
\text { ting }\end{array}$ & $\begin{array}{l}\text { Patients with potentially resectable pancreatic adenocarcinoma (after CT scan) } \\
\text { Setting: Germany (setting not clear) }\end{array}$
\end{tabular}

Diagnostic accuracy of laparoscopy following computed tomography (CT) scanning for assessing the resectability with curative intent in 
Arnold 1999 (Continued)

$\begin{array}{ll}\text { Index tests } & \begin{array}{l}\text { Diagnostic laparoscopy } \\ \text { Criteria for positive diagnosis: Biopsies of lesions suspicious of metastases }\end{array}\end{array}$

Target condition and reference standard(s)

Target condition: Unresectability

Reference standard: Laparotomy for patients with no evidence of metastases on laparoscopy; biopsy with histolopathological confirmation of spread for patients with suspected metastases

Criteria for positive diagnosis: Not stated

Flow and timing

Number of indeterminates for whom the results of reference standard were available: Not stated Number of patients who were excluded from the analysis: $14(29.8 \%)$

Comparative

Notes

\section{Methodological quality}

\begin{tabular}{lll}
\hline Item & Authors' judgement & Risk of bias Applicability concerns
\end{tabular}

\section{DOMAIN 1: Patient Selection}

Was a consecutive or random Unclear sample of patients enrolled?

Was a case-control design Yes avoided?

Did the study avoid inappropri- No ate exclusions?

Low

\section{DOMAIN 2: Index Test All tests}

Were the index test results in- Yes terpreted without knowledge of the results of the reference standard?

\section{Low}

\section{DOMAIN 3: Reference Standard}

Is the reference standards likely Unclear to correctly classify the target condition? 


\section{Arnold 1999 (Continued)}

Were the reference standard re- No sults

interpreted without knowledge

of the results of the index tests?

Low

\section{DOMAIN 4: Flow and Timing}

Was there an appropriate inter- Unclear val between index test and reference standard?

Did all patients receive the same No reference standard?

Were all patients included in the No analysis?

\section{Arnold 2001a}

\section{Study characteristics}

\begin{tabular}{ll}
\hline Patient sampling & Sample size: 61 \\
& Females: Not stated \\
& Age: Not stated
\end{tabular}

Patient characteristics and set- Patients with potentially resectable pancreatic adenocarcinoma (after CT scan)

ting Setting: Germany (setting not clear)

Index tests $\quad$ Diagnostic laparoscopy

Criteria for positive diagnosis: Biopsies of lesions suspicious of metastases

Target condition and reference standard(s)

Flow and timing
Target condition: Unresectability

Reference standard: Laparotomy for patients with no evidence of metastases on laparoscopy; biopsy with histolopathological confirmation of spread for patients with suspected metastases Criteria for positive diagnosis: Not stated

Number of indeterminates for whom the results of reference standard were available: Not stated Number of patients who were excluded from the analysis: Not stated

Comparative

Notes

\section{Methodological quality}

Diagnostic accuracy of laparoscopy following computed tomography (CT) scanning for assessing the resectability with curative intent in 
Arnold 2001a (Continued)

\begin{tabular}{|c|c|c|c|}
\hline Item & Authors' judgement & Risk of bias & Applicability concerns \\
\hline \multicolumn{4}{|l|}{ DOMAIN 1: Patient Selection } \\
\hline $\begin{array}{l}\text { Was a consecutive or random } \\
\text { sample of patients enrolled? }\end{array}$ & Unclear & & \\
\hline $\begin{array}{l}\text { Was a case-control design } \\
\text { avoided? }\end{array}$ & Yes & & \\
\hline
\end{tabular}

Did the study avoid inappropri- Unclear ate exclusions?

Low

DOMAIN 2: Index Test All tests

Were the index test results in- Yes terpreted without knowledge of the results of the reference standard?

Low

DOMAIN 3: Reference Standard

Is the reference standards likely Unclear to correctly classify the target condition?

Were the reference standard re- No sults

interpreted without knowledge

of the results of the index tests?

Low

\section{DOMAIN 4: Flow and Timing}

Was there an appropriate inter- Unclear val between index test and reference standard?

Did all patients receive the same No reference standard?

Were all patients included in the Unclear analysis?

Diagnostic accuracy of laparoscopy following computed tomography (CT) scanning for assessing the resectability with curative intent in 
Arnold 2001a (Continued)

Beenen 2014

Study characteristics

\begin{tabular}{ll}
\hline Patient sampling & Sample size: 131 \\
& Females: Not stated \\
& Age: Not stated
\end{tabular}

Patient characteristics and set- Patients with CT and ultrasound resectable periampullary cancer ting

Setting: Secondary/tertiary care, the Netherlands

Index tests Diagnostic laparoscopy

Criteria for positive diagnosis: Biopsy confirmation of suspicious lesions

Target condition and reference standard(s)

Target condition: Unresectability

Reference standard: Laparotomy

Criteria for positive diagnosis: Locally advanced pancreatic cancer or metastatic pancreatic cancer

Flow and timing

Number of indeterminates for whom the results of reference standard were available: 0

Number of patients who were excluded from the analysis: $74(36.1 \%)$

Comparative

Notes

Methodological quality

\begin{tabular}{|c|c|c|c|}
\hline Item & Authors' judgement & Risk of bias & Applicability concerns \\
\hline
\end{tabular}

DOMAIN 1: Patient Selection

Was a consecutive or random No sample of patients enrolled?

Was a case-control design Yes avoided?

Did the study avoid inappropri- Unclear ate exclusions?

High

DOMAIN 2: Index Test All tests

Diagnostic accuracy of laparoscopy following computed tomography (CT) scanning for assessing the resectability with curative intent in 
Beenen 2014 (Continued)

Were the index test results in- No terpreted without knowledge of the results of the reference standard?

Low

\section{DOMAIN 3: Reference Standard}

Is the reference standards likely Unclear

to correctly classify the target

condition?

Were the reference standard re- No sults

interpreted without knowledge

of the results of the index tests?

Low

DOMAIN 4: Flow and Timing

Was there an appropriate inter- Unclear

val between index test and ref-

erence standard?

Did all patients receive the same Yes

reference standard?

Were all patients included in the No analysis?

Brooks 2002

Study characteristics

\begin{tabular}{ll}
\hline Patient sampling & Sample size: 144 \\
& Females: Not stated \\
& Age: Not stated
\end{tabular}

Patient characteristics and set- Patients with potentially resectable periampullary carcinoma other than pancreatic cancer ting Setting: Surgical centre in the USA

Index tests

Diagnostic laparoscopy

Criteria for positive diagnosis: Patients were deemed unresectable at diagnostic laparoscopy or laparotomy if they were found to have histologically proved peritoneal or hepatic metastases, distant nodal involvement, arterial involvement, or local extension outside the resection field 
Brooks 2002 (Continued)

\begin{tabular}{ll}
$\begin{array}{l}\text { Target condition and reference } \\
\text { standard(s) }\end{array}$ & $\begin{array}{l}\text { Target condition: Unresectability } \\
\text { Reference standard: Laparotomy for patients with no evidence of metastases on laparoscopy; biop } \\
\text { with histolopathological confirmation of spread for patients with suspected metastases } \\
\text { Criteria for positive diagnosis: Patients were deemed unresectable at diagnostic laparoscopy } \\
\text { laparotomy if they were found to have histologically proven peritoneal or hepatic metastases, dista } \\
\text { nodal involvement, arterial involvement, or local extension outside the resection field }\end{array}$ \\
\hline Flow and timing & $\begin{array}{l}\text { Number of indeterminates for whom the results of reference standard were available: } 10(6.9 \%) \\
\text { Number of patients who were excluded from the analysis: Not stated }\end{array}$
\end{tabular}

Comparative

Notes

Methodological quality

\begin{tabular}{l|l|l}
\hline Item & Authors' judgement & Risk of bias
\end{tabular}

\section{DOMAIN 1: Patient Selection}

Was a consecutive or random Unclear sample of patients enrolled?

Was a case-control design Yes avoided?

Did the study avoid inappropri- Unclear ate exclusions?

Low

DOMAIN 2: Index Test All tests

Were the index test results in- Yes terpreted without knowledge of the results of the reference standard?

Low

\section{DOMAIN 3: Reference Standard}

Is the reference standards likely Unclear to correctly classify the target condition?

Were the reference standard re- No sults

Diagnostic accuracy of laparoscopy following computed tomography (CT) scanning for assessing the resectability with curative intent in 
Brooks 2002 (Continued)

interpreted without knowledge

of the results of the index tests?

Low

DOMAIN 4: Flow and Timing

Was there an appropriate inter- Unclear val between index test and ref-

erence standard?

Did all patients receive the same No

reference standard?

Were all patients included in the Unclear analysis?

Contreras 2009

\section{Study characteristics}

$\begin{array}{ll}\text { Patient sampling } & \text { Sample size: } 25 \\ & \text { Females: } 12(32.5 \%) \\ & \text { Age: } 68 \text { years }\end{array}$

Patient characteristics and set- Patients with potentially resectable pancreatic adenocarcinoma (after CT scan) ting Setting: Surgical referral centre in the USA

Index tests

Diagnostic laparoscopy

Criteria for positive diagnosis: Biopsies of lesions suspicious of metastases

Target condition and reference standard(s)

Target condition: Unresectability

Reference standard: Laparotomy for patients with no evidence of metastases on laparoscopy; biopsy with histolopathological confirmation of spread for patients with suspected metastases

Criteria for positive diagnosis: Not stated

Flow and timing

Number of indeterminates for whom the results of reference standard were available: Not stated Number of patients who were excluded from the analysis: $52(67.5 \%)$

Comparative

Notes

Methodological quality

Item

Authors' judgement

Risk of bias Applicability concerns

Diagnostic accuracy of laparoscopy following computed tomography (CT) scanning for assessing the resectability with curative intent in 
Contreras 2009 (Continued)

\section{DOMAIN 1: Patient Selection}

Was a consecutive or random Unclear sample of patients enrolled?

Was a case-control design Yes avoided?

Did the study avoid inappropri- No ate exclusions?

Low

DOMAIN 2: Index Test All tests

Were the index test results in- Yes terpreted without knowledge of the results of the reference standard?

\section{Low}

DOMAIN 3: Reference Standard

Is the reference standards likely Unclear

to correctly classify the target

condition?

Were the reference standard re- No sults

interpreted without knowledge

of the results of the index tests?

Low

\section{DOMAIN 4: Flow and Timing}

Was there an appropriate inter- Unclear val between index test and reference standard?

Did all patients receive the same No reference standard?

Were all patients included in the No analysis? 
Fernandez-Castillo 1995

\section{Study characteristics}

$\begin{array}{ll}\text { Patient sampling } & \text { Sample size: } 109 \\ & \text { Females: Not stated } \\ \text { Age: Not stated }\end{array}$

Patient characteristics and set- Patients with potentially resectable pancreatic adenocarcinoma (on CT scan) without gastric outlet ting obstruction

Setting: Surgical centre in the USA

Index tests Diagnostic laparoscopy

Criteria for positive diagnosis: Biopsies of lesions suspicious of metastases

Target condition and reference Target condition: Unresectability standard(s)

Reference standard: Laparotomy for patients with no evidence of metastases on laparoscopy; biopsy with histolopathological confirmation of spread for patients with suspected metastases

Criteria for positive diagnosis: Not stated

Flow and timing

Number of indeterminates for whom the results of reference standard were available: not stated Number of patients who were excluded from the analysis: 5 (4.2\%)

Comparative

Notes

Methodological quality

\begin{tabular}{|c|c|c|c|}
\hline Item & Authors' judgement & Risk of bias & Applicability concerns \\
\hline
\end{tabular}

DOMAIN 1: Patient Selection

Was a consecutive or random Yes sample of patients enrolled?

Was a case-control design Yes avoided?

Did the study avoid inappropri- No ate exclusions?

Low

DOMAIN 2: Index Test All tests

Were the index test results in- Yes terpreted without knowledge of the results of the reference standard? 


\section{Low}

\section{DOMAIN 3: Reference Standard}

Is the reference standards likely Unclear

to correctly classify the target

condition?

Were the reference standard re- No sults

interpreted without knowledge

of the results of the index tests?

Low

\section{DOMAIN 4: Flow and Timing}

Was there an appropriate inter- Unclear val between index test and ref-

erence standard?

Did all patients receive the same No reference standard?

Were all patients included in the No analysis?

\section{John 1995}

\section{Study characteristics}

\begin{tabular}{ll}
\hline Patient sampling & Sample size: 40 \\
& Females: $22(100 \%)$ \\
& Age: 59 years
\end{tabular}

Patient characteristics and set- Patients with potentially resectable pancreatic or periampullary carcinoma ting Setting: Tertiary referral centre in the UK

Index tests Diagnostic laparoscopy

Criteria for positive diagnosis: Biopsies of lesions suspicious of metastases

Target condition and reference Target condition: Unresectability standard(s)

Reference standard: Laparotomy for patients with no evidence of metastases on laparoscopy; biopsy with histolopathological confirmation of spread for patients with suspected metastases Criteria for positive diagnosis: The criteria used to define primary tumour advancement and locoregional unresectability were as follows: 
John 1995 (Continued)

1. tumour size of $5 \mathrm{~cm}$ or greater;

2. extrapancreatic invasion of adjacent tissues (i.e. duodenum, stomach, common bile duct, retroperitoneum); and

3. occlusion or stenosis of the portal or superior mesenteric veins, or major branches of the coeliac trunk or superior mesenteric artery

Flow and timing

Number of indeterminates for whom the results of reference standard were available: Not stated

Number of patients who were excluded from the analysis: Not stated

Comparative

Notes

Methodological quality

Item Authors' judgement $\quad$ Risk of bias Applicability concerns

\section{DOMAIN 1: Patient Selection}

Was a consecutive or random Unclear

sample of patients enrolled?

Was a case-control design Yes

avoided?

Did the study avoid inappropri- Unclear

ate exclusions?

Low

DOMAIN 2: Index Test All tests

Were the index test results in- Yes

terpreted without knowledge of

the results of the reference stan-

dard?

Low

\section{DOMAIN 3: Reference Standard}

Is the reference standards likely Unclear

to correctly classify the target

condition?

Were the reference standard re- No

sults

interpreted without knowledge

of the results of the index tests?

Diagnostic accuracy of laparoscopy following computed tomography (CT) scanning for assessing the resectability with curative intent in 
John 1995 (Continued)

\section{Low}

\section{DOMAIN 4: Flow and Timing}

Was there an appropriate inter- Unclear val between index test and reference standard?

Did all patients receive the same No reference standard?

Were all patients included in the Unclear analysis?

Kishiwada 2002

\section{Study characteristics}

\begin{tabular}{ll}
\hline Patient sampling & Sample size: 16 \\
& Females: Not stated \\
& Age: Not stated
\end{tabular}

Patient characteristics and setting

\begin{tabular}{l} 
Index tests \\
\hline $\begin{array}{l}\text { Target condition and reference } \\
\text { standard(s) }\end{array}$
\end{tabular}

Flow and timing

Number of patients who were excluded from the analysis: Not stated in diameter were subject to diagnostic laparoscopy)

Setting: Surgical centre in Japan

\section{Diagnostic laparoscopy}

Criteria for positive diagnosis: Biopsies of lesions suspicious of metastases

Target condition: Unresectability with histolopathological confirmation of spread for patients with suspected metastases

Criteria for positive diagnosis: Not stated

Patients with potentially resectable pancreatic cancer (only patients with tumours more than $2 \mathrm{~cm}$

Reference standard: Laparotomy for patients with no evidence of metastases on laparoscopy; biopsy

Comparative

Notes

Methodological quality

\begin{tabular}{|c|c|c|c|}
\hline Item & Authors' judgement & Risk of bias & Applicability concerns \\
\hline
\end{tabular}

\section{DOMAIN 1: Patient Selection}

Diagnostic accuracy of laparoscopy following computed tomography (CT) scanning for assessing the resectability with curative intent in 
Kishiwada 2002 (Continued)

Was a consecutive or random No

sample of patients enrolled?

Was a case-control design Yes

avoided?

Did the study avoid inappropri- Unclear

ate exclusions?

High

DOMAIN 2: Index Test All tests

Were the index test results in- Yes

terpreted without knowledge of

the results of the reference stan-

dard?

Low

DOMAIN 3: Reference Standard

Is the reference standards likely Unclear

to correctly classify the target

condition?

Were the reference standard re- No

sults

interpreted without knowledge

of the results of the index tests?

Low

DOMAIN 4: Flow and Timing

Was there an appropriate inter- Unclear

val between index test and ref-

erence standard?

Did all patients receive the same No

reference standard?

Were all patients included in the No analysis? 
Lavy 2012

\section{Study characteristics}

\begin{tabular}{ll}
\hline Patient sampling & $\begin{array}{l}\text { Sample size: } 52 \\
\text { Females: Not stated } \\
\text { Age: Not stated }\end{array}$ \\
\hline $\begin{array}{l}\text { Patient characteristics and set- } \\
\text { ting }\end{array}$ & $\begin{array}{l}\text { Patients with potentially resectable pancreatic adenocarcinoma (after CT scan and EUS) } \\
\text { Setting: Surgical centre in Israel }\end{array}$ \\
\hline Index tests & $\begin{array}{l}\text { Diagnostic laparoscopy } \\
\text { Criteria for positive diagnosis: Biopsies of lesions suspicious of metastases }\end{array}$ \\
\hline $\begin{array}{l}\text { Target condition and reference } \\
\text { standard(s) }\end{array}$ & $\begin{array}{l}\text { Target condition: Unresectability } \\
\text { Reference standard: Laparotomy for patients with no evidence of metastases on laparoscopy; biopsy } \\
\text { with histopathological confirmation of spread for patients with suspected metastases } \\
\text { Criteria for positive diagnosis: Not stated }\end{array}$ \\
\hline Flow and timing & $\begin{array}{l}\text { Number of indeterminates for whom the results of reference standard were available: Not stated } \\
\text { Number of patients who were excluded from the analysis: Not stated }\end{array}$ \\
\hline Comparative & \begin{tabular}{l} 
Notes \\
\hline
\end{tabular} \\
\hline
\end{tabular}

Methodological quality

\begin{tabular}{lll}
\hline Item & Authors' judgement & Risk of bias Applicability concerns
\end{tabular}

\section{DOMAIN 1: Patient Selection}

Was a consecutive or random Yes sample of patients enrolled?

Was a case-control design Yes avoided?

Did the study avoid inappropri- $\quad$ Yes ate exclusions?

\section{Low}

\section{DOMAIN 2: Index Test All tests}

Were the index test results in- Yes terpreted without knowledge of the results of the reference standard? 
Lavy 2012 (Continued)

DOMAIN 3: Reference Standard

Is the reference standards likely Unclear

to correctly classify the target

condition?

Were the reference standard re- No

sults

interpreted without knowledge

of the results of the index tests?

Low

\section{DOMAIN 4: Flow and Timing}

Was there an appropriate inter- Unclear val between index test and ref-

erence standard?

Did all patients receive the same No

reference standard?

Were all patients included in the Unclear analysis?

\section{Menack 2001}

\section{Study characteristics}

\begin{tabular}{l|l}
\hline Patient sampling & $\begin{array}{l}\text { Sample size: } 27 \\
\text { Females: } 10(100 \%) \\
\text { Age: } 66 \text { years }\end{array}$ \\
\hline $\begin{array}{l}\text { Patient characteristics and set- } \\
\text { ting }\end{array}$ & $\begin{array}{l}\text { Patients with potentially resectable pancreatic or periampullary cancer (after CT scan) } \\
\text { Setting: Surgical centre in the USA }\end{array}$ \\
\hline Index tests & $\begin{array}{l}\text { Diagnostic laparoscopy } \\
\text { Criteria for positive diagnosis: Biopsies of lesions suspicious of metastases }\end{array}$ \\
\hline $\begin{array}{l}\text { Target condition and reference } \\
\text { standard(s) }\end{array}$ & $\begin{array}{l}\text { Target condition: Unresectability } \\
\text { Reference standard: Laparotomy for patients with no evidence of metastases on laparoscopy; biopsy } \\
\text { with histolopathological confirmation of spread for patients with suspected metastases } \\
\text { Criteria for positive diagnosis: Patients were considered unresectable if they had histologically proven } \\
\text { metastatic disease or carcinomatosis }\end{array}$ \\
\hline
\end{tabular}

Diagnostic accuracy of laparoscopy following computed tomography (CT) scanning for assessing the resectability with curative intent in 


\section{Menack 2001 (Continued)}

Flow and timing

Comparative

Notes
Number of indeterminates for whom the results of reference standard were available: Not stated

Number of patients who were excluded from the analysis: Not stated

\begin{tabular}{|c|c|c|c|}
\hline \multicolumn{4}{|c|}{ Methodological quality } \\
\hline Item & Authors' judgement & Risk of bias & Applicability concerns \\
\hline
\end{tabular}

\section{DOMAIN 1: Patient Selection}

Was a consecutive or random Unclear sample of patients enrolled?

Was a case-control design Yes avoided?

Did the study avoid inappropri- Unclear ate exclusions?

Low

\section{DOMAIN 2: Index Test All tests}

Were the index test results in- Yes terpreted without knowledge of the results of the reference standard?

\section{Low}

\section{DOMAIN 3: Reference Standard}

Is the reference standards likely Unclear to correctly classify the target condition?

Were the reference standard re- No sults

interpreted without knowledge of the results of the index tests?

DOMAIN 4: Flow and Timing 


\section{Menack 2001 (Continued)}

Was there an appropriate inter- Unclear val between index test and reference standard?

Did all patients receive the same No reference standard?

Were all patients included in the Unclear analysis?

\section{Merchant 1998}

\section{Study characteristics}

$\begin{array}{ll}\text { Patient sampling } & \text { Sample size: } 303 \\ & \text { Females: Not stated } \\ & \text { Age: Not stated }\end{array}$

Patient characteristics and set- Patients with potentially resectable pancreatic or periampullary cancer (after CT scan) ting Setting: Surgical centre in the USA

Index tests

Diagnostic laparoscopy

Criteria for positive diagnosis: Biopsies of lesions suspicious of metastases

Target condition and reference standard(s)
Target condition: Unresectability

Reference standard: Laparotomy for patients with no evidence of metastases on laparoscopy; biopsy with histolopathological confirmation of spread for patients with suspected metastases

Criteria for positive diagnosis: Unresectable if one or more of the following were confirmed histopathologically:

1. hepatic, serosal/peritoneal, or omental metastases;

2. extrapancreatic extension of tumour (i.e. mesocolic involvement);

3. celiac or high portal nodal involvement by tumour; and

4. invasion or encasement of the coeliac axis, hepatic artery, or superior mesenteric artery

Flow and timing

Number of indeterminates for whom the results of reference standard were available: Not stated Number of patients who were excluded from the analysis: 36 (10.6\%)

Comparative

Notes

Methodological quality

\begin{tabular}{|c|c|c|c|}
\hline Item & Authors' judgement & Risk of bias & Applicability concerns \\
\hline
\end{tabular}

\section{DOMAIN 1: Patient Selection}

Diagnostic accuracy of laparoscopy following computed tomography (CT) scanning for assessing the resectability with curative intent in 


\section{Merchant 1998 (Continued)}

Was a consecutive or random Yes sample of patients enrolled?

Was a case-control design Yes avoided?

Did the study avoid inappropri- No ate exclusions?

\section{Low}

\section{DOMAIN 2: Index Test All tests}

Were the index test results in- Yes terpreted without knowledge of the results of the reference standard?

\section{Low}

\section{DOMAIN 3: Reference Standard}

Is the reference standards likely Unclear to correctly classify the target condition?

Were the reference standard re- No sults

interpreted without knowledge

of the results of the index tests?

\section{Low}

\section{DOMAIN 4: Flow and Timing}

Was there an appropriate inter- Unclear val between index test and reference standard?

Did all patients receive the same No reference standard?

Were all patients included in the Unclear analysis? 
Reddy 1999

\section{Study characteristics}

\begin{tabular}{ll}
\hline Patient sampling & Sample size: 98 \\
& Females: $47(49 \%)$ \\
& Age: 65 years
\end{tabular}

Patient characteristics and set- Patients with potentially resectable pancreatic cancer (on CT scan)

ting Setting: Surgical centre in the USA

Index tests Diagnostic laparoscopy

Criteria for positive diagnosis: Biopsies of lesions suspicious of metastases

Target condition and reference standard(s)

Flow and timing

Comparative

Notes
Target condition: Unresectability

Reference standard: Laparotomy for patients with no evidence of metastases on laparoscopy; biopsy with histolopathological confirmation of spread for patients with suspected metastases

Criteria for positive diagnosis: Not stated

Number of indeterminates for whom the results of reference standard were available: Not stated Number of patients who were excluded from the analysis: $1(1 \%)$

\section{Methodological quality}

$\begin{array}{lll}\text { Item Authors' judgement } & \text { Risk of bias Applicability concerns }\end{array}$

\section{DOMAIN 1: Patient Selection}

Was a consecutive or random Yes sample of patients enrolled?

Was a case-control design Yes avoided?

Did the study avoid inappropri- No ate exclusions?

\section{Low}

\section{DOMAIN 2: Index Test All tests}

Were the index test results in- Yes terpreted without knowledge of the results of the reference standard? 
Reddy 1999 (Continued)

\section{DOMAIN 3: Reference Standard}

Is the reference standards likely Unclear

to correctly classify the target

condition?

Were the reference standard re- No

sults

interpreted without knowledge

of the results of the index tests?

Low

\section{DOMAIN 4: Flow and Timing}

Was there an appropriate inter- Unclear val between index test and ref-

erence standard?

Did all patients receive the same No

reference standard?

Were all patients included in the No analysis?

Reed 1997

\section{Study characteristics}

\begin{tabular}{ll}
\hline Patient sampling & Sample size: 11 \\
& Females: Not stated \\
& Age: Not stated
\end{tabular}

Patient characteristics and set- Patients with potentially resectable pancreatic cancer (on CT scan)

ting Setting: Surgical centre in the USA

Index tests Diagnostic laparoscopy

Criteria for positive diagnosis: Biopsies of lesions suspicious of metastases

Target condition and reference standard(s)
Target condition: Unresectability

Reference standard: Laparotomy for patients with no evidence of metastases on laparoscopy; biopsy with histolopathological confirmation of spread for patients with suspected metastases Criteria for positive diagnosis: Not stated

Flow and timing

Number of indeterminates for whom the results of reference standard were available: Not stated

Number of patients who were excluded from the analysis: Not stated 
Reed 1997 (Continued)

Comparative

Notes

Methodological quality

\begin{tabular}{|c|c|c|c|}
\hline Item & Authors' judgement & Risk of bias & Applicability concerns \\
\hline
\end{tabular}

Was a consecutive or random Unclear

sample of patients enrolled?

Was a case-control design Yes

avoided?

Did the study avoid inappropri- Unclear

ate exclusions?

Low

DOMAIN 2: Index Test All tests

Were the index test results in- Yes

terpreted without knowledge of

the results of the reference stan-

dard?

Low

\section{DOMAIN 3: Reference Standard}

Is the reference standards likely Unclear

to correctly classify the target

condition?

Were the reference standard re- No sults

interpreted without knowledge

of the results of the index tests?

\section{Low}

DOMAIN 4: Flow and Timing

Was there an appropriate inter- Unclear val between index test and reference standard? 
Reed 1997 (Continued)

Did all patients receive the same No reference standard?

Were all patients included in the Unclear analysis?

Shah 2008

\section{Study characteristics}

\begin{tabular}{ll}
\hline Patient sampling & Sample size: 19 \\
& Females: Not stated \\
& Age: Not stated
\end{tabular}

Patient characteristics and set- Patients with potentially resectable pancreatic cancer (on CT scan)

ting Setting: Surgical centre in the USA

Index tests Diagnostic laparoscopy

Criteria for positive diagnosis: Biopsies of lesions suspicious of metastases

Target condition and reference standard(s)

Flow and timing

Notes

\section{Comparative}

Target condition: Unresectability

Reference standard: Laparotomy for patients with no evidence of metastases on laparoscopy; biopsy with histolopathological confirmation of spread for patients with suspected metastases

Criteria for positive diagnosis: Not stated

Number of indeterminates for whom the results of reference standard were available: Not stated

Number of patients who were excluded from the analysis: 30 (61.2\%)

Methodological quality

\begin{tabular}{lll}
\hline Item Authors' judgement & Risk of bias Applicability concerns
\end{tabular}

\section{DOMAIN 1: Patient Selection}

Was a consecutive or random Yes sample of patients enrolled?

Was a case-control design Yes avoided?

Did the study avoid inappropri- No ate exclusions?

Diagnostic accuracy of laparoscopy following computed tomography (CT) scanning for assessing the resectability with curative intent in 
Shah 2008 (Continued)

\section{Low}

DOMAIN 2: Index Test All tests

Were the index test results in- Yes terpreted without knowledge of the results of the reference standard?

Low

\section{DOMAIN 3: Reference Standard}

Is the reference standards likely Unclear

to correctly classify the target

condition?

Were the reference standard re- No sults

interpreted without knowledge

of the results of the index tests?

Low

\section{DOMAIN 4: Flow and Timing}

Was there an appropriate inter- Unclear

val between index test and ref-

erence standard?

Did all patients receive the same No

reference standard?

Were all patients included in the No analysis?

Warshaw 1986

Study characteristics

\begin{tabular}{ll} 
Patient sampling & $\begin{array}{l}\text { Sample size: } 40 \\
\text { Females: Not stated } \\
\text { Age: Not stated }\end{array}$ \\
\hline $\begin{array}{l}\text { Patient characteristics and set- } \\
\text { ting }\end{array}$ & $\begin{array}{l}\text { Patients with potentially resectable pancreatic adenocarcinoma (after CT scan) } \\
\text { Setting: Surgical centre in the USA }\end{array}$
\end{tabular}

Diagnostic accuracy of laparoscopy following computed tomography (CT) scanning for assessing the resectability with curative intent in 


\section{Warshaw 1986 (Continued)}

$\begin{array}{ll}\text { Index tests } & \begin{array}{l}\text { Diagnostic laparoscopy } \\ \text { Criteria for positive diagnosis: Biopsies of lesions suspicious of metastases }\end{array}\end{array}$

Target condition and reference standard $(s)$

Target condition: Unresectability

Reference standard: Laparotomy for patients with no evidence of metastases on laparoscopy; biopsy with histolopathological confirmation of spread for patients with suspected metastases

Criteria for positive diagnosis: Not stated

Flow and timing

Number of indeterminates for whom the results of reference standard were available: Not stated Number of patients who were excluded from the analysis: Not stated

Comparative

Notes

Methodological quality

\begin{tabular}{lll}
\hline Item & Authors' judgement & Risk of bias Applicability concerns
\end{tabular}

\section{DOMAIN 1: Patient Selection}

Was a consecutive or random Unclear sample of patients enrolled?

Was a case-control design Yes avoided?

Did the study avoid inappropri- Unclear ate exclusions?

Low

\section{DOMAIN 2: Index Test All tests}

Were the index test results in- Yes terpreted without knowledge of the results of the reference standard?

\section{Low}

\section{DOMAIN 3: Reference Standard}

Is the reference standards likely Unclear to correctly classify the target condition? 


\section{Warshaw 1986 (Continued)}

Were the reference standard re- No sults

interpreted without knowledge

of the results of the index tests?

Low

\section{DOMAIN 4: Flow and Timing}

Was there an appropriate inter- Unclear val between index test and reference standard?

Did all patients receive the same No reference standard?

Were all patients included in the No analysis?

CT: computed tomography

EUS: endoscopic ultrasound

Characteristics of excluded studies [ordered by study ID]

\begin{tabular}{l|l}
\hline Study & Reason for exclusion \\
\hline Abdalla 2003 & Insufficient diagnostic test accuracy data available for diagnostic laparoscopy \\
\hline Adisa 2014 & No separate data available for pancreatic or periampullary cancers \\
\hline Alexakis 2015 & No diagnostic test accuracy data available for diagnostic laparoscopy \\
\hline Altieri 1982 & Wrong target condition \\
\hline Andren-Sandberg 1998 & Includes participants who were considered to be unresectable by CT scan \\
\hline \begin{tabular}{l} 
Arnold 2001 \\
\hline Atanov 1972
\end{tabular} & Not a diagnostic accuracy study \\
\hline $\begin{array}{l}\text { Awad } 1997 \\
\text { No separate data available for pancreatic or periampullary cancers }\end{array}$ \\
\hline $\begin{array}{l}\text { Diagnostic accuracy of laparoscopy following computed tomography (CT) scanning for assessing the resectability with curative intent in } \\
\text { Coprigh } \odot 2016 \text { The Cochrane Collaboration. Published by John Wiley \& Sons, Ltd. }\end{array}$ \\
\hline $\mathbf{5 7}$
\end{tabular}


(Continued)

\begin{tabular}{|c|c|}
\hline Baghbanian 2013 & Not clear whether histopathological confirmation of metastasis was obtained \\
\hline Baghbanian 2014 & Not clear whether histopathological confirmation of metastasis was obtained \\
\hline Balcom 2000 & Not a diagnostic accuracy study \\
\hline Barabino 2011 & No diagnostic test accuracy data available for diagnostic laparoscopy \\
\hline Barrat 1998 & No separate data available for pancreatic or periampullary cancers \\
\hline Barreiro 2002 & Not a diagnostic accuracy study \\
\hline Barthet 2007 & Not a diagnostic accuracy study \\
\hline Baumgarten 1984 & No diagnostic test accuracy data available for diagnostic laparoscopy \\
\hline Beger 1997 & Not a diagnostic accuracy study \\
\hline Belagyi 2000 & Not a diagnostic accuracy study \\
\hline Bemelman 1995 & No diagnostic test accuracy data available for diagnostic laparoscopy \\
\hline Bohmig 2001 & Not a diagnostic accuracy study \\
\hline Borbath 2005 & No diagnostic test accuracy data available for diagnostic laparoscopy \\
\hline Boselli 2000 & No diagnostic test accuracy data available for diagnostic laparoscopy \\
\hline Bottger 1998 & No diagnostic test accuracy data available for diagnostic laparoscopy \\
\hline Boyce 1992 & Not a diagnostic accuracy study \\
\hline Caldironi 1996 & The proportion of participants who were considered to be resectable after CT scan is not known \\
\hline Callery 1997 & No separate data available for pancreatic or periampullary carcinoma \\
\hline Callery 2009 & Not a diagnostic accuracy study \\
\hline Camacho 2005 & Not a diagnostic accuracy study \\
\hline Carmichael 1995 & Not a diagnostic accuracy study \\
\hline Carpenter 1996 & Not a diagnostic accuracy study \\
\hline Catheline 1998 & No diagnostic test accuracy data available for diagnostic laparoscopy \\
\hline
\end{tabular}

Diagnostic accuracy of laparoscopy following computed tomography (CT) scanning for assessing the resectability with curative intent in 58 pancreatic and periampullary cancer (Review)

Copyright $\odot 2016$ The Cochrane Collaboration. Published by John Wiley \& Sons, Ltd. 
(Continued)

\begin{tabular}{|c|c|}
\hline Catheline 1999 & No diagnostic test accuracy data available for diagnostic laparoscopy \\
\hline Chambon 1995 & No diagnostic test accuracy data available for diagnostic laparoscopy \\
\hline Champault 1996 & No diagnostic test accuracy data available for diagnostic laparoscopy \\
\hline Champault 1997 & No diagnostic test accuracy data available for diagnostic laparoscopy \\
\hline Charukhchyan 1998 & No diagnostic test accuracy data available for diagnostic laparoscopy \\
\hline Cipollone 2012 & No diagnostic test accuracy data available for diagnostic laparoscopy \\
\hline Conlon 1997 & The number of participants with pancreatic or periampullary cancers is not stated \\
\hline Conlon 1999 & Not a diagnostic accuracy study \\
\hline Conlon 2002 & Not a diagnostic accuracy study \\
\hline Connor 2004 & Not a diagnostic accuracy study \\
\hline Croome 2009 & Insufficient diagnostic test accuracy data available for diagnostic laparoscopy \\
\hline Croome 2010 & Insufficient diagnostic test accuracy data available for diagnostic laparoscopy \\
\hline Cuesta 1993 & No diagnostic test accuracy data available for diagnostic laparoscopy \\
\hline Cuschieri 1978 & No diagnostic test accuracy data available for diagnostic laparoscopy \\
\hline Cuschieri 1988 & The proportion of participants who were considered to be resectable after CT scan is not known \\
\hline D’Angelica 2003 & Wrong target condition \\
\hline Dadan 1980 & Insufficient diagnostic test accuracy data available for diagnostic laparoscopy \\
\hline Doran 2004 & No diagnostic test accuracy data available for diagnostic laparoscopy \\
\hline Doucas 2007 & No diagnostic test accuracy data available for diagnostic laparoscopy \\
\hline Duffy 2008 & Not a diagnostic accuracy study \\
\hline Durup Scheel-Hincke 1999 & No diagnostic test accuracy data available for diagnostic laparoscopy \\
\hline Eigler 1999 & Not a diagnostic accuracy study \\
\hline Ellsmere 2005 & No diagnostic test accuracy data available for diagnostic laparoscopy \\
\hline
\end{tabular}

Diagnostic accuracy of laparoscopy following computed tomography (CT) scanning for assessing the resectability with curative intent in 59 pancreatic and periampullary cancer (Review)

Copyright $\odot 2016$ The Cochrane Collaboration. Published by John Wiley \& Sons, Ltd. 
(Continued)

\begin{tabular}{|c|c|}
\hline Enestvedt 2008 & Includes participants who were considered to be unresectable by CT scan \\
\hline Fernandez-del Castillo 1994 & Not a diagnostic accuracy study \\
\hline Fernandez-del Castillo 1998 & Not a diagnostic accuracy study \\
\hline Ferrone 2006 & No diagnostic test accuracy data available for diagnostic laparoscopy \\
\hline Feussner 2000 & No separate data available for pancreatic or periampullary cancer \\
\hline Fevery 1985 & No separate data available for pancreatic or periampullary cancer \\
\hline Fockens 1993 & Not a diagnostic accuracy study \\
\hline Friess 1997 & No diagnostic test accuracy data available for diagnostic laparoscopy \\
\hline Friess 1998 & No separate data available for pancreatic or periampullary cancer \\
\hline Fristrup 2006 & No diagnostic test accuracy data available for diagnostic laparoscopy \\
\hline Fukumoto 1989 & No separate data available for pancreatic or periampullary cancer \\
\hline Garcea 2012 & No diagnostic test accuracy data available for diagnostic laparoscopy \\
\hline Garofalo 2009 & No diagnostic test accuracy data available for diagnostic laparoscopy \\
\hline Gouma 1996 & No diagnostic test accuracy data available for diagnostic laparoscopy \\
\hline Gouma 1999 & Not a diagnostic accuracy study \\
\hline Gouma 2002 & Not a diagnostic accuracy study \\
\hline Hann 1997 & No diagnostic test accuracy data available for diagnostic laparoscopy \\
\hline Hashimoto 2015 & $\begin{array}{l}\text { In this study, all } 11 \text { participants who underwent diagnostic laparoscopy and laparotomy had resectable } \\
\text { pancreatic cancers. There were therefore no true positives and false negatives for estimation of sensi- } \\
\text { tivity, and this study was excluded }\end{array}$ \\
\hline Healthcare 1999 & Not a diagnostic accuracy study \\
\hline Heger 2008 & Not a diagnostic accuracy study \\
\hline Hernandezguio 1965 & Not a diagnostic accuracy study \\
\hline Herrera 2003 & No diagnostic test accuracy data \\
\hline
\end{tabular}

Diagnostic accuracy of laparoscopy following computed tomography (CT) scanning for assessing the resectability with curative intent in 60 pancreatic and periampullary cancer (Review)

Copyright $\odot 2016$ The Cochrane Collaboration. Published by John Wiley \& Sons, Ltd. 
(Continued)

\begin{tabular}{|c|c|}
\hline Hidalgo 2004 & Not a diagnostic accuracy study \\
\hline Hohenberger 2000 & Not a diagnostic accuracy study \\
\hline Holzman 1997 & No diagnostic test accuracy data available for diagnostic laparoscopy \\
\hline Hunerbein 1999 & Not a diagnostic accuracy study \\
\hline Hunerbein 2001 & No diagnostic test accuracy data available for diagnostic laparoscopy \\
\hline Ialongo 2010 & Not a diagnostic accuracy study \\
\hline Ialongo 2015 & Not a diagnostic accuracy study \\
\hline Ido 1982 & No diagnostic test accuracy data available for diagnostic laparoscopy \\
\hline Ihse 1984 & Not a diagnostic accuracy study \\
\hline Ishida 1983 & No diagnostic test accuracy data available for diagnostic laparoscopy \\
\hline Ishida 1984 & Wrong target condition \\
\hline Ivanov 1989 & No diagnostic test accuracy data available for diagnostic laparoscopy \\
\hline Jackowski 1997 & No diagnostic test accuracy data available for diagnostic laparoscopy \\
\hline Jakobs 1999 & Not a diagnostic accuracy study \\
\hline Jarnagin 2000 & Wrong target condition \\
\hline Jayakrishnan 2015 & Not a diagnostic accuracy study \\
\hline Jerby 1998 & Not a diagnostic accuracy study \\
\hline Jimenez 2000 & Not a diagnostic accuracy study \\
\hline Jimenez 2000a & No diagnostic test accuracy data available for diagnostic laparoscopy \\
\hline John 1999 & No diagnostic test accuracy data available for diagnostic laparoscopy \\
\hline Juzkow 1996 & Not a diagnostic accuracy study \\
\hline Kadar 1997 & No diagnostic test accuracy data available for diagnostic laparoscopy \\
\hline
\end{tabular}

Kanazawa $1983 \quad$ No separate data available for pancreatic or periampullary cancer

Diagnostic accuracy of laparoscopy following computed tomography (CT) scanning for assessing the resectability with curative intent in 61 pancreatic and periampullary cancer (Review)

Copyright $(2016$ The Cochrane Collaboration. Published by John Wiley \& Sons, Ltd. 
(Continued)

\begin{tabular}{|c|c|}
\hline Kaplan 1979 & Not a diagnostic accuracy study \\
\hline Karachristos 2005 & Intervention between index test and reference standard \\
\hline Kellokumpu 1996 & Not a diagnostic accuracy study \\
\hline Kelly 2009 & No diagnostic test accuracy data available for diagnostic laparoscopy \\
\hline Khamdanov 1983 & Not a diagnostic accuracy study \\
\hline Kiyonaga 1982 & Wrong target condition \\
\hline Klingler 2000 & No diagnostic test accuracy data available for diagnostic laparoscopy \\
\hline Krahenbuhl 1997 & Not a diagnostic accuracy study \\
\hline Krustev 1998 & No diagnostic test accuracy data available for diagnostic laparoscopy \\
\hline Kubyshkin 2000 & No diagnostic test accuracy data available for diagnostic laparoscopy \\
\hline Kuster 1967 & No diagnostic test accuracy data available for diagnostic laparoscopy \\
\hline Kwon 2002 & No diagnostic test accuracy data available for diagnostic laparoscopy \\
\hline Lavonius 2001 & Includes participants who were considered to be unresectable by CT scan \\
\hline Lightdale 1992 & Not a diagnostic accuracy study \\
\hline Liu 2004 & Not a diagnostic accuracy study \\
\hline Long 2005 & Not a diagnostic accuracy study \\
\hline Luque-de Leon 1998 & No diagnostic test accuracy data available for diagnostic laparoscopy \\
\hline Luque-de Leon 1999 & No diagnostic test accuracy data available for diagnostic laparoscopy \\
\hline Macutkiewicz 2009 & No diagnostic test accuracy data available for diagnostic laparoscopy \\
\hline Madsen 1994 & No separate data available for pancreatic or periampullary cancer \\
\hline Madsen 1994a & No separate data available for pancreatic or periampullary cancer \\
\hline Maire 2004 & No diagnostic test accuracy data available for diagnostic laparoscopy \\
\hline Maithel 2008 & No diagnostic test accuracy data available for diagnostic laparoscopy \\
\hline
\end{tabular}

Diagnostic accuracy of laparoscopy following computed tomography (CT) scanning for assessing the resectability with curative intent in 62 pancreatic and periampullary cancer (Review)

Copyright $\odot 2016$ The Cochrane Collaboration. Published by John Wiley \& Sons, Ltd. 
(Continued)

\begin{tabular}{|c|c|}
\hline Meduri 1994 & The proportion of participants who were considered to be resectable after CT scan is not known \\
\hline Metcalfe 2003 & Not a diagnostic accuracy study \\
\hline Meyer 1973 & No diagnostic test accuracy data available for diagnostic laparoscopy \\
\hline Misra 2012 & No diagnostic test accuracy data available for diagnostic laparoscopy \\
\hline Molnar 2010 & The proportion of patients who were considered to be resectable after CT scan is not known \\
\hline Morak 2009 & No diagnostic test accuracy data available for diagnostic laparoscopy \\
\hline Morganti 2005 & No diagnostic test accuracy data available for diagnostic laparoscopy \\
\hline Mortensen 1996 & No diagnostic test accuracy data available for diagnostic laparoscopy \\
\hline Muniraj 2013 & Not a diagnostic accuracy study \\
\hline Muntean 2009 & No diagnostic test accuracy data available for diagnostic laparoscopy \\
\hline Munteanu 2010 & No diagnostic test accuracy data available for diagnostic laparoscopy \\
\hline Murugiah 1993 & The proportion of participants who were considered to be resectable after CT scan is not known \\
\hline Nagy 1999 & Not a diagnostic accuracy study \\
\hline Nieveen 1996 & No diagnostic test accuracy data available for diagnostic laparoscopy \\
\hline Nieveen 1997 & No diagnostic test accuracy data available for diagnostic laparoscopy \\
\hline Nieveen 1998 & No diagnostic test accuracy data available for diagnostic laparoscopy \\
\hline Nieveen 1999 & No diagnostic test accuracy data available for diagnostic laparoscopy \\
\hline Nieveen 2000 & No diagnostic test accuracy data available for diagnostic laparoscopy \\
\hline Nieveen 2003 & No diagnostic test accuracy data available for diagnostic laparoscopy \\
\hline Nieveen 2003a & No diagnostic test accuracy data available for diagnostic laparoscopy \\
\hline Occelli 1999 & No diagnostic test accuracy data available for diagnostic laparoscopy \\
\hline Palanivelu 2001 & Not a diagnostic accuracy study \\
\hline Parks 2000 & Not a diagnostic accuracy study \\
\hline
\end{tabular}

Diagnostic accuracy of laparoscopy following computed tomography (CT) scanning for assessing the resectability with curative intent in 63 pancreatic and periampullary cancer (Review)

Copyright $\odot 2016$ The Cochrane Collaboration. Published by John Wiley \& Sons, Ltd. 
(Continued)

\begin{tabular}{|c|c|}
\hline Pedrazzoli 1994 & No diagnostic test accuracy data available for diagnostic laparoscopy \\
\hline Pelton 1998 & Insufficient diagnostic test accuracy data available for diagnostic laparoscopy \\
\hline Pietrabissa 1996 & No diagnostic test accuracy data available for diagnostic laparoscopy \\
\hline Pietrabissa $1996 \mathrm{a}$ & No diagnostic test accuracy data available for diagnostic laparoscopy \\
\hline Pietrabissa 1999 & Includes participants who were considered to be unresectable by CT scan \\
\hline Pisters 2001 & Not a diagnostic accuracy study \\
\hline Potkonjak 1974 & No diagnostic test accuracy data available for diagnostic laparoscopy \\
\hline Ramshaw 1999 & Not a diagnostic accuracy study \\
\hline Ribero 1994 & No diagnostic test accuracy data available for diagnostic laparoscopy \\
\hline Rodgers 2003 & No separate data available for pancreatic or periampullary cancer \\
\hline Rothlin 1996 & Not a diagnostic accuracy study \\
\hline Rumstadt 1997 & No diagnostic test accuracy data available for diagnostic laparoscopy \\
\hline Rumstadt $1997 \mathrm{a}$ & No diagnostic test accuracy data available for diagnostic laparoscopy \\
\hline Saeian 1999 & Not a diagnostic accuracy study \\
\hline Sand 1996 & No separate data available for pancreatic or periampullary cancer \\
\hline Santoro 2012 & No information on whether the distant metastases were confirmed histologically as metastases \\
\hline Sato 1985 & Not a diagnostic accuracy study \\
\hline Satoi 2011 & No diagnostic test accuracy data available for diagnostic laparoscopy \\
\hline Schachter 1999 & Wrong target condition \\
\hline Schmidt 1997 & No diagnostic test accuracy data available for diagnostic laparoscopy \\
\hline Schmied 2000 & Not a diagnostic accuracy study \\
\hline Schmielau 1997 & Not a diagnostic accuracy study \\
\hline
\end{tabular}

Schneider 2003 The proportion of participants who were considered to be resectable after CT scan is not known

Diagnostic accuracy of laparoscopy following computed tomography (CT) scanning for assessing the resectability with curative intent in 64 pancreatic and periampullary cancer (Review)

Copyright $\odot 2016$ The Cochrane Collaboration. Published by John Wiley \& Sons, Ltd. 
(Continued)

\begin{tabular}{|c|c|}
\hline Schnelldorfer 2014 & Not clear whether histopathological confirmation of metastasis was obtained \\
\hline Schrenk 1994 & Number of participants with pancreatic or periampullary cancer was not reported \\
\hline Schrenk 1995 & No diagnostic test accuracy data available for diagnostic laparoscopy \\
\hline Schwab 1996 & Includes participants with unresectable cancers on CT scan \\
\hline Sperlongano 2005 & Not a diagnostic accuracy study \\
\hline Sperlongano 2006 & Not a diagnostic accuracy study \\
\hline Tang 2001 & No separate data available for pancreatic or periampullary cancer \\
\hline Tapper 2011 & No diagnostic test accuracy data available for diagnostic laparoscopy \\
\hline Taylor 2001 & No diagnostic test accuracy data available for diagnostic laparoscopy \\
\hline Terrosu 2000 & Number of participants with pancreatic or periampullary cancer was not reported \\
\hline Thomson 2006 & No diagnostic test accuracy data available for diagnostic laparoscopy \\
\hline Tilleman 2004 & Not a diagnostic accuracy study \\
\hline Tilleman 2004a & No diagnostic test accuracy data available for diagnostic laparoscopy \\
\hline Toughrai 2013 & Not a diagnostic accuracy study \\
\hline van Delden 1996 & No diagnostic test accuracy data available for diagnostic laparoscopy \\
\hline van Dijkum 1997 & The proportion of participants who were considered to be resectable after CT scan is not known \\
\hline Velanovich 1998 & No separate data available for pancreatic or periampullary cancer \\
\hline Velanovich 2004 & No diagnostic test accuracy data available for diagnostic laparoscopy \\
\hline Velasco 2000 & The proportion of participants who were considered to be resectable after CT scan is not known \\
\hline Vollmer 2002 & Includes participants who were considered to be unresectable by CT scan \\
\hline Warshaw 1990 & Not a diagnostic accuracy study \\
\hline Warshaw 1990a & Includes participants who were considered to be unresectable by CT scan \\
\hline Watanabe 1993 & No diagnostic test accuracy data available for diagnostic laparoscopy \\
\hline
\end{tabular}

Diagnostic accuracy of laparoscopy following computed tomography (CT) scanning for assessing the resectability with curative intent in 
(Continued)

\begin{tabular}{ll}
\hline Weiner 1995 & No separate data available for pancreatic or periampullary cancer \\
\hline White 2001 & Intervention between index test and reference standard \\
\hline White 2004 & Not a diagnostic accuracy study \\
\hline White 2008 & Wrong target condition \\
\hline Wilson 2010 & Not a diagnostic accuracy study \\
\hline Yoshida 2002 & No diagnostic test accuracy data available for diagnostic laparoscopy \\
\hline Zhao 2003 & No diagnostic test accuracy data available for diagnostic laparoscopy \\
\hline
\end{tabular}

CT: computed tomography 


\section{A T A}

Presented below are all the data for all of the tests entered into the review.

Tests. Data tables by test

\begin{tabular}{lcc} 
Test & $\begin{array}{c}\text { No. of } \\
\text { studies }\end{array}$ & $\begin{array}{c}\text { No. of } \\
\text { participants }\end{array}$ \\
\hline $\begin{array}{c}\text { Diagnostic laparoscopy (all } \\
\text { studies) }\end{array}$ & 16 & 1146 \\
$\begin{array}{c}\text { Diagnostic laparoscopy } \\
\text { (pancreatic cancer only) }\end{array}$ & 7 & 340 \\
\hline
\end{tabular}

\section{Test I. Diagnostic laparoscopy (all studies).}

Review: Diagnostic accuracy of laparoscopy following computed tomography (CT) scanning for assessing the resectability with curative intent in pancreatic and periampullary cancer

Test: I Diagnostic laparoscopy (all studies)

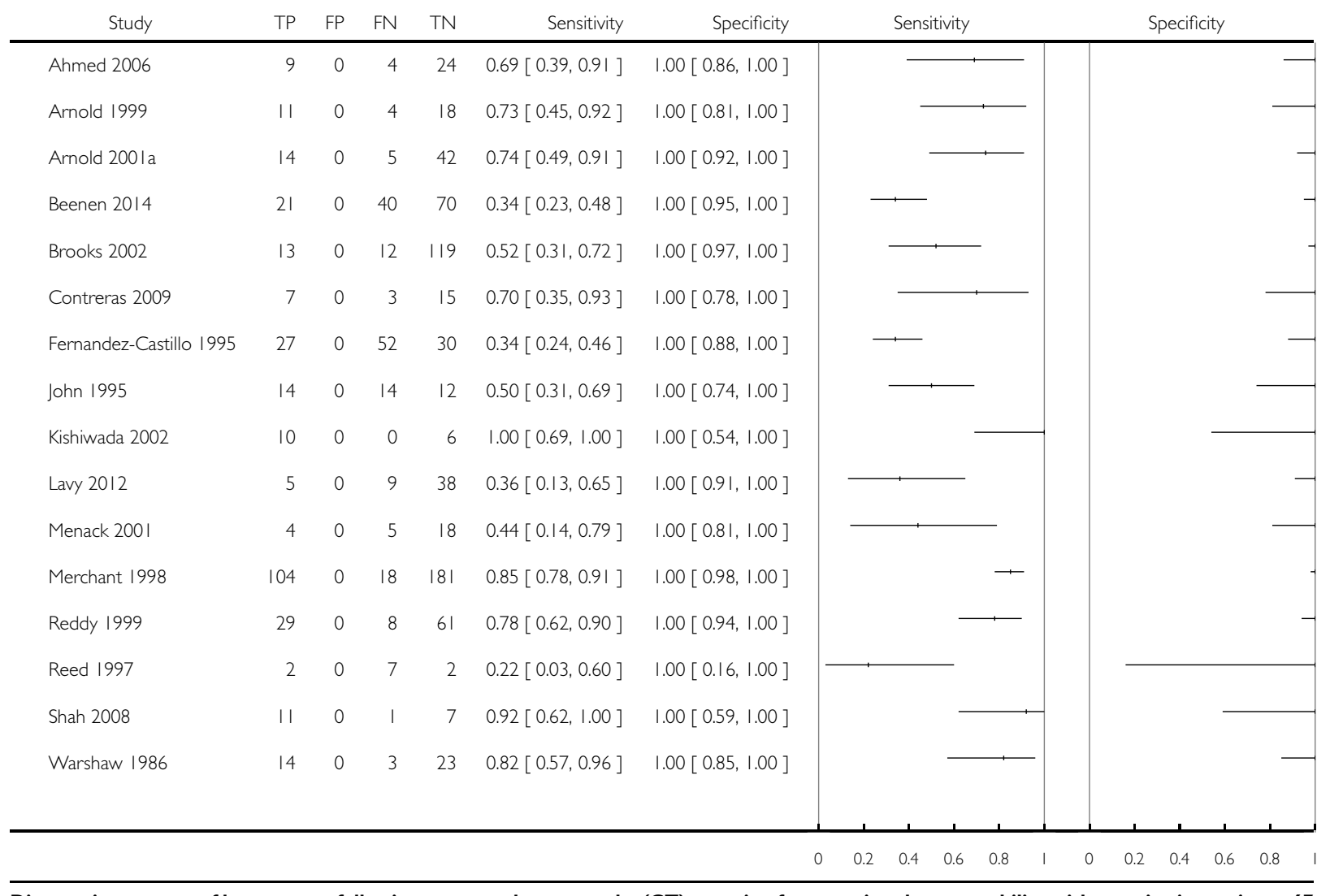

Diagnostic accuracy of laparoscopy following computed tomography (CT) scanning for assessing the resectability with curative intent in 67 pancreatic and periampullary cancer (Review)

Copyright $(2016$ The Cochrane Collaboration. Published by John Wiley \& Sons, Ltd. 
Test 2. Diagnostic laparoscopy (pancreatic cancer only).

Review: Diagnostic accuracy of laparoscopy following computed tomography (CT) scanning for assessing the resectability with curative intent in pancreatic and periampullary cancer

Test: 2 Diagnostic laparoscopy (pancreatic cancer only)

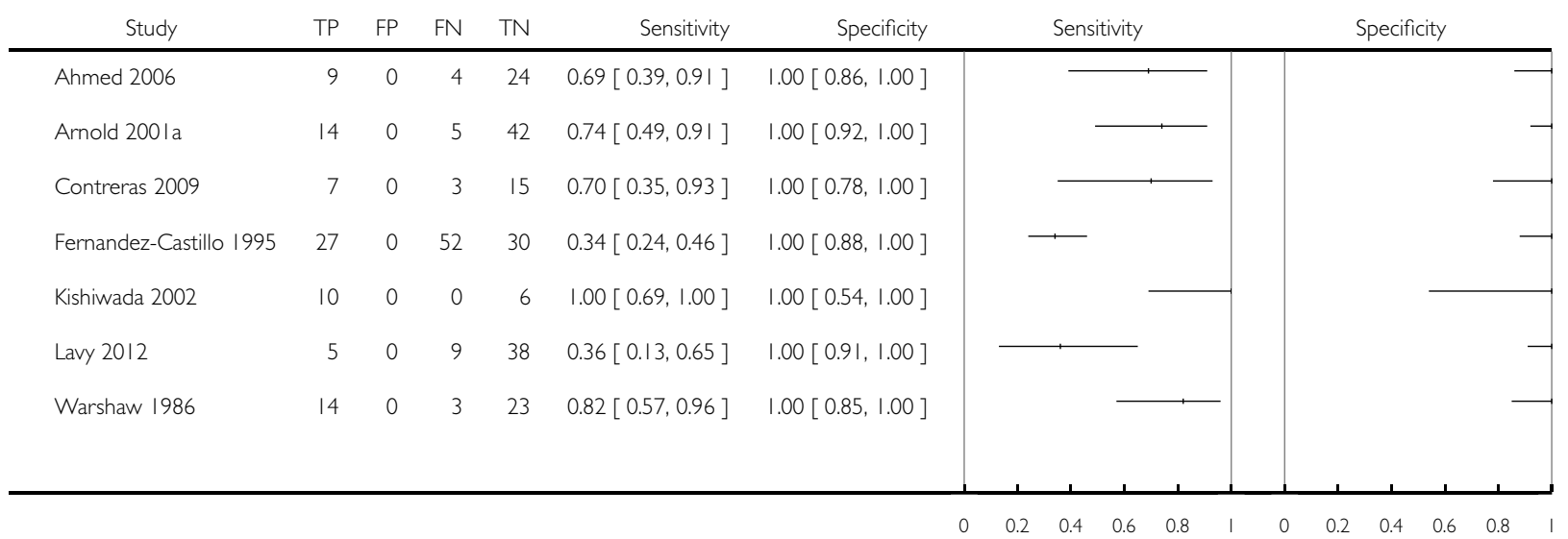

ADDITIONAL TABLES

Table 1. QUADAS-2 classification

Domain 1: Patient selection
Patient sampling

Patients with pancreatic and periampullary cancer considered eligible for surgical resection following a CT scan

Was a consecutive or random sample of patients enrolled?
Yes: If a consecutive sample or a random sample of patients with pancreatic and periampullary cancer eligible for surgical resection after CT scan was included in the study

No: If a consecutive sample or a random sample of patients with pancreatic and periampullary cancer eligible for surgical re-

Diagnostic accuracy of laparoscopy following computed tomography (CT) scanning for assessing the resectability with curative intent in 
section after CT scan was not included in the study

Unclear: If this information was not available

Was a case-control design avoided?
Yes: If a cohort of patients about to undergo surgical resection were studied

No: If patients who underwent unsuccessful laparotomy (cases) were compared with patients who underwent successful surgical resection (controls). Such studies were excluded

Unclear: We anticipated that we would be able to determine whether the design was case-control

As anticipated, we were able to determine the study design and were able to exclude all case-control studies. So, all studies included in this review were classified as 'yes' for this item

Did the study avoid inappropriate exclusions?

Yes: If all patients with pancreatic and periampullary cancer eligible for surgical resection were included

No: If the study excluded patients based on high probability of resectability (for example, small tumours)

Unclear: If this information was not available

Could the selection of patients have introduced bias?

Low risk of bias: If 'yes' classification for all the above 3 questions; high risk of bias: if 'no' classification for any of the above 3 questions; unclear risk of bias: if 'unclear' classification for any of the above 3 questions but without a 'no' classification for any of the above 3 questions

Patient characteristics and setting
Yes: We included only patients with pancreatic and periampullary cancer who were considered eligible for surgical resection following a CT scan. So, we anticipated all the included studies to be classified as 'yes' No: We excluded studies where patients were considered unsuitable for surgery after a CT scan. So, we did use this classification Unclear: We excluded studies in which it was not clear whether the patients had undergone CT scan following which they 
Table 1. QUADAS-2 classification (Continued)

were still considered suitable for surgical resection

Are there concerns that the included patients and setting do not match the review question?

Considering the inclusion criteria of this review, we anticipated that all of the included studies would be classified as 'low concern'. However, this was not the case, as shown in Figure 5

Domain 2: Index test
Index test(s)

Were the index test results interpreted without knowledge of the results of the reference standard?

If a threshold was used, was it prespecified? Not applicable

Could the conduct or interpretation of the index test have introduced bias?
Diagnostic laparoscopy with histologic confirmation of metastases

The index test would always be conducted and interpreted before the reference standard. So, this classification was always 'yes'

We anticipated classifying all studies as 'low risk of bias' because diagnostic laparoscopy indicates that structures within the abdomen were inspected, diagnostic laparoscopy would be conducted and interpreted before reference standard, and because we excluded any studies without histological confirmation of the metastatic spread

As anticipated, all of the studies were classified as 'low risk of bias' for this domain

Are there concerns that the index test, its conduct, or interpretation differ from the review question?
Considering the inclusion criteria for this review, we anticipated that all of the included studies will be classified as 'low concern'

As anticipated, all of the studies were classified as 'low concern' for this domain
Domain 3: Target condition and refer- Target condition and reference standard(s) ence standard
Unresectability. The reasons for unresectability include involvement of adjacent structures or distant metastases. There is currently no universal criteria for unresectability. Consensus exists for the definition of borderline resectable cancers ( Abrams 2009). Therefore where there is less tissue involvement than in a borderline resectable cancer, the tumour can be considered as resectable

Positive reference standard: Confirmation of liver or peritoneal involvement by 
Table 1. QUADAS-2 classification (Continued)

histopathological examination of suspicious (liver or peritoneal) lesions (irrespective of how the tissues were obtained for histopathological examination). We accepted only paraffin section histology as the reference standard. We also accepted the surgeon's judgement of unresectability on laparotomy when biopsy confirmation was not possible (e.g. the surgeon may not resect the tumour if it invaded the adjacent blood vessels but will not obtain a biopsy confirmation of this because of the danger posed by resecting a part of a large blood vessel)

Negative reference standard: Cancer was fully resected, i.e. clear resection margins on histology

Is the reference standard likely to correctly classify the target condition?

Yes: If histological confirmation of distant spread or local infiltration of adjacent structures making the cancer unresectable was obtained. The report on the resection margins showed clearly that the cancer was completely resected. We did not anticipate that any studies would meet these criteria because of the danger that biopsy of infiltration of adjacent structures poses

No: If resection margins were not clear of cancer

Unclear: If surgeon's judgement was used to assess unresectability or if the information about the resection margins was not available. We anticipated that most studies would be classified as 'unclear' because surgeon's judgement is generally used as a criterion for unresectability in clinical practice

As anticipated, all of the studies were classified as 'unclear' for this item

Were the reference standard results interpreted without knowledge of the results of the index tests?

It is not possible to perform the reference standard without knowledge of the results of the index test. However, only patients with suspicious lesions on laparoscopy undergo biopsy, and only patients with negative laparoscopy would undergo laparotomy. The results of the index test are unlikely to influence the results of the reference standard. All studies were classified as

Diagnostic accuracy of laparoscopy following computed tomography (CT) scanning for assessing the resectability with curative intent in 7 pancreatic and periampullary cancer (Review) 
Table 1. QUADAS-2 classification (Continued)

'no' for this question

Could the reference standard, its conduct, or its interpretation have introduced bias?

Are there concerns that the target condition as defined by the reference standard does not match the question?
Risk of bias was determined as 'low' if the answer to the first question was 'yes', 'high' if the answer to the first question was 'no', and 'unclear' if the answer to the first question was 'unclear'

Considering the inclusion criteria for this review, we anticipated that all of the included studies would be classified as 'low concern'

As anticipated, all of the studies were classified as 'low concern' for this domain

\section{Domain 4: Flow and timing}

Flow and timing

The cancer may progress if there is long time interval between diagnostic laparoscopy and laparotomy. So, we chose an arbitrary time interval of 2 months as an acceptable time interval between diagnostic laparoscopy and laparotomy

Was there an appropriate interval between index test and reference standard?

Yes: If the time interval between diagnostic laparoscopy and laparotomy was less than 2 months

No: If the time interval between diagnostic laparoscopy and laparotomy was more than 2 months

Unclear: If the time interval between diagnostic laparoscopy and laparotomy was unclear

Did all patients receive the same reference standard?

Yes: If all of the patients received the same reference standard (we anticipated that all the studies would be classified as 'yes') No: If different patients received different reference standards Unclear: If this information was not clear

Were all patients included in the analysis?

Yes: If all of the patients were included in the analysis irrespective of whether the results were uninterpretable

No: If some patients were excluded from the analysis because of uninterpretable results

Unclear: If this information was not clear

Could the patient flow have introduced bias?
Low risk of bias: if 'yes' classification for all of the above 3 questions; high risk of bias: if 'no' classification for any of the above 3

Diagnostic accuracy of laparoscopy following computed tomography (CT) scanning for assessing the resectability with curative intent in 72 pancreatic and periampullary cancer (Review) 
Table 1. QUADAS-2 classification (Continued)

questions; unclear risk of bias: if 'unclear' classification for any of the above 3 questions but without a 'no' classification for any of the above 3 questions

CT: computed tomography

Table 2. Prior testing and unresectability

\begin{tabular}{|c|c|c|c|c|c|c|}
\hline Study name & Type of CT scan & $\begin{array}{l}\text { Prior testing in } \\
\text { addition to } \mathrm{CT} \\
\text { scan }\end{array}$ & $\begin{array}{l}\text { Prob- } \\
\text { ability of CT re- } \\
\text { sectable disease } \\
\text { identified as un- } \\
\text { resectable by di- } \\
\text { agnostic la- } \\
\text { paroscopy or la- } \\
\text { parotomy } \\
\text { (Pre-test proba- } \\
\text { bility) }\end{array}$ & $\begin{array}{l}\text { Number of par- } \\
\text { ticipants } \\
(\mathrm{N}) \text { and reasons } \\
\text { for CT re- } \\
\text { sectable disease } \\
\text { identified as un- } \\
\text { resectable by di- } \\
\text { agnostic } \\
\text { laparoscopy }\end{array}$ & $\begin{array}{l}\text { Prob- } \\
\text { ability of CT } \\
\text { and diagnostic } \\
\text { laparoscopy re- } \\
\text { sectable disease } \\
\text { identified as un- } \\
\text { resectable at la- } \\
\text { parotomy } \\
\text { (Post-test prob- } \\
\text { ability of neg- } \\
\text { ative diagnostic } \\
\text { laparoscopy) }\end{array}$ & $\begin{array}{l}\text { Number of par- } \\
\text { tic- } \\
\text { ipants }(\mathrm{N}) \text { and } \\
\text { reasons for } \mathrm{CT} \\
\text { and diagnostic } \\
\text { laparoscopy re- } \\
\text { sectable disease } \\
\text { identified as un- } \\
\text { resectable at la- } \\
\text { parotomy }\end{array}$ \\
\hline Ahmed 2006 & Helical CT scan & None described & 35.1 & $\begin{array}{l}\mathrm{N}=9 \\
\text { Liver metastases } \\
=6 \\
\text { Peritoneal } \\
\text { metastases = } 1 \\
\text { Peritoneal and } \\
\text { liver metastases = } \\
2\end{array}$ & 14.3 & $\begin{array}{l}\mathrm{N}=4 \\
\text { Metastatic } \\
\text { disease }=2 \\
\text { Locally } \\
\text { advanced disease } \\
\text { (1 coeliac artery } \\
\text { lymph } \\
\text { node, } 1 \text { mesen- } \\
\text { teric vascular in- } \\
\text { volvement })=2\end{array}$ \\
\hline Arnold 1999 & $\begin{array}{l}\text { No further infor- } \\
\text { mation on CT } \\
\text { scan was avail- } \\
\text { able }\end{array}$ & $\begin{array}{l}\text { All par- } \\
\text { ticipants under- } \\
\text { went endoscopy } \\
\text { and ultrasound. } \\
\text { Some partici- } \\
\text { pants underwent } \\
\text { EUS, proportion } \\
\text { unclear }\end{array}$ & 45.5 & $\begin{array}{l}\mathrm{N}=11 \\
\text { Liver metastases } \\
=6 \\
\text { Peritoneal } \\
\text { metastasis = } 1 \\
\text { Peritoneal and } \\
\text { liver metastases = } \\
3 \\
\text { Peritoneal and } \\
\text { omental metas- } \\
\text { tases = } 1\end{array}$ & 18.2 & $\begin{array}{l}\mathrm{N}=4 \\
\text { Liver metastases } \\
=2 \\
\text { Peritoneal } \\
\text { metastases = } 1 \\
\text { Liver and peri- } \\
\text { toneal metastases } \\
=1\end{array}$ \\
\hline Arnold 2001 & $\begin{array}{l}\text { No further infor- } \\
\text { mation on CT } \\
\text { scan was avail- }\end{array}$ & $\begin{array}{l}\text { Endoscopy, } \\
\text { ultrasound, } \\
\text { and MRI. Pro- }\end{array}$ & 31.1 & $\begin{array}{l}\mathrm{N}=14 \\
\text { Liver metastases } \\
=8\end{array}$ & 10.6 & $\begin{array}{l}N=5 \\
\text { Liver metastases }\end{array}$ \\
\hline
\end{tabular}


Table 2. Prior testing and unresectability (Continued)

\begin{tabular}{|c|c|c|c|c|c|c|}
\hline & able & $\begin{array}{l}\text { portion of par- } \\
\text { ticipants who re- } \\
\text { ceived } \\
\text { each modality is } \\
\text { unclear }\end{array}$ & & $\begin{array}{l}\text { Peritoneal } \\
\text { metastases }=2 \\
\text { Liver and peri- } \\
\text { toneal metastases } \\
=4\end{array}$ & & $\begin{array}{l}=3 \\
\text { Peritoneal } \\
\text { metastases }=2 \\
\text { Metastases in the } \\
\text { omentum and } \\
\text { mesocolon = } 2 \\
\text { Some had spread } \\
\text { to more than } 1 \\
\text { location }\end{array}$ \\
\hline Beenen 2014 & $\begin{array}{l}\text { No further infor- } \\
\text { mation on CT } \\
\text { scan was avail- } \\
\text { able }\end{array}$ & $\begin{array}{l}\text { All par- } \\
\text { ticipants under- } \\
\text { went abdominal } \\
\text { ultrasound and } \\
\text { ERCP }\end{array}$ & 46.6 & $\begin{array}{l}\mathrm{N}=21 \\
\text { Reasons for un- } \\
\text { resectability not } \\
\text { stated }\end{array}$ & 36.3 & $\begin{array}{l}\mathrm{N}=40 \\
\text { Reasons for un- } \\
\text { resectability not } \\
\text { stated }\end{array}$ \\
\hline Brooks 2002 & $\begin{array}{l}\text { Con- } \\
\text { trast enhanced, } \\
\text { thin slice }\end{array}$ & $\begin{array}{l}85 \% \text { of partici- } \\
\text { pants underwent } \\
\text { ERCP }\end{array}$ & 17.4 & $\begin{array}{l}\mathrm{N}=13 \\
\text { Liver metastases } \\
=6 \\
\text { Peritoneal } \\
\text { metastases }=5 \\
\text { Other metastatic } \\
\text { disease = } 2\end{array}$ & 9.2 & $\begin{array}{l}\mathrm{N}=10 \\
\text { Liver metastases } \\
=3 \\
\text { Vascular } \\
\text { invasion }=3 \\
\text { Peritoneal } \\
\text { metastases = } 1 \\
\text { Local extension } \\
=1 \\
\text { Benign disease = } \\
2\end{array}$ \\
\hline Contreras 2009 & $\begin{array}{l}\text { Pancreas proto- } \\
\text { col CT scan }\end{array}$ & $\begin{array}{l}\text { EUS used } \\
\text { in some partic- } \\
\text { ipants, propor- } \\
\text { tion unclear }\end{array}$ & 40.0 & $\begin{array}{l}\mathrm{N}=7 \\
\text { Liver metastases } \\
=4 \\
\text { Peritoneal } \\
\text { metastases }=2 \\
\text { Gross regional } \\
\text { lymphadenopa- } \\
\text { thy }=1\end{array}$ & 16.7 & $\begin{array}{l}\mathrm{N}=3 \\
\text { Aortocaval node } \\
\text { disease }=1 \\
\text { Liver metastases } \\
=1 \\
\text { Coeliac node } \\
\text { disease }=1\end{array}$ \\
\hline $\begin{array}{l}\text { Fernandez- } \\
\text { Castillo } 1995\end{array}$ & $\begin{array}{l}\text { Further details } \\
\text { not known }\end{array}$ & None described & 72.4 & $\begin{array}{l}\mathrm{N}=27 \\
\text { Liver metastases } \\
=11 \\
\text { Peritoneal } \\
\text { metastases = } 3 \\
\text { Omental metas- } \\
\text { tases = } 2 \\
\text { Metastases in } \\
\text { more than } 1 \text { site } \\
=11\end{array}$ & 63.4 & $\begin{array}{l}\mathrm{N}=87 \\
\text { Vascular in- } \\
\text { vasion at subse- } \\
\text { quent angiogra- } \\
\text { phy and did not } \\
\text { undergo laparo- } \\
\text { tomy = } 42 \\
\text { Peritoneal } \\
\text { disease at laparo- } \\
\text { tomy = } 2 \\
\text { Reasons } \\
\text { for unresectabil- }\end{array}$ \\
\hline
\end{tabular}

Diagnostic accuracy of laparoscopy following computed tomography (CT) scanning for assessing the resectability with curative intent in 74 pancreatic and periampullary cancer (Review)

Copyright $\Subset 2016$ The Cochrane Collaboration. Published by John Wiley \& Sons, Ltd. 


\begin{tabular}{|c|c|c|c|c|c|c|}
\hline & & & & & & $\begin{array}{l}\text { ity at laparotomy } \\
\text { not stated }=43\end{array}$ \\
\hline John 1995 & $\begin{array}{l}\text { Contrast-en- } \\
\text { hanced dynamic } \\
\text { CT scan }\end{array}$ & $\begin{array}{l}\text { Various scanning } \\
\text { techniques used. } \\
\text { Exact techniques } \\
\text { and pro- } \\
\text { portion who re- } \\
\text { ceived them were } \\
\text { unclear }\end{array}$ & 70.0 & $\begin{array}{l}\mathrm{N}=14 \\
\text { Liver metastases } \\
=10 \\
\text { Peritoneal } \\
\text { metastases = } 8 \\
\text { Hilar } \\
\text { lymph node in- } \\
\text { volvement = } 2 \\
\text { Some had spread } \\
\text { to more than } 1 \\
\text { location }\end{array}$ & 53.8 & $\begin{array}{l}\mathrm{N}=14 \\
\text { Metastatic } \\
\text { disease = } 2 \\
\text { Locally } \\
\text { advanced and } \\
\text { metastatic } \\
\text { disease = } 1 \\
\text { Locoregional } \\
\text { spread = } 11\end{array}$ \\
\hline Kishiwada 2002 & Helical CT scan & $\begin{array}{l}\text { All participants } \\
\text { received } \\
\text { ultrasound }\end{array}$ & 62.5 & $\begin{array}{l}\text { Reasons for un- } \\
\text { resectability not } \\
\text { stated }\end{array}$ & 0 & $\begin{array}{l}\text { Reasons } \\
\text { for unresectabil- } \\
\text { ity at laparotomy } \\
\text { not stated }\end{array}$ \\
\hline Lavy 2012 & $\begin{array}{l}\text { No further infor- } \\
\text { mation on CT } \\
\text { scan was avail- } \\
\text { able }\end{array}$ & $\begin{array}{l}\text { All participants } \\
\text { received EUS }\end{array}$ & 26.9 & $\begin{array}{l}\text { Peritoneal } \\
\text { metastases }=5\end{array}$ & 19.1 & $\begin{array}{l}\mathrm{N}=9 \\
\text { Metastatic } \\
\text { disease = } 2 \\
\text { Locally ad- } \\
\text { vanced cancer = } \\
7\end{array}$ \\
\hline Menack 2001 & $\begin{array}{l}\text { Contrast-en- } \\
\text { hanced CT scan } \\
\text { with thin slices } \\
\text { of pancreas }\end{array}$ & $\begin{array}{l}\text { Transabdom- } \\
\text { inal ultrasound, } \\
\text { EUS, and ERCP } \\
\text { performed } \\
\text { in some partic- } \\
\text { ipants, propor- } \\
\text { tion unclear }\end{array}$ & 33.3 & $\begin{array}{l}\text { Reasons for un- } \\
\text { resectability not } \\
\text { stated }\end{array}$ & 21.7 & $\begin{array}{l}\mathrm{N}=5 \\
\text { Portal vein oc- } \\
\text { clusion = } 1 \\
\text { Metastatic dis- } \\
\text { ease in the lymph } \\
\text { nodes or liver } \\
\text { on laparoscopic } \\
\text { ultrasound and } \\
\text { biopsy = } 2 \\
\text { Portal vein en- } \\
\text { casement = } 1 \\
\text { Locally ad- } \\
\text { vanced disease at } \\
\text { laparotomy = } 1\end{array}$ \\
\hline Merchant 1998 & $\begin{array}{l}\text { Further details } \\
\text { not known }\end{array}$ & $\begin{array}{l}\text { Ul- } \\
\text { trasound, ERCP, } \\
\text { and angiography } \\
\text { performed } \\
\text { on some partic- } \\
\text { ipants, propor- } \\
\text { tion unclear }\end{array}$ & 40.3 & $\begin{array}{l}\mathrm{N}=104 \\
\text { Liver metastases } \\
=48 \\
\text { Extrapancreatic } \\
\text { spread = } 41 \\
\text { Nodal spread = } \\
20\end{array}$ & 9.0 & $\begin{array}{l}\mathrm{N}=18 \\
\text { Liver metastases } \\
=6 \\
\text { Extrapancreatic } \\
\text { disease = } 3 \\
\text { Positive nodal } \\
\text { disease }=3\end{array}$ \\
\hline
\end{tabular}

Diagnostic accuracy of laparoscopy following computed tomography (CT) scanning for assessing the resectability with curative intent in 75 pancreatic and periampullary cancer (Review) 
Table 2. Prior testing and unresectability (Continued)

\begin{tabular}{|c|c|c|c|c|c|c|}
\hline & & & & $\begin{array}{l}\text { Vascular } \\
\text { invasion = } 37 \\
\text { Some had spread } \\
\text { to more than } 1 \\
\text { location }\end{array}$ & & $\begin{array}{l}\text { Vascular } \\
\text { invasion = } 2 \\
\text { Benign disease = } \\
4\end{array}$ \\
\hline Reddy 1999 & $\begin{array}{l}\text { Further details } \\
\text { not known }\end{array}$ & None described & 37.8 & $\begin{array}{l}\mathrm{N}=29 \\
\text { Liver metastases } \\
=23 \\
\text { Liver and peri- } \\
\text { toneal metastases } \\
=3 \\
\text { Hep- } \\
\text { atic, peritoneal, } \\
\text { and mesenteric } \\
\text { metastases = } 1 \\
\text { Mesenteric } \\
\text { involvement }=2\end{array}$ & 11.6 & $\begin{array}{l}\mathrm{N}=6 \\
\text { Liver metastases } \\
=4 \\
\text { Peripancre- } \\
\text { atic lymph node } \\
\text { involvement = } 2\end{array}$ \\
\hline Reed 1997 & $\begin{array}{l}\text { Further details } \\
\text { not known }\end{array}$ & None described & 81.8 & $\begin{array}{l}\text { Reasons for un- } \\
\text { resectability not } \\
\text { stated }\end{array}$ & 77.8 & $\begin{array}{l}\mathrm{N}=7 \\
\text { Local tumour } \\
\text { spread }=5 \\
\text { Omental spread } \\
=1 \\
\text { Unclear }=1\end{array}$ \\
\hline Shah 2008 & $\begin{array}{l}\text { Multi- } \\
\text { detector row CT } \\
\text { using pancreatic } \\
\text { protocol }\end{array}$ & None described & 63.2 & $\begin{array}{l}\mathrm{N}=9 \\
\text { Metastases = } 6 \\
\text { Locally } \\
\text { advanced disease } \\
=3\end{array}$ & 12.5 & $\begin{array}{l}\text { Liver metastasis } \\
=1\end{array}$ \\
\hline Warshaw 1986 & $\begin{array}{l}\text { Further details } \\
\text { not known }\end{array}$ & $\begin{array}{l}\text { All participants } \\
\text { received chest } \\
\text { roentgenogra- } \\
\text { phy, transhepatic } \\
\text { cholangiog- } \\
\text { raphy, or ERCP } \\
\text { and } \\
\text { abdominal ultra- } \\
\text { sound. Some re- } \\
\text { ceived } \\
\text { coeliac and supe- } \\
\text { rior mesenteric } \\
\text { angiography }\end{array}$ & 42.5 & $\begin{array}{l}\mathrm{N}=14 \\
\text { Liver metastases } \\
=6 \\
\text { Parietal peri- } \\
\text { toneal metastases } \\
=7 \\
\text { Omental } \\
\text { metastatic } \\
\text { disease }=1\end{array}$ & 11.5 & $\begin{array}{l}\text { Liver metastases } \\
=3\end{array}$ \\
\hline
\end{tabular}

CT: computed tomography

DL: diagnostic laparoscopy

ERCP: endoscopic retrograde cholangio-pancreatography

EUS: endoscopic ultrasound

Diagnostic accuracy of laparoscopy following computed tomography (CT) scanning for assessing the resectability with curative intent in 
MRI: magnetic resonance imaging

All probabilities in the table are reported as percentages.

\section{A P PENDICES}

\section{Appendix I. Glossary of terms}

Index test: The diagnostic test being evaluated. In this review the index test is diagnostic laparoscopy after CT scanning QUADAS: A tool for assessing the methodological quality of diagnostic accuracy studies in terms of risk of bias and applicability to the review question. The assessment parameters are described in more detail in the main text of the review

Reference standard: The test that is accepted as the best available to classify the target condition correctly in a particular setting. In this review the reference standard is biopsy with histopathological confirmation after diagnostic laparoscopy or laparotomy, or the surgeon's judgement of unresectability at laparotomy when biopsy confirmation was not possible

Sensitivity: Proportion of diseased individuals correctly identified as having the disease by the index test i.e. True positives/(True positives + False negatives)

Specificity: Proportion of disease-free individuals correctly identified as being disease-free by the index test i.e. True negatives/(False positives + True negatives)

Target condition: The disease or condition to be diagnosed. In this review the target condition is unresectable pancreatic and periampullary cancer

\section{Appendix 2. Cochrane Register of Diagnostic Test Accuracy Studies and CENTRAL search strategy}

\#1 ((ampulla near/2 vater*) or ampullovateric or (papilla near/2 vater*) or periampulla* OR peri-ampulla* OR choledoch* or alcholedoch* or bile duct* or biliary or cholangio* or gall duct or duoden* or small bowel or small intestin* or enter* or pancrea*)

\#2 (carcin* or cancer* or neoplas* or tumour* or tumor* or cyst* or growth* or adenocarcin* or malign*)

\#3 (\#1 AND \#2)

\#4 (pancreatect* OR pancreaticojejunost* OR pancreaticogastros* OR pancreaticoduodenect* OR duodenopancreatectom*)

\#5 (\#3 OR \#4)

\#6 (laparoscop* or peritoneoscop* or celioscop* or coelioscop*)

\#7 (\#5 AND \#6)

\section{Appendix 3. MEDLINE search strategy}

((((ampulla vateri[tiab] OR “Ampulla of Vater" [Mesh] OR ampullovateric[tiab] OR papilla vateri[tiab] OR vater papilla[tiab] OR vater ampulla[tiab] OR peri-ampull*[tiab] OR periampull*[tiab] OR choledoch*[tiab] OR alcholedoch*[tiab] OR bile duct*[tiab] OR biliary[tiab] OR cholangio*[tiab] OR gall duct[tiab] OR duodenum[tiab] OR duodenal[tiab] OR duoden*[tiab] OR small bowel[tiab] OR small instestin*[tiab] OR enteral[tiab] OR enteric[tiab] OR enter*[tiab] OR pancreatic[tiab] OR pancreato*[tiab] OR pancreas*[tiab]) AND (carcinoma[tiab] OR carcinomas[tiab] OR carcin*[tiab] OR cancer*[tiab] OR neoplas*[tiab] OR tumor[tiab] OR tumors[tiab] OR tumorous[tiab] OR tumour*[tiab] OR tumor*[tiab] OR cyst[tiab] OR cysts[tiab] OR cystic[tiab] OR cyst*[tiab] OR growth*[tiab] OR adenocarcin*[tiab] OR malignant[tiab] OR malignancy[tiab])) OR "Duodenal Neoplasms"[Mesh] OR "Pancreatic Neoplasms"[Mesh] OR “Common Bile Duct Neoplasms”[Mesh]) AND (surger*[tiab] OR operat*[tiab] OR resection*[tiab] OR surgical*[tiab] OR Surgical Procedures, Operative[MeSH] OR General Surgery[MeSH])) OR (pancreatect*[tiab] OR pancreaticojejunost*[tiab] OR pancreaticogastros*[tiab] OR pancreaticoduodenect*[tiab] OR duodenopancreatectom*[tiab] OR Pancreatectomy[MeSH] OR Pancreaticojejunostomy[MeSH] OR Pancreaticoduodenectomy[MeSH])) AND (laparoscop*[tiab] OR peritoneoscop*[tiab] OR celioscop*[tiab] OR coelioscop*[tiab] OR "Laparoscopy”[Mesh])

Diagnostic accuracy of laparoscopy following computed tomography (CT) scanning for assessing the resectability with curative intent in 


\section{Appendix 4. EMBASE search strategy}

1 ((ampulla vateri or ampullovateric or papilla vateri or vater papilla or vater ampulla or periampull* or peri-ampull* or choledoch* or alcholedoch* or bile duct* or biliary or cholangio* or gall duct or duoden* or small bowel or small intestin* or enter* or pancrea*) and (carcin* or cancer* or neoplas* or tumour* or tumor* or cyst* or growth* or adenocarcin* or malign*)).ti,ab.

2 exp duodenum cancer/ or Vater papilla tumor/ or exp pancreas cancer/ or exp bile duct tumor/

31 or 2

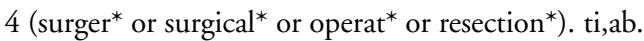

5 exp Surgery/

64 or 5

73 and 6

8 (pancreatect* OR pancreaticojejunost* OR pancreaticogastros* OR pancreaticoduodenect* OR duodenopancreatectom*). ti,ab.

9 exp pancreas surgery/

107 or 8 or 9

11 (laparoscop* or peritoneoscop* or celioscop* or coelioscop*). ti,ab.

12 laparoscopy/ or laparoscopic surgery/

1311 or 12

1410 and 13

\section{Appendix 5. Science Citation Index search strategy}

\#1 TS=(((ampulla vateri or ampullovateric or papilla vateri or vater papilla or vater ampulla or periampull* or peri-ampull* or choledoch* or alcholedoch* or bile duct* or biliary or cholangio* or gall duct or duoden* or small bowel or small intestin* ${ }^{*}$ or enter* ${ }^{*}$ or pancrea* $^{*}$ and (carcin* ${ }^{*}$ or cancer* or neoplas* or tumour* or tumor* or cyst* or growth* or adenocarcin* or malign $\left.\left.{ }^{*}\right)\right)$ )

$\# 2$ TS=(operat* OR surger* OR surgical* OR resection*)

\#3 \#1 AND \#2

\#4 TS=(pancreatect* OR pancreaticojejunost* OR pancreaticogastros* OR pancreaticoduodenect* OR duodenopancreatectom*)

\#5 \#3 OR \#4

\#6 TS=(laparoscop* or peritoneoscop* or celioscop* or coelioscop*)

\#7 \#5 AND \#6

\section{Appendix 6. SAS code for analysis}

data DiagnosticTestMetaAnalysis; input Study id TP FP FN TN;

datalines;

190424

2110418

3140542

42104070

513012119

670315

72705230

81401412

910006

1050938

1140518

12104018181

13290861

142072

1511017

16140323

Diagnostic accuracy of laparoscopy following computed tomography (CT) scanning for assessing the resectability with curative intent in 
run;

$I^{*}$ Modify the dataset for the analysis */

data dt;

set DiagnosticTestMetaAnalysis;

sens $=1$; pec $=0$; true $=\mathrm{tp} ; \mathrm{n}=\mathrm{tp}+\mathrm{fn}$; output;

sens $=0 ;$ spec $=1 ;$ true $=\mathrm{tn} ; \mathrm{n}=\mathrm{tn}+\mathrm{fp}$; output;

run;

$I^{*}$ Ensure that both records for a study are clustered together */

proc sort data $=\mathrm{dt}$;

by study id ;

run;

ods output ParameterEstimates=pet 4 FitStatistics=fitt 4 additionalestimates=addest 4 ;

$l^{*}$ Run random effects logistic regression model for sensitivity only*/

proc nlmixed data $=\mathrm{dt}$ tech $=$ quanew lis $=5$ qpoints $=10$;

parms msens $=2$ s 2 usens $=0$;

$\operatorname{logitp}=(\text { msens+usens })^{*}$ sens;

$\mathrm{p}=\exp (\log$ itp $) /(1+\exp (\log i t \mathrm{p}))$;

model true $-\operatorname{binomial}(n, p)$;

random usens $\sim \operatorname{normal}([0],[$ s2usens $])$ subject=study $\cdot$ id out=randeffs;

$l^{*} \operatorname{logLR}$ based on spec $=1 * /$

estimate ' $\log L R-' \log ((1-(\exp ($ msens $) /(1+\exp ($ msens $)))))$;

run;

$I^{*}$ Obtain summary sens and spec from the model $4 * /$

data summary 4 ;

set pet4;

if parameter = 'msens' then name = 'Sensitivity';

if parameter = 'msens' then summary $=100 * \exp ($ estimate $) /(1+\exp ($ estimate $))$;

if parameter $=$ 'msens' then summlower $=100 * \exp ($ lower $) /(1+\exp ($ lower $))$;

if parameter $=$ 'msens' then summupper $=100 * \exp ($ upper $) /(1+\exp ($ upper $))$;

output;

run;

/* Obtain summary LR- */

data summaryLR;

set addest 4 ;

summary=exp(estimate);

summlower=exp(lower);

summupper=exp(upper);

output;

run;

\section{Appendix 7. Calculation of post-test probability of unresectable disease for patients with a negative test result}

The post-test probability of unresectable disease for patients with a negative test result can be calculated from the pre-test probability of unresectable disease and the negative likelihood ratio. The calculation using the median pre-test probability from the included studies, as an example, is shown below.

Pre-test probability $=0.414$

Pre-test odds $=$ Pre-test probability $/(1-$ Pre-test probability $)=0.414 / 0.586=0.706$

Post-test odds of negative test $=$ Post-test odds ${ }^{*}$ negative likelihood ratio $=0.706 *$ negative likelihood ratio

Post-test probability of unresectable disease for patients with a negative test result $=$ Post-test odds $/(1+$ Post-test odds $)$

Diagnostic accuracy of laparoscopy following computed tomography (CT) scanning for assessing the resectability with curative intent in 


\section{WHAT'S NEW}

Last assessed as up-to-date: 15 May 2016.

\begin{tabular}{ll|l}
\hline Date & Event & Description \\
\hline 2 June 2016 & New search has been performed & $\begin{array}{l}\text { Searches were updated. One new study was added and the } \\
\text { data re-analysed }\end{array}$ \\
\hline 2 June 2016 & New citation required but conclusions have not changed & The conclusions remain unchanged. \\
\hline
\end{tabular}

\section{H I S T O R Y}

Protocol first published: Issue 10, 2011

Review first published: Issue 11, 2013

\begin{tabular}{|c|c|c|}
\hline Date & Event & Description \\
\hline 28 August 2014 & Amended & Review republished solely to include the plain language summary \\
\hline
\end{tabular}

\section{CONTRIBUTIONSOFAUTHORS}

VB Allen selected studies for inclusion, extracted the data, and wrote the draft of the review. KS Gurusamy wrote the protocol, selected studies for inclusion, and extracted the data and critically commented on the review. Y Takwoingi helped in the statistical analysis and critically commented on the review. A Kalia selected the studies for inclusion and extracted the data for some of the studies. BR Davidson critically commented on the review.

\section{DECLARATIONSOF INTEREST}

VB Allen: None.

KS Gurusamy: None.

Y Takwoingi: None.

A Kalia: None.

BR Davidson: None. 


\section{SOURCES OF SUPPORT}

\section{Internal sources}

- University College London, UK.

This was part of a BSc project for University College London. Funding was available for obtaining the full texts of articles.

\section{External sources}

- None, Other.

\section{DIFFERENCESBETWEEN PROTOCOLANDREVIEW}

The QUADAS tool was replaced by the QUADAS-2 tool.

The software used for meta-analysis was different from the one stated in the protocol.

The median pre-test probability rather than the pre-test probability calculated by a meta-analysis of proportions was used to calculate the post-test probability.

\section{INDEX TERMS}

\section{Medical Subject Headings (MeSH)}

*Ampulla of Vater; *Unnecessary Procedures; Common Bile Duct Neoplasms [diagnostic imaging; pathology; *surgery]; Laparoscopy [* methods]; Laparotomy [*utilization]; Neoplasm Staging [methods]; Pancreatic Neoplasms [diagnostic imaging; pathology; ${ }^{*}$ surgery]; Randomized Controlled Trials as Topic; Tomography, X-Ray Computed

\section{MeSH check words}

Humans 